\title{
Reviewing Evidence for the Relationship of EEG Abnormalities and RTT Phenotype Paralleled by Insights from Animal Studies
}

\author{
Kirill Smirnov $^{1}\left(\mathbb{D}\right.$, Tatiana Stroganova ${ }^{2}$, Sophie Molholm ${ }^{3,4}$ and Olga Sysoeva ${ }^{1, *}$ \\ 1 Institute of Higher Nervous Activity and Neurophysiology, Russian Academy of Science, \\ 117485 Moscow, Russia; kirillsmirnov@ihna.ru \\ 2 Center for Neurocognitive Research (MEG-Center), Moscow University of Psychology and Education, \\ 123290 Moscow, Russia; stroganova56@mail.ru \\ 3 The Cognitive Neurophysiology Laboratory, Ernest J. Del Monte Institute for Neuroscience, \\ Department of Neuroscience, University of Rochester School of Medicine and Dentistry, \\ Rochester, NY 14642, USA; sophie.molholm@einsteinmed.org \\ 4 The Cognitive Neurophysiology Laboratory, Departments of Pediatrics and Neuroscience, \\ Albert Einstein College of Medicine \& Montefiore Medical Center, Bronx, NY 10461, USA \\ * Correspondence: olga.v.sysoeva@gmail.com
}

Citation: Smirnov, K.; Stroganova, T.; Molholm, S.; Sysoeva, O. Reviewing Evidence for the Relationship of EEG Abnormalities and RTT Phenotype Paralleled by Insights from Animal Studies. Int. J. Mol. Sci. 2021, 22, 5308. https://doi.org/10.3390/ ijms22105308

Academic Editor: Ashok Patowary

Received: 7 April 2021

Accepted: 12 May 2021

Published: 18 May 2021

Publisher's Note: MDPI stays neutral with regard to jurisdictional claims in published maps and institutional affiliations.

Copyright: () 2021 by the authors. Licensee MDPI, Basel, Switzerland. This article is an open access article distributed under the terms and conditions of the Creative Commons Attribution (CC BY) license (https:// creativecommons.org/licenses/by/ $4.0 /)$.

\begin{abstract}
Rett syndrome (RTT) is a rare neurodevelopmental disorder that is usually caused by mutations of the $M E C P 2$ gene. Patients with RTT suffer from severe deficits in motor, perceptual and cognitive domains. Electroencephalogram (EEG) has provided useful information to clinicians and scientists, from the very first descriptions of RTT, and yet no reliable neurophysiological biomarkers related to the pathophysiology of the disorder or symptom severity have been identified to date. To identify consistently observed and potentially informative EEG characteristics of RTT pathophysiology, and ascertain areas most worthy of further systematic investigation, here we review the literature for EEG abnormalities reported in patients with RTT and in its disease models. While pointing to some promising potential EEG biomarkers of RTT, our review identify areas of need to realize the potential of EEG including (1) quantitative investigation of promising clinical-EEG observations in RTT, e.g., shift of mu rhythm frequency and EEG during sleep; (2) closer alignment of approaches between patients with RTT and its animal models to strengthen the translational significance of the work (e.g., EEG measurements and behavioral states); (3) establishment of large-scale consortium research, to provide adequate Ns to investigate age and genotype effects.
\end{abstract}

Keywords: resting state EEG; spontaneous EEG; Rett syndrome; MECP2; translational biomarker

\section{Introduction}

Rett syndrome (RTT) is a neurodevelopmental disorder, occurring in approximately one of 10,000 live female births irrespective of country and ethnicity [1-4]. It is one of the most common causes of mental retardation in girls. Rett syndrome takes its name after the Austrian psychiatrist, Dr Andreas Rett, who first described girls with this condition in 1966. Since that time, the clinical symptoms of RTT have been refined several times, but still the most prominent feature of RTT is the striking stereotypic hand movements. Other prominent features of the syndrome are cognitive and motor deficits, autistic traits, seizures and dysfunction of autonomic nervous system, including respiratory abnormalities [5-7]. The full range of clinical symptoms of RTT and current diagnostic criteria can be found in the review of Neul and colleagues [8].

Rett syndrome is characterized by a developmental progression described as a sequence of age-related stages. Stage I, "early onset stagnation" starts at about 6-18 months of age and can be preceded by a period of seemingly normal development. Stage II, "developmental regression", occurs at about 1-4 years of age and is characterized by regression of purposeful hand use and spoken language; hand stereotypies and gait abnormalities 
also occur in this period, during which many girls with RTT are losing their ability to walk, even if they previously acquired this skill. Stage III, the "pseudostationary period", is the longest stage in RTT. It is characterized by relative stabilization of clinical manifestations and even slight improvements in cognitive and communicative domains, accompanied by slow regression in neuromotor functions. Stage IV, "late motor deterioration", is also reported in girls with RTT where pronounced motor deterioration eventually leads to death. According to recent views this stage can be shifted to late adulthood or even fully avoided though rehabilitative therapy $[9,10]$.

In 1999 mutations in the X-linked gene $M E C P 2$, which encodes the transcriptional regulator methyl-CpG-binding protein 2 (MECP2), was found to be the main cause of RTT [11]. The most common de novo MECP2 mutations in patients with RTT are R106W, R133C, T158M, R168X, R255X, R270X, R294X and R306C, which are responsible in total for about $60 \%$ of RTT cases and C-terminal deletions (9\%) and large deletions (8.5\%) [12-14]. Discovery of the role of the Mecp 2 gene in RTT and the fact that it is highly conserved in vertebrates allowed for the development of animal models, providing critical insight into the pathological processes, and testing of potential treatments. The initial models were male mice with a total knockout of the Mecp 2 gene and hence complete disruption of the production of the MECP2 protein $[15,16]$. Although RTT in humans is caused by less extensive disturbances in MECP2 structure, these models recapitulate many of the features of Rett syndrome including pronounced stereotypic forelimb motions, uncoordinated gait, reduced spontaneous movement and irregular breathing.

Methodological advances have allowed the development of several female animal models with local mutations recapitulating the specific variants of human RTT such as R168X [17], T158A [18], R255X [19] and A140V [20]. Still, these models are relatively recent, and the full knockout male mouse model dominated in the literature to date, possibly due to earlier symptom onset and a more pronounced phenotype. Additional models of MECP2 abnormalities include the heterologous expression of human MECP2 in Drosophila [21]; the disruption of Mecp2 expression in zebrafish [22,23]; Mecp2 knockout in rats [24,25]. Cellular cultures that use stem cells from mouse models of RTT [26] or human induced pluripotent stem cells (hIPSC) [27] are another perspective way to investigate how MECP2 disruption affects neuronal development, including impaired proliferation and proneness to senescence [28].

An important feature of face validity of animal models of RTT is the presence of a period of relatively normal development followed by regression. Studies in presymptomatic animals and animals in the beginning of regression can shed light on the primary mechanisms that are disrupted first and might trigger the subsequent abnormalities. To assess disease severity in animal models of RTT, the scale is used in which inertia, gait, hind-limb clasping, tremor, irregular breathing and poor general condition are scored from 0 to 2 ( 0 - the symptom is absent, 1 -symptom is present and 2-the symptom is severe) (Guy et al., 2007). Male mice with T158A mutation in Mecp2 gene start to develop symptoms after 4 weeks of life, while female mice with the same mutation develop symptoms after the 16th week [29]. In relation to human lifespan, adolescence in mice lasts from postnatal week 3 to 9 (with sexual maturation starting around day 47); adulthood ends approximately around week 107 and is followed by the post reproductive stage [30]. Thus, males of the animal model of RTT develop a disease phenotype during adolescence before puberty and females become symptomatic at the young adult stage.

Animal research has revealed the multifaceted role of MECP2 in cell functioning. Initially defined as a transcriptional repressor, MECP2 was then found not only to repress but also to activate transcription, to modify chromatin structure and affect miRNA processing. MECP2 regulates gene expression in a subtle but widespread manner affecting thousands of genes [31]. Transcriptomic methods showed that the influence of $M E C P 2$ mutations is extensive, affecting over 60 molecular pathways, including PI3/Akt/mTOR signaling pathway, important for dendritic complexity, soma size and spine morphology [32]. Noteworthy, two other genes, also identified to cause RTT, cyclin-dependent 
kinase-like 5 (CDKL5) and forkhead box protein G1 (FOXG1), are thought to converge on MECP2 [33,34]: MECP2 is an enzymatic target of CDKL5, while FOXG1 interacts with the MECP2-isoform (MECP2-e2; one of two MECP2-isoforms) that prevents cell death of cerebellar neurons [35]. FOXG1 and MECP2 also have overlapping expressions in differentiating forebrain cortex [33]. Animal models have been used to gain understanding of neural dysfunction and the genesis of seizures in RTT. We will review these EEG data under the subhead Animal Studies in the results section.

Electrical brain activity in the form of EEG can be recorded both in humans and animals and might serve as common neural biomarkers that reflect specific neural network dysfunction and provide validity of between-species translation. Electroencephalography (EEG) reflects summed slow dendritic potentials of many cortical pyramidal neurons. EEG rhythms in different frequency bands emerge from the dynamic interaction between neuronal populations and have been associated with a range of different cognitive processes $[36,37]$. Thus, recordings of spontaneous EEG (i.e., EEG recorded in the absence of controlled stimulation or task conditions and not stimulus or task locked) can be used to make inferences about abnormalities in brain functioning. The first description of Rett syndrome by Dr. Rett in 1966 contains reference to the atypical EEG patterns that were later detailed in the seminal work of Hagberg [38]. Distinct EEG patterns were described for the different stages of RTT, with a "characteristic EEG development" suggested as one of the supportive criteria for RTT diagnosis [5,39]. However, well-characterized EEG activity with known neurophysiological underpinnings are still lacking for RTT. Here we provide a review of studies on spontaneous EEG with the goal of identifying potential EEG biomarkers of MECP2 dysfunction. We draw on animal studies to capitalize on the in depth molecular and neurophysiological data that have been collected using invasive approaches and connect this with available non-invasive EEG data from patients with RTT. We assess correspondence between animal and human EEG, and how these can be used to understand the underlying pathological processes assessed by more invasive measures in animal models. We believe this is a critical step to advancing the potential of preclinical studies.

For this review we focus on papers reporting data collected during recordings of spontaneous EEG, which constitutes the majority of studies that applied the EEG method to patients with RTT since they are commonly made in the clinic to assess the presence of clinically relevant EEG abnormalities. Evidence of atypicalities in the event-related potentials in RTT are summarized elsewhere [40].

\section{Results}

The results are organized into the following sections: 1 . epilepsy/seizures; 2 . abnormalities in resting EEG spectra and their neurophysiological underpinnings; 3. EEG abnormalities associated with sleep disturbances, and their neurophysiological underpinnings; 4 . seizures and EEG abnormalities through developmental changes; 5 . behavioral and EEG abnormalities in relation to RTT genotype; 6 . EEG as a biomarker of treatment efficacy. These are subdivided into human studies and animal studies. Finally, we summarize and integrate these findings in a conclusion section.

\subsection{Epilepsy/Seizures}

\subsubsection{Patient Studies}

Seizure Semiology

Most studies resulting from our search concerned epileptiform abnormalities/seizures in RTT (Figure 1, Table 1). Seizures of various semiology were described, with the most common being generalized seizures, tonic-clonic seizures and complex partial seizures [41-45]. Reports on the prevalence of epilepsy in patients with RTT ranged between 50 and $90 \%$, and about $30-50 \%$ of cases were drug-resistant $[41,44,46-53]$. This wide range of results might be related to different methods used to identify seizures. Notably, many authors agreed on the fact that in patients with RTT, seizures are difficult to distinguish clinically from 
disorganized movements such as hand stereotypies, tremor and dystonia, or breathing abnormalities, which are typical in RTT [41,43,46,51,54-58]. While not always feasible, future work in which long-term video EEG polygraphy is used for seizure diagnostics would yield more reliable results. At the same time, there are a significant number of RTT cases with seizure-like abnormalities manifested behaviorally, but not in EEG (socalled vacant spells). Whether it is a detectability issue, or these vacant spells are indeed unrelated to epileptiform activity and represent peculiar behavioral phenomena remains to be examined in future studies.

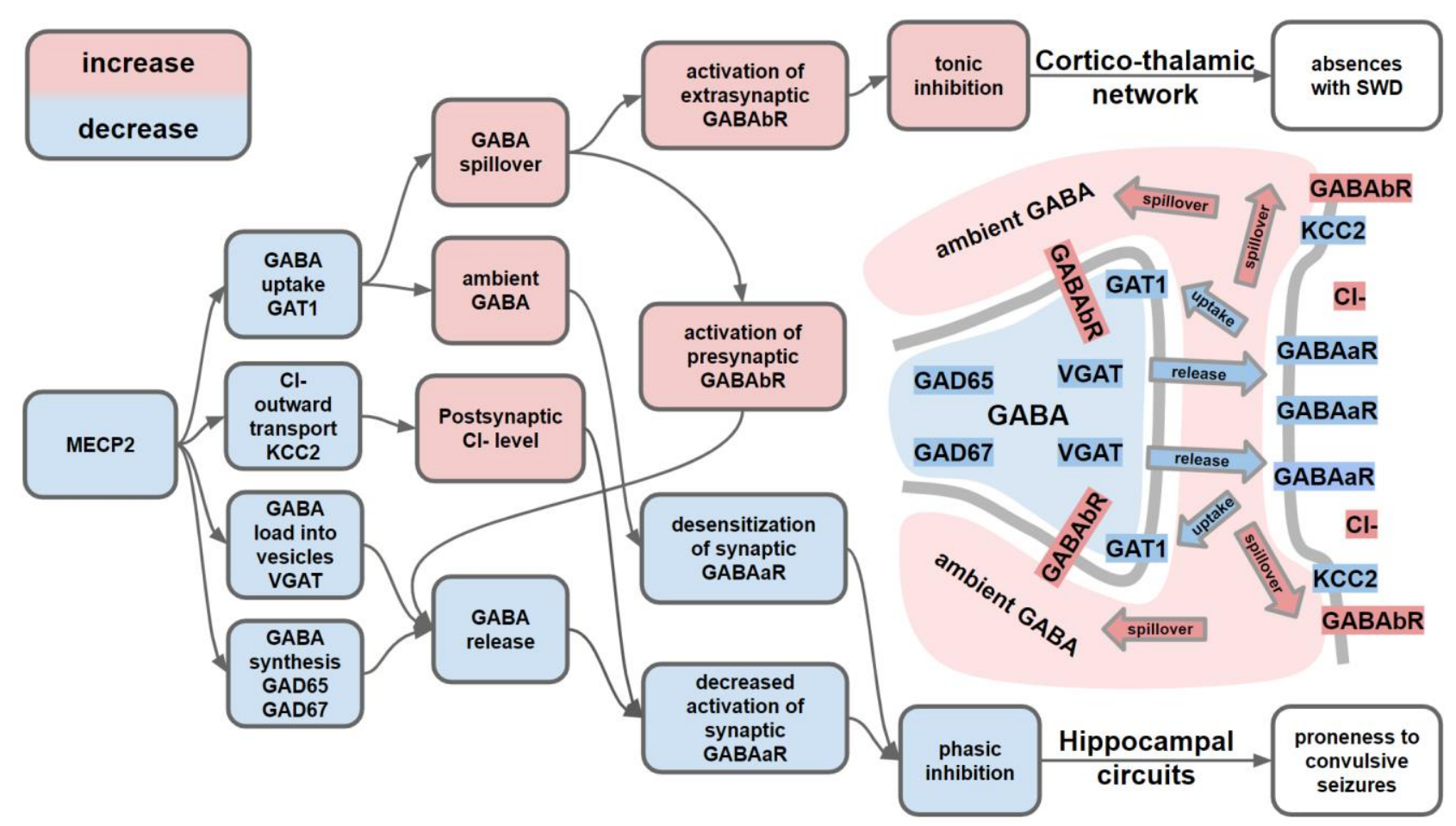

Figure 1. Role of GABAergic impairment in pathogenesis of epileptic activity in the animal model of RTT.

Unlike plenty of large-sample clinical studies on epilepsy/seizures (generally $n>100$ ), quite a few studies $[38,48,49,55,62,63,73,80,81,83,87]$ provided description of epileptiform activity in RTT patients with reference to EEG recording (with largest $n=78$ ). These studies reported a much higher incidence of epileptiform activity than epilepsy in patients with RTT. In the two largest studies, epileptiform activity was present in $78-82 \%$ of patients with RTT [74,84], while epilepsy was confirmed only in $50-76 \%$ of these patients. More recent study of Buoni and colleagues reported even higher incidence of epileptiform activity in RTT as each of their 16 RTT patients has some form of epileptiform abnormalities, while clinical seizures were observed in only 6 patients [50]. A broad range of baseline epileptiform activity was reported in patients with RTT, such as single or grouped spikes and sharp wave discharges, often followed by relative attenuation of background activity, slow spike and wave, or continuous spike and wave $[44,55,63,80,87,90]$. The most frequently reported epileptiform activity in RTT is centro-temporal spikes (CTS), which we will return to in a subsequent section. 
Table 1. Characteristics of studies with qualitative, clinical description of EEG abnormalities.

\begin{tabular}{|c|c|c|c|}
\hline Study & Sample (n: Age) & EEG Settings & EEG Characteristics \\
\hline [59] & RTT: 1, 4 y o & Video EEG & $\begin{array}{c}\begin{array}{c}\text { Needle-like central spikes evoked by contralateral passive finger-tapping } \\
\text { drug-resistant }\end{array}\end{array}$ \\
\hline$[60]$ & RTT: 1,5 y o & Video EEG (24 h) & $\begin{array}{c}\text { Multifocal bilateral discharges precipitated by right-hand tapping lips (but not cheek } \\
\text { or abdomen, or the left-hand tapping lips, or observer's hand tapping the lips) and } \\
\text { immediately disappearing when the movement stopped. }\end{array}$ \\
\hline$[61]$ & RTT: 1,12 y o & EEG & $\begin{array}{l}\text { Paroxysmal runs of fluctuating } 4-\text { to } 5-\mathrm{Hz} \text { rhythmic frontocentral theta activity at rest } \\
\text { that abated with movement or tactile stimulation }\end{array}$ \\
\hline$[63]$ & $\begin{array}{l}6 \text { RTT among } \\
74 \text { genetic-dysmorphic syndromes }\end{array}$ & $\begin{array}{l}\text { EEG video monitoring with at least one EEG } \\
\text { including awake and spontaneous afternoon } \\
\text { nap recording }\end{array}$ & Abnormal EEG in 3 RTT \\
\hline$[64]$ & $\begin{array}{c}\text { RTT: } 1,7 \text { y o } \\
\text { Lhermitte-Duclos } \\
\text { syndrome// Neurofibromatosis: } 1,8 \text { y o }\end{array}$ & Multiple daytime and sleep EEGs & $\begin{array}{l}\text { Continuous spike and wave in slow-wave sleep } \\
\text { Focal epileptiform discharges while awake }\end{array}$ \\
\hline$[65]$ & RTT: 64: 3-9 & Awake and sleep video EEG (24 h) & $\begin{array}{l}\text { Unilateral, highly rhythmic hand tapping accompanied by contralateral synchronous } \\
\text { centrotemporal spikes and not responsive to drugs }(n=5)\end{array}$ \\
\hline$[56]$ & RTT: 8: 7-20 у о & $\begin{array}{l}\text { Video-polygraphic, } \mathrm{EEG}+\mathrm{EMG}+\mathrm{EKG} \\
\text { recording }\end{array}$ & $\begin{array}{c}- \text { Slowing of the background activity } \\
\text { - Epileptiform abnormalities (spike and sharp wave discharges) } \\
-\quad \text { Abnormal sleep patterns } \\
- \text { Epilepsy: drug-resistant in half / / misdiagnosed }(n=6) \\
- \text { Multifocal and asynchronous cortical myoclonus }(n=5), \text { myoclonic seizures } \\
(n=4), \text { myoclonic status }(n=2)\end{array}$ \\
\hline$[66]$ & RTT: 3: $14,18,22$ у о & $\begin{array}{l}\text { Video-EEG and polygraphy (with confirmed } \\
\text { reflex seizures in } n=1)\end{array}$ & $\begin{array}{l}\text { Reflex seizures, triggered by food intake }(n=1) \text { or self-provoked by rhythmic } \\
\text { pressure on hands }(n=2) \text { or by taking someone's hand or holding on to a table }(n=1)\end{array}$ \\
\hline$[50]$ & $\begin{array}{c}\text { Zappella RTT MECP2 } \\
\text { high-intermediate performance (HIP): 11: } \\
\text { 11-38 y o } \\
\text { low-performance } \\
\text { (LP): 5: 8-19 y o }\end{array}$ & $\begin{array}{l}\text { 8-channel EEG referenced to linked mastoids } \\
\text { continuous awake and sleep (at least } 30 \mathrm{~min} \text { ) }\end{array}$ & $\begin{array}{c}\text { Centro-temporal spikes: HIP > LP } \\
\text { Multifocal EEG activity: HIP }<\text { LP } \\
\text { EEG encephalopathy: HIP }<\text { LP } \\
\text { Spindles and K-complex: HIP > LP } \\
\text { Epilepsy (recurrent unproved seizures): HIP < LP (ns) }\end{array}$ \\
\hline
\end{tabular}


Table 1. Cont.

\begin{tabular}{|c|c|c|c|}
\hline Study & Sample (n: Age) & EEG Settings & EEG Characteristics \\
\hline [49] & $\begin{array}{l}\text { RTT: } 18: 7-21 \text { y o } \\
\text { All with seizures }\end{array}$ & 20-30 min video EEG awake & $\begin{array}{l}\text { Correlation between epilepsy and behavior: } \\
\text { EEG stage III (moderate to marked slowing of background activity with dominant } \\
\text { theta and delta activity) } \\
\text { EEG stage IV (no occipital dominant rhythm and marked slowing of background } \\
\text { activity). } \\
\text { (1) theta slow activity over the frontal and central regions (eight cases) } \\
\text { (2) frontocentroparietal spikes (eight cases) } \\
\text { (3) generalized spike and waves (one case) } \\
\text { (4) diffuse subcontinuous spike and waves suggestive of epileptic encephalopathy } \\
\text { (one case) }\end{array}$ \\
\hline$[44]$ & $\begin{array}{c}\text { RTT (165 including Classic (140) } \\
\text { Preserved speech variant (PSV) (15) Hanefeld } \\
(6) \\
130(78 \%) \text { with epilepsy }\end{array}$ & $\begin{array}{l}\text { Video EEG (not reported) } \\
\text { Italian multicenter retrospective study }\end{array}$ & $\begin{array}{l}\text { Epilepsy and RTT variants / / mutation type } \\
\text { no epilepsy }(n=35) \text {, drug-responsive }(n=81) \text { and drug-resistant }(n=49)\end{array}$ \\
\hline [67] & RTT: 2: 7, 12 у о & EEG and lower limb EMG during gait & $\begin{array}{l}\text { EMG burst were not associated with clinical jerking but EMG burst-locked } \\
\text { averaging of the EEG showed contralateral centroparietal spiking preceding the } \\
\text { burst by about } 35 \mathrm{~ms} \text {, indicating a cortical reflex myoclonus. }\end{array}$ \\
\hline$[68]$ & RTT: 11: 1-33 у о & & $\begin{array}{c}\text { Seizures }(n=8) \\
\text { Epileptiform activity }(n=7)\end{array}$ \\
\hline [69] & $\begin{array}{l}\text { RTT: } 3: 9.5,7.4 \text { and } 9.4 \text { y o, each with a } \\
\text { mutation of the CDKL5 gene. }\end{array}$ & Video EEGs & Seizure onset 1.5 months \\
\hline$[70]$ & $\begin{array}{l}\text { Girl with mutation of MECP2 but no clear } \\
\text { RTT phenotype: } 8 \text { y o }\end{array}$ & EEG & $\begin{array}{c}5 \text { and } 7 \text { y o EEG: presence of high-amplitude delta waves with a notched } \\
\text { appearance and a persistent theta activity over posterior regions (EEG of Angelman } \\
\text { Syndrome) }\end{array}$ \\
\hline [71] & RTT: 50: 1-14 у о & 16-channel EEG & $\begin{array}{c}\text { Descriptive EEG, epilepsy presence is not reported } \\
\text { Changes with RTT progression }\end{array}$ \\
\hline [72] & $\begin{array}{l}\text { RTT: 1: MECP2 mutation } \\
\text { At age } 2 \text { and } 6\end{array}$ & EEG & $\begin{array}{l}\text { Age 6: rhythmic triphasic 2- to 3-Hz, high voltage }(200-500 \mathrm{mkV}) \text { activity, mixed } \\
\text { with spikes or sharp waves, with a maximum over the frontal regions (EEG of } \\
\text { Angelman Syndrome) }\end{array}$ \\
\hline
\end{tabular}


Table 1. Cont

\begin{tabular}{|c|c|c|c|}
\hline Study & Sample (n: Age) & EEG Settings & EEG Characteristics \\
\hline [73] & $\begin{array}{l}\text { RTT: } 10:<5 \text { y o } \\
\text { Angelman Syndrome (AS):10 } \\
\text { Mental retardation:10 }\end{array}$ & & Central and/or centro-temporal spike-wave complexes as specific to RTT \\
\hline [74] & $\begin{array}{l}\text { RTT: } 191 \text { (detailed survey) } \\
\text { 78-EEG }\end{array}$ & Awake and sleep EEG & $\begin{array}{l}76 \% \text { clinical seizures } \\
78 \% \text { epileptiform activity that preceded seizure onset }\end{array}$ \\
\hline [75] & RTT: 13: 2-17 y o & Awake and sleep EEG, SPECT & $\begin{array}{l}\text { Epileptiform activity }(n=10) \\
\text { Frontal hypoperfusion that is not correlated with EEG abnormalities }\end{array}$ \\
\hline [77] & $\begin{array}{c}\text { RTT: 16: } 8 \text { months-20 y o } \\
44 \text { EEG }\end{array}$ & EEG, respiration & $\begin{array}{l}\text { Pseudoperiodic pattern, the short bursts of high-amplitude slow waves tending to be } \\
\text { associated with apnea and the lower-amplitude faster rhythms with normal breathing or } \\
\text { with hyperventilation }(n=8)\end{array}$ \\
\hline [79] & RTT: 4: $4-11$ у о & $\begin{array}{c}\text { All-night electroencephalograms } \\
\text { (EEGs)/polysomnograms on } 2 \text { consecutive } \\
\text { nights }\end{array}$ & Epileptiform activity maximum over 1-2 SWS sleep stage and in the morning hours \\
\hline$[80]$ & RTT: 4: 3.5, 6, 11 and 12 y o & $\begin{array}{l}\text { Light no-REM sleep or the state lethargy } \\
\text { (wake without slight index of awareness) }\end{array}$ & $\begin{array}{c}\text { Epileptiform activity, in particular, CTS, blocked or attenuated by passive finger } \\
\text { movements }\end{array}$ \\
\hline
\end{tabular}


Table 1. Cont.

\begin{tabular}{|c|c|c|c|}
\hline Study & Sample (n: Age) & EEG Settings & EEG Characteristics \\
\hline [81] & $\begin{array}{l}\text { RTT: 30: 2-22 y o } \\
\text { 127 EEG-recordings }\end{array}$ & Awake and sleep EEG, EMG & $\begin{array}{l}\text { Epileptiform activity }(n=26) \\
\text { CTS }(n=10) \\
\text { Pseudoperiodic delta bursts }(n=13) \\
\text { Flat record }(n=2) \\
\text { Developmental changes }\end{array}$ \\
\hline$[82]$ & RTT: 13: 2-17 у о & Awake and sleep EEG, EMG & $\begin{array}{l}\text { Seizures }(n=5) \\
\text { Epileptiform activity }(n=10) \\
\text { Pseudorhythmic flattering }(n=4)\end{array}$ \\
\hline [83] & RTT: 8: 2-16 у о & Awake and sleep EEG & $\begin{array}{c}\text { Background EEG slowing } \\
\text { Epileptiform activity } \\
\text { A monotonous theta rhythm (MTR), which was not influenced by either opening or } \\
\text { closing of the eyes but attenuated only by a big noise or strong pain stimuli, } \\
\text { characteristically dominated the waking tracing } \\
\text { EEG through disease progression }\end{array}$ \\
\hline$[84]$ & $\begin{array}{l}\text { RTT: } 52: 1-13 \text { y o } \\
83 \text { EEG recordings }\end{array}$ & Awake and sleep 8-channels EEG, EMG & $\begin{array}{l}\text { Seizures }(n=26+3) \\
\text { Epileptiform activity, enhanced during sleep }(n=43) \\
\text { CTS often coincided with stereotyped hand wringing or tapping and facilitated } \\
\text { over the contralateral central regions by passive tactile stimulation }(9 \text { of } 26 \text { girls } \\
\text { tested) } \\
\text { Excesses of theta and delta activity }(n=12, n=7)\end{array}$ \\
\hline [39] & $\begin{array}{l}\text { RTT: 9: } 1-6 \text { y o } \\
22 \text { EEG recordings }\end{array}$ & EEG, video EEG in two patients & $\begin{array}{c}\text { Seizures }(n=7) \\
\text { Epileptiform activity ( } n=9, \text { in } 3 \text { epileptiform activity preceded development of } \\
\text { seizures) } \\
\text { Abnormalities increases with age }\end{array}$ \\
\hline$[85]$ & RTT: 7: 1-7 y o & Awake and sleep EEG & $\begin{array}{l}\text { Reactive Theta, Excessed Delta, Flattering EEG, epileptiform activity, atypical sleep } \\
\text { EEG } \\
\text { CTS }(n=4) \text { including those evoked by tactile stimulation }(n=2) \\
\text { Changes with RTT progression }\end{array}$ \\
\hline [86] & RTT: 18: 1-17 y o & $\begin{array}{l}\text { Awake and sleep EEG, respiration } \\
\text { biogenic amine metabolites }\end{array}$ & $\begin{array}{c}\text { Reduced \% stage REM }(n=15) \\
\text { EEG slowing } \\
\text { Epileptiform activity } \\
\text { Absent vertex transients and spindles during NREM }\end{array}$ \\
\hline
\end{tabular}


Table 1. Cont.

\begin{tabular}{|c|c|c|c|}
\hline Study & Sample (n: Age) & EEG Settings & EEG Characteristics \\
\hline [87] & RTT: 11: 4-14 у о & Awake and sleep EEG & $\begin{array}{c}\text { Slowing of background EEG }(n=11) \\
\text { activity while awake } \\
\text { Multifocal spike-waves (centrotemporal regions) }(n=9) \\
\text { Intermittent, high-amplitude discharges followed by relative attenuation of } \\
\text { background activity during sleep }(n=6)\end{array}$ \\
\hline [88] & $\begin{array}{l}\text { RTT: 9: } 2-15 \text { y o } \\
35 \text { EEG recordings }\end{array}$ & EEG & $\begin{array}{l}\text { Seizures }(n=7) \\
\text { Epileptiform activity }(n=7) \\
\text { Slowing of background EEG } \\
\text { Progression through disease }\end{array}$ \\
\hline [89] & RTT: 8: 4-13 у о & Awake and sleep EEG, EMG & $\begin{array}{l}\text { Myoclonic jerks }(n=8) \\
\text { EEG is poorly organized with high amplitude slow waves short, non-periodic } \\
\text { bursts; focal or diffuse spike and wave complexes increased in sleep }\end{array}$ \\
\hline [90] & RTT: 1, 2 y o & EEG & Unspecific modification on EEG, no seizures \\
\hline
\end{tabular}




\section{Centro-Temporal Spikes as a Frequent Epileptiform Abnormality in RTT}

Among the broad range of epileptiform abnormalities seen in RTT, centro-temporal spikes (CTS) of short duration are the most common and have the earliest manifestation $[38,80,90]$. CTS are particularly associated with idiopathic focal epilepsy syndrome in childhood (aka, benign epilepsy of childhood with CTS: BECTS). BECTS is the most common pediatric epilepsy syndrome, usually occurring in asymptomatic children aged 4-15 years, with cessation of seizures by adulthood. In contrast to the previously assumed benign course, a growing literature has documented pervasive cognitive and/or behavioral problems in children with BECTS, especially in the domains of language, verbal memory and fine motor skills [91,92].

CTS can be suggested to reflect altered excitability of the perisylvian cortical areas that may contribute to motor and speech disturbances in RTT patients. Evidence for the relevance of CTS to motor control comes from studies that found a suppression of focal CTS by hand tapping/clapping in a subgroup of patients with RTT with six representative cases described in the literature $[60,61,75,93]$. In line with these observations, Cooper and colleagues reported a decrease in EEG abnormality during hyperventilation that is accompanied by increased movement in young girls with RTT [74]. The suppression of CTS by hand movements is a rare phenomenon, and we are aware of only one other neurological condition, in which this phenomenon was also described-BECTS [93]. The authors suggested that decreased top-down inhibitory control over the motor cortex is the main cause for such motor cortex hyperexcitability at rest [80,94]. In line with this hypothesis, frontal hypoperfusion was reported in patients with RTT [75] and recent research demonstrated that BECTS is associated with decreased fMRI functional connectivity in dorsal frontal network [95], and with a deficit in executive functioning [96]. Niedermeyer's suggestion is also in accord with recent animal findings of reduced excitatory synaptic connectivity in the prefrontal cortex of mice lacking MECP2 [97], and with evidence proving a causal role of disrupted inhibitory transmission in RTT animal models [98].

Interestingly, some patients with RTT exhibit the opposite relationship between CTS and movements, such that centro-temporal spikes in their EEG are triggered by hand movements and disappear when movements stop. Hand stereotypes were a major trigger of this epileptiform activity with six patients introduced in case reports $[59,65]$. Hand stereotypes often coincides with spikes over central region with passive tactile stimulation leading to its facilitation in about $30 \%$ of patients with RTT as reported in the first EEG studies on RTT ( 2 out of 7 patients in [85] and in 9 of 26 in [84]), suggesting high incidence of this response in RTT. Noteworthy, in some cases CTS can be precipitated by specific movements. In a case reported by Luo and colleagues, CTS were only induced by right hand-to-lips tapping but not by right hand tapping cheek or abdomen, the left hand tapping lips or observer's hand tapping the lips [60]. Roche Martínez and colleagues reported three epileptic Rett patients with reflex seizures triggered by food intake or proprioception [66]. Conceivably, unlike those CTSs that are suppressed by movements, CTSs that are triggered by movements may be related to enhanced excitability of somato-sensory cortex, which receives proprioceptive feedback during movement execution. Indeed, some patients with RTT display exaggerated cortical somato-sensory responses to incoming somatosensory input in the form of "giant somatosensory potentials" [99-101]. The "giant somatosensory potentials" in RTT patients are similar to those in patients with cortical reflex myoclonus, which are often associated with myoclonic jerks $[55,67,99]$. Reduced phasic inhibition, mediated by GABAa receptor activity, that is described in the subsequent session on animal models, might also play a role in the generation of this seizure type.

Thus, centro-temporal spikes in RTT seem to be related to movement atypicalities, although how they are induced or ameliorated across participants varies, suggesting different paths to this movement associated epileptic activity. Excitatory/inhibitory balance seems to be altered in different ways in various parts of the brain and even cortical areas. Type of mutation and X-inactivation profile may play major roles in the relationship between 
reduced top-down control from prefrontal cortex and hyperexcitability of somatosensory cortex in RTT patents determining the mechanism of CTS induction and suppression.

Development of Seizures and Severity of RTT Symptoms

Average age of seizure onset in patients with RTT is about 4 years of age, that is greater as compared to other patients with severe mental retardation, who develop seizure much earlier before children reach their first birthday [102]. At the same time, earlier seizure onset in RTT was associated with a more severe course of seizure but not with the severity of the other RTT symptoms [103]. Many patients with RTT are seizure-free at stage II when the clear symptoms of the deterioration in motor and cognitive behavior are already present.

Nonetheless, there is some evidence for association of epileptic seizures with greater severity of RTT. Pintaudi and colleagues showed that less severe forms of the condition, characterized by the preservation of speech, is associated with lower incidence of epilepsy than classic forms of the syndrome [44]. Tarquinio and colleagues reported that another atypical form of RTT with more profound developmental delay exhibited higher prevalence of seizures [43]. In line with this link between RTT severity and epilepsy, patients with a classic RTT phenotype who are more severely affected are more likely to have seizures [43,51,104]. As standardized measures of cognition cannot typically be used to assess cognitive function in individuals with RTT, we highlight the study of Vignolli and colleagues [49] that implicated eye-tracking to objectively evaluate cognitive performance of 18 girls with RTT at clinical stage III and IV on several cognitive tasks. For example, voluntary gaze behavior served to demonstrate the ability to follow verbal instructions, and recognition and categorization of visual images. Performance on these tasks, and more traditional measures of behavioral functioning (vineland adaptive behavior scales) were directly compared with severity of epilepsy and EEG epileptiform abnormalities in the RTT sample. The authors reported that earlier age of epilepsy onset and higher seizure frequency were associated with poorer cognitive outcome (fixation time on correct stimuli). In addition to these clinical features, relatively worse cognitive functioning in girls with RTT was also associated with severely disturbed spontaneous EEG patterns that were characterized by more diffuse and multifocal epileptiform discharges. In accord with this conclusion, Buoni and colleagues [50] observed that multifocal epileptiform discharges were absent in EEG of high functioning girls with RTT with preserved speech, although they still had focal EEG centro-temporal spikes. Nevertheless, causal relationships between seizures and developmental trajectory of RTT disorder remains unclear. For example, a recent large-scale study of 793 individuals reported that there were no significant associations between age of developmental regression and age of seizure onset in patients with RTT or in patients with so-called RTT-like disorders [42]. Thus, findings of the above correlative nature do not ascertain whether the epilepsy plays a crucial role in deteriorated cognitive abilities in RTT, or if it alternatively reflects the more severe underlying pathophysiology [105]. In support of the latter explanation, Cooper and colleagues reported that increases in EEG abnormalities and seizures follows developmental regression rather than precedes it in patients with RTT, thus reflecting the consequences of pathological processes that trigger the regression [74]. In sum, epilepsy is hardly an underlying cause, rather it displays comorbidity with RTT disorder. While at the extremes (e.g., when comparing atypical forms of RTT) it seems that seizure frequency relates to RTT severity and this is certainly of interest, by itself it is unlikely to be a valuable biomarker of RTT.

\subsubsection{Animal Studies}

Animal models of RTT partly recapitulate a seizure phenotype described in patients with RTT [106-108]. The most confirmed form of seizures in mice with MECP2 deficiency are spontaneous absences accompanied by spike-wave discharges (SWDs) [107,109-112], which undergo dramatic increase in incidence and duration from 13 to 104 weeks [113] (Table 2). SWDs observed in mouse models of RTT have a frequency of around 6-8 Hz and are suppressed by ethosuximide, which is similar to findings in inbred strains (i.e., 
nearly genetically identical animals due to long inbreeding), which were used to create RTT models [114]. At the same time in comparison to inbred strains, RTT mouse models have increased number of SWD episodes and prolonged duration of these episodes pointing to the modulatory role of MECP2 deficit in the development of this type of seizures. Despite being the most prevalent type of epileptic seizures in animal models of RTT, typical absences are rarely observed in human patients with RTT [41]. Partly it could be explained by difficulties in their detection in patients as this type of seizures can be easily missed without prolonged EEG recording. Another explanation might be related to betweenspecies differences in thalamocortical interactions and the role of sensory inflow: in rodents, sensory inflow from whiskers into somatosensory cortex, the dominant area of SWD, is crucial for generation of absences [115]. Differences between epileptic phenomenology in human patients and animal models also can be explained by the much more pronounced Mecp2 abnormalities in the most common animal models of RTT-Mecp2-knockout male mice as compared to female patients with $M E C P 2$ mutations. In line with this explanation, study on male mice with MECP2 truncated at C-terminal domain found myoclonic jerks accompanied by single SWDs [106]. Thus, the milder Mecp2-dysfunction may lead to the generation of single SWDs but in contrast to Mecp2-null mice prevents the development of full-blown absences with SWD complexes. Noteworthy, myoclonus is frequently reported in patients with RTT $[55,67,99]$. 
Table 2. Characteristics of EEG and epileptic phenotype in animal models of RTT.

\begin{tabular}{|c|c|c|c|c|}
\hline Study & Genotype (Age) & $\begin{array}{l}\text { Electrode Position, } \\
\text { Behavioral State }\end{array}$ & EEG Characteristics & Seizure Characteristics (Prevalence) \\
\hline [113] & Mecp-/+ (from 13 to 104 weeks) & $\begin{array}{l}\text { hippocampal CA1 and } \\
\text { contralateral } \\
\text { somatosensory cortex, } \\
\text { free behavior }\end{array}$ & & $\begin{array}{c}\text { cortical discharges, behavioral freezing } \\
13 \text { weeks } \\
\text { average number per hour: } 20.7 \pm 11.7 \\
\text { duration: } 0.9 \pm 0.28 \mathrm{~s} \\
104 \text { weeks } \\
\text { average number per hour: } 116.8 \pm 44.2 \\
\text { duration: } 1.7 \pm 0.23 \mathrm{~s} \\
\text { aggravated by levetiracetam } \\
\text { reduced by valproic acid and acetazolamide } \\
\text { suppressed by ethosuximide }\end{array}$ \\
\hline [116] & $\begin{array}{c}\text { Vglut2-Mecp2flox/y (10 weeks) } \\
\text { Vglut2-Mecp2LSL/y (25-30 weeks) }\end{array}$ & $\begin{array}{l}\text { right frontal cortex and } \\
\text { somatosensory cortex } \\
\text { left hippocampal CA1 and } \\
\text { dentate regions }\end{array}$ & & $\begin{array}{c}\text { Vglut2-Mecp } 2 \text { flox/y }(37.5 \%) \\
\text { cortical spike-and-wave discharges } \\
\text { average number per hour: } 3.3 \pm 2.1 \\
\text { duration: } 4.1 \pm 0.4 \mathrm{~s} \\
\text { Vglut2-Mecp } 2 L S L / y(25 \%) \\
\text { cortical spike-and-wave discharges } \\
\text { average number per hour: } 3.3 \\
\text { duration: } 4.5 \pm 0.8 \mathrm{~s}\end{array}$ \\
\hline [110] & $\begin{array}{l}\text { PV-Mecp2-/y } \\
\text { SOM-Mecp2-/y }\end{array}$ & & & $\begin{array}{c}\text { SOM-Mecp2-/y (50\%) } \\
\text { epileptic seizures starting at } 12 \text { weeks generalized tonic-clonic } \\
\text { seizures observed during routine handling } \\
\text { PV-Mecp2-/y } \\
\text { no seizures }\end{array}$ \\
\hline
\end{tabular}


Table 2. Cont.

\begin{tabular}{|c|c|c|c|c|}
\hline Study & Genotype (Age) & $\begin{array}{l}\text { Electrode Position, } \\
\text { Behavioral State }\end{array}$ & EEG Characteristics & Seizure Characteristics (Prevalence) \\
\hline [111] & $\begin{array}{c}\text { Rosa26-Esr/Cre-Mecp2 Stop/ }+ \\
\text { (around } 36 \text { week) } \\
\text { Rosa26-Esr/Cre-Mecp2Stop/y } \\
\text { (5.5-8.5 weeks) }\end{array}$ & $\begin{array}{l}\text { hippocampal CA1 and } \\
\text { contralateral } \\
\text { somatosensory cortex, } \\
\text { free behavior }\end{array}$ & $\begin{array}{c}\boldsymbol{\nabla} \text { gamma }(35-60 \mathrm{~Hz}) \text { power } \\
(\text { Rosa26-Esr/Cre-Mecp2Stop/+; } \\
\text { Rosa26-Esr/Cre-Mecp2Stop/y) } \\
\text { rescue in Rosa26-Esr/Cre-Mecp2Stop/y } \\
\boldsymbol{\nabla} \text { theta frequency } \\
\text { rescue in Rosa26-Esr/Cre-Mecp2Stop/y }\end{array}$ & $\begin{array}{c}\text { Rosa26-Esr/Cre-Mecp2Stop/y } \\
\text { cortical discharges } \\
\text { average number per hour: } 45 \pm 8 \\
\text { duration: } 2.8 \pm 0.7 \mathrm{~s} \\
\text { frequency: } 6.2 \pm 0.3 \mathrm{~Hz} \\
\text { Rosa26-Esr/Cre-Mecp } 2 \text { Stop/y-rescue } \\
\text { cortical discharges } \\
\text { average number per hour: } 21 \pm 3 \\
\text { duration: } 1.0 \pm 0.1 \mathrm{~s} \\
\text { frequency: } 6.8 \pm 0.2 \mathrm{~Hz} \\
\text { Rosa26-Esr/Cre- Mecp } 2 \mathrm{Stop} /+ \\
\text { cortical discharges } \\
\text { average number per hour: } 76 \pm 17 \\
\text { duration: } 1.11 \pm 0.1 \mathrm{~s} \\
\text { frequency: } 7.9 \pm 0.4 \mathrm{~Hz} \\
\text { Rosa26-Esr/Cre-Mecp } 2 \text { Stop/ }+ \text {-rescue } \\
\text { cortical discharges } \\
\text { average number per hour: } 32 \pm 4 \\
\text { duration: } 1.2 \pm 0.1 \mathrm{~s} \\
\text { frequency: } 7.7 \pm 0.3 \mathrm{~Hz}\end{array}$ \\
\hline [117] & Mecp2tm1.1Bird (6-7 weeks) & $\begin{array}{l}\text { the M1 region of the frontal } \\
\text { cortex, free behavior }\end{array}$ & $\boldsymbol{\nabla}$ delta power during NREM & $\begin{array}{l}\text { cortical discharges, behavioral freezing } \\
13 \text { weeks } \\
\text { average number per } 20.7 \pm 11.7 \text { versus } 116.8 \pm 44.2 \\
104 \text { weeks }\end{array}$ \\
\hline$[98]$ & $\begin{array}{c}\text { Emx1-Mecp2, Dlx6a-Mecp2 } \\
\text { (6-8 weeks) }\end{array}$ & frontal and parietal cortex & & $\begin{array}{c}E m x 1-M e c p 2 \\
\text { spike-wave discharges, absence seizures } \\
\text { average number per hour: } 36 \pm 7 \\
\text { duration: } 1.3 \pm 0.1 \mathrm{~s} \\
\text { Dlx6a-Mecp } 2 \\
\text { no discharges }\end{array}$ \\
\hline
\end{tabular}


Table 2. Cont.

\begin{tabular}{|c|c|c|c|c|}
\hline Study & Genotype (Age) & $\begin{array}{l}\text { Electrode Position, } \\
\text { Behavioral State }\end{array}$ & EEG Characteristics & Seizure Characteristics (Prevalence) \\
\hline [109] & $\begin{array}{c}\text { Mecp22lox/y; Dlx5/6-Cre } \\
\text { Mecp22lox/y; Emx1-Cre Mecp2Stop/y; } \\
\text { Emx1-Cre }(8,7 \text { weeks) } \\
\text { Mecp22lox/y; PV-Cre (13 weeks) } \\
\text { Mecp22lox/y; SOM-Cre } \\
\text { (13 weeks) }\end{array}$ & hippocampus & & $\begin{array}{c}\text { Mecp22lox/y; Dlx5/6-Cre } \\
\text { behavioral seizures following handling } \\
\text { spikes and wave discharges, behavioral arrest } \\
\text { Mecp22lox/y; Emx } 1 \text {-Cre } \\
\text { no behavioral or electrographic seizures } \\
\text { Mecp2Stop/y; Emx1-Cre } \\
\text { behavioral seizures } \\
\text { Mecp22lox/y; PV-Cre } \\
\text { no behavioral seizures } \\
\text { Mecp22lox/y; SOM-Cre } \\
\text { no behavioral seizures }\end{array}$ \\
\hline [118] & $\begin{array}{c}\text { Mecp2-/+, } \\
\text { Mecp2-/y, } \\
\text { TH-Mecp Stop/+ (around 36 weeks) } \\
\text { TH-Mecp2Stop/y (5.5-8.5 weeks) }\end{array}$ & $\begin{array}{l}\text { hippocampal CA1 and } \\
\text { contralateral } \\
\text { somatosensory cortex, } \\
\text { free behavior }\end{array}$ & $\begin{array}{l}\qquad \boldsymbol{\nabla} \text { theta frequency } \\
\text { partial preservation in TH-Mecp2Stop/y } \\
\boldsymbol{\nabla} \text { gamma (35-60 Hz) power } \\
\text { partial preservation in TH-Mecp2Stop/y }\end{array}$ & $\begin{array}{c}\text { Mecp } 2-/ y(100 \%) \\
\text { cortical discharges } \\
\text { average number per hour: } 42.1 \pm 7.9 \\
\text { duration: } 2.8 \pm 0.7 \mathrm{~s} \\
\text { frequency: } 6.2 \pm 0.3 \mathrm{~Hz} \\
\text { TH-Mecp } 2 \text { Stop/y }(100 \%) \\
\text { cortical discharges } \\
\text { average number per hour: } 20.5 \pm 6.3 \\
\text { duration: } 2.2 \pm 0.6 \mathrm{~s} \\
\text { frequency: } 6.5 \pm 0.36 \mathrm{~Hz} \\
\text { Mecp2- } /+ \\
\text { cortical discharges } \\
\text { average number per hour: } 69.6 \pm 15.5 \\
\text { TH-Mecp Stop/+ } \\
\text { cortical discharges } \\
\text { average number per hour: } 67.1 \pm 13.9\end{array}$ \\
\hline [29] & $\begin{array}{c}\text { Mecp2T158A/y (4.2 weeks and } 12.9 \\
\text { weeks), Mecp2-/y (12.9 weeks) }\end{array}$ & $\begin{array}{l}\text { hippocampal electrode, } \\
\text { free behavior }\end{array}$ & $\begin{array}{l}\text { ه gamma high }(70-140 \mathrm{~Hz}) \text { power } \\
\text { seizure behaviors (unspecified) }\end{array}$ & \\
\hline [112] & Mecp2-/+ (42-57 weeks) & $\begin{array}{l}\text { parietal cortex, } \\
\text { free behavior }\end{array}$ & 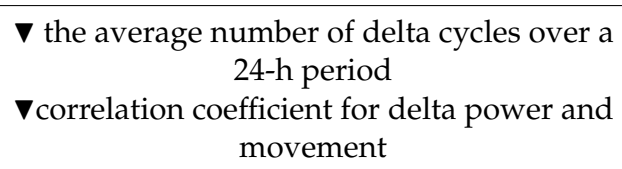 & $\begin{array}{c}\text { cortical discharges, behavioral freezing } \\
\text { average number per hour: } 10.7 \pm 1.6 \\
\text { duration: } 0.76 \pm 0.01 \mathrm{~s} \\
\text { frequency: } 8.6 \pm 0.02 \mathrm{~Hz}\end{array}$ \\
\hline
\end{tabular}


Table 2. Cont.

\begin{tabular}{|c|c|c|c|c|}
\hline Study & Genotype (Age) & $\begin{array}{l}\text { Electrode Position, } \\
\text { Behavioral State }\end{array}$ & EEG Characteristics & Seizure Characteristics (Prevalence) \\
\hline [119] & $\begin{array}{c}\text { Viaat-Mecp } 2-/ y \text { (9 weeks) } \\
\text { Dlx5/6-Mecp2-/y (39 weeks) }\end{array}$ & $\begin{array}{l}\text { cortical electrodes, free } \\
\text { behavior }\end{array}$ & & $\begin{array}{c}\text { Viaat-Mecp } 2-/ y \\
\text { hyperexcitability discharges, no electrographic seizures } \\
D l x 5 / 6-M e c p 2-/ y \\
\text { no hyperexcitability discharges }\end{array}$ \\
\hline [107] & $\begin{array}{l}\text { Mecp2-/y (7-10 weeks) } \\
\text { Mecp -/+ (35-52 weeks) }\end{array}$ & $\begin{array}{l}\text { hippocampal CA1 and } \\
\text { contralateral } \\
\text { somatosensory cortex, } \\
\text { free behavior }\end{array}$ & $\begin{array}{c}\boldsymbol{\nabla} \text { theta frequency (hippocampus) } \\
\text { desynchronized, low-amplitude cortical } \\
\text { activity } \\
=\text { cortical delta and hippocampal sharp-wave } \\
\text { activity during sleep }\end{array}$ & $\begin{array}{c}\text { Mecp }-/+(100 \%) \\
\text { cortical discharges, immobile animal, no myoclonus } \\
\text { average number per hour: } 9.1 \pm 1.3 \\
\text { duration: } 1-2 \mathrm{~s} \\
\text { frequency: } 8.8 \pm 1.3 \mathrm{~Hz} \\
\text { suppressed by ethosuximide }\end{array}$ \\
\hline
\end{tabular}

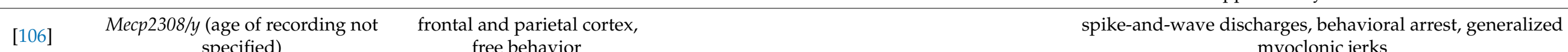

$$
\text { specified) }
$$

free behavior

myoclonic jerks

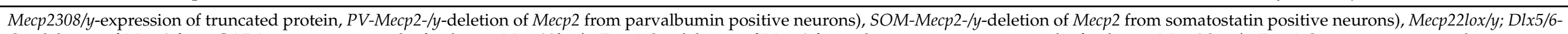

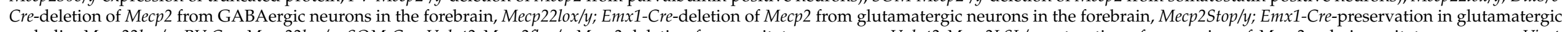

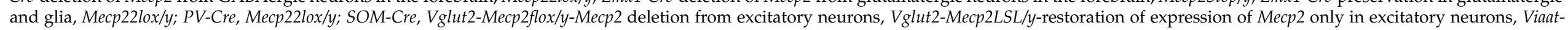

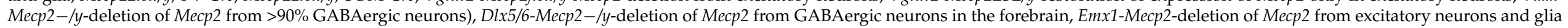

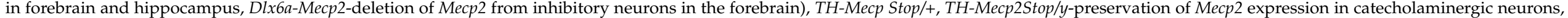
Mecp2tm1.1Bird-Mecp2 knockout. 
Nevertheless, there is a question why and how MECP2 deficiency leads to the increase in the occurrence of seizures. Lang and colleagues reinstated MECP2 expression in Mecp2-deficient adult mice and observed a significant attenuation of abundant SWD in their spontaneous EEG [111]. Thus, even in adult subjects constitutively lacking Mecp2 the absence seizures may be abolished through restoring a normal MECP2 function in the whole brain. More specifically, the restoration of MECP2 function specifically in GABAergic neurons rescues the seizure phenotype [120], suggesting that abnormal inhibitory transmission is both necessary and sufficient for absence seizures induction in RTT. The selective removal of Mecp 2 from glutamatergic neurons also induces absence seizures but only in $37.5 \%$ of animals, and the restoration of MECP2 expression only in these neurons does not lead to freedom from seizures [116]. Thus, abnormal inhibitory transmission has a primary role in absence seizure generation, while impaired excitation may also contribute to this process but probably in an indirect way through activation of inhibitory neurons [98]. Although not being necessary for development of absences, altered excitation may be causative for convulsive seizures. Activation of kainate receptors leads to increased power of gamma oscillations in Mecp2-null mice in comparison to wild type in vitro and induces more pronounced behavioral seizures in vivo [121].

Closer look into GABAergic impairment in MECP2-deficient animals can explain the occurrence and specificity of epileptic activity (Figure 1). MECP2 is highly expressed in GABAergic neurons (150\% compared to neurons lacking GABA) and the loss-of-function of MECP2 leads to decreased intracellular concentration of GABA [119]. Proteins involved in GABA synthesis (GAD65, GAD67), vesicular packing (VGAT) and reuptake (GAT1) are downregulated in animal models of RTT [108,119,122]. Increased GABA spillover due to downregulated GAT1 induces activation of extrasynaptic GABA receptors, which increases tonic inhibition. At the same time, the increased tonic inhibition was shown to be associated with the development of SWDs [123,124]. In line with this logic, Zhang and colleagues proved that in animal model of RTT increased spillover concentration of GABA is consequential for seizures, as application of GAT- 1 inhibitor further increases epileptiform discharges in MECP2-deficient mice, and at a higher dose induces the epileptiform discharges even in the wild type animals [108]. In firm support of a causative role of increased tonic inhibition for seizure generation in mice lacking MECP2, this study demonstrated that enhancing a sensitivity of GABAb receptors by acting on them with selective activity-dependent receptor enhancer increased seizure incidence and duration but slowed down the frequency of oscillations, while agonist of extrasynaptic GABAa receptors decreased their incidence. Such changes are well-predicted by a computational model in which increased GABAb receptors' conductance led to a higher incidence, a longer duration and lower frequency of SWDs and the opposite effects were observed after increasing activation of GABAa receptors [125]. The extend of Mecp2 dysfunction was also found to be related to SWD characteristics: male mice RTT model, with full absence of X-linked Mecp2, have longer duration and slower frequency of SWD than females which have the intact Mecp2 gene on one X chromosome [111]. Thus, characteristics of SWD may serve as a biomarker of GABAergic impairment in animal models of RTT. As for RTT patients, more attention to detection of SWD in this group will clarify the true prevalence and etiology of this epileptiform activity in RTT patients. In line with causative role of imbalance between extrasynaptic GABAa and GABAb receptors in the development of SWDs, Okamoto and colleagues described the female patient with mutation in gene encoding extrasynaptic GABAa $\delta$-subunit, which was diagnosed with RTT and showed SWD [126].

Tactile stimulation by routine handling evokes convulsive seizure in animals lacking MECP2 in GABAergic neurons [109]. These seizures were observed at age of 12 weeks when behavioral symptoms were already pronounced resembling the development of epilepsy in RTT patients, which is usually diagnosed after the developmental regression [46]. Ito-Ishida and colleagues showed that handling induced tonic-clonic seizures only after conditional deletion of Mecp 2 from somatostatin-positive but not parvalbumin-positive inhibitory neurons [110]. Meng and colleagues observed similar tonic-clonic seizures in mice with 
selective preservation of MECP2 in glutamatergic neurons, which underlines the crucial role of MECP2 in inhibitory neurons in the development of this type of seizures in animal models of RTT [116]. Induction of seizures by handling can be caused by evoked hyperexcitability of neuronal networks due to reduced phasic inhibition. Indeed, application of GABAa antagonist bicuculline leads to higher incidence and duration of epileptiform spikes in hippocampal slices [121]. Noteworthy, GABAa mediated tonic inhibition was also decreased in the hippocampus, which can also participate in proneness to convulsive seizures [127].

The screwed crosstalk between GABAa and GABAb in RTT might be related to potassium chloride cotransporter 2 (KCC2), which contributes to the low intracellular chloride concentrations found in mature neurons and thus establishes the conditions for the hyperpolarizing effect of GABAaRs [128]. KCC2 is downregulated in RTT patients and mouse models [129-131]. Activation of the GABAbR results in reduced levels of KCC2 at the cell surface, which parallels an increase in intracellular chloride, thus making GABAa-mediated inhibition less efficient [132]. Affecting the ratio of KCC2 to Na-K-Cl Cotransporter 1 (NKCC1), a membrane transporter that is functionally antagonized to $\mathrm{KCC} 2$, seems to be a promising direction in RTT therapy restoring electrophysiological and morphological characteristics in MECP2-deficient animals and neurons cultured from RTT patients $[133,134]$.

Besides the inhibitory transmission by itself, a preponderance of seizures in RTT is affected by a plethora of factors modulating the inner excitatory state of inhibitory circuitry. For example, seizure predisposition may be provoked by a selective loss of MECP2 in cholinergic neurons via decreased expression of excitatory cholinergic receptors $(\alpha 7 \mathrm{nAChR})$ in parvalbumin-positive inhibitory neurons [135]. Thus, the genesis of seizures in RTT can be attributed to a multilevel disruption of neuronal circuits consequential to the dysfunction in several different molecular pathways with the major role of inhibitory signaling, particularly the balance between tonic and phasic inhibition.

\subsection{Abnormalities in Resting EEG Spectra and Their Neurophysiological Underpinnings}

\subsubsection{Patient Studies}

\section{General Slowing of Background EEG Activity}

EEG abnormalities in RTT are not limited to epileptiform activity. General slowing of background EEG activity was consistently reported in patients with RTT and is observed even at the earliest stage of the disorder $[39,49,76,79,81,84,87,94,136,137]$. General slowing of EEG rhythms in clinical studies is often referring to as one of two qualitatively distinct phenomena. This term designates either an abnormally low peak frequency of oscillations within particular functionally distinct EEG rhythm e.g., sensory-motor mu rhythm or visual alpha rhythm, or heightened amplitude and/or abundance of theta and delta waves in spontaneous EEG in combination with abnormally low prominence of higher frequency activity within alpha and beta frequency bands. Both phenomena have been described for EEG of patients with RTT [49,71,76,80,81,94,99,137].

Several authors reported that the sensory-motor mu rhythm, with typical functional reactivity to passive/active movements and topographical maximum at central scalp electrodes, had abnormally low frequency in patients with RTT $[76,137]$. The shift of mu rhythm towards lower frequency was on average almost $5 \mathrm{~Hz}$, with mu frequencies varying from 8 to $13 \mathrm{~Hz}$ in typical subjects to $4-6 \mathrm{~Hz}$ in some patients with RTT. However, since none of the above studies employed statistical between-group comparisons, it is unclear whether "mu rhythm slowing" represents a general feature of RTT disorder or if it rather characterizes a specific subset of patients. Regarding visual alpha rhythm, occasional observations suggest that alpha frequency in people with RTT varies from unremarkable posterior alpha rhythm [76] to abnormally slow alpha variant [81]. However, the specific characteristics of these phenomena have not been quantified to date. Clearly, rigorous investigations into the spectral characteristics, cortical topography and functional reactivity of alpha rhythms in somatosensory and visual modalities are needed to confirm and 
extend the available qualitative observations of their abnormalities in people with RTT. Linking these EEG features to distinct RTT phenotypes appears to be a promising area of future research.

A more frequently reported EEG abnormality in RTT is atypical prevalence of low frequency activity in EEG spectra. This abnormality was well characterized both by clinical description $[71,82,87,89,90,136]$ and by statistical analysis (Tables 1 and 3). Since the first clinical reports EEG slowing was consistently reported in girls with RTT, e.g., in the form of delta and theta bursts $[89,136]$. Abnormal theta activity may be present either in the form of highly regular and prolonged fronto-temporal rhythmic episodes, or as the diffuse fronto-temporal theta waves with amplitudes twice as much as the background activity in the resting EEG [49,71,76,80,81,87,99,137,138].

Quantitative studies of spontaneous EEG recorded under eyes-open or eyes-closed conditions show the attenuation of alpha and beta band power with concomitant generalized increase of theta and delta activity in RTT $[137,139,142,143]$. Moreover, abnormally increased delta activity in girls with RTT was reported also during slow wave sleep (SWS), suggesting that predominance of low-frequency activity might characterize EEG in RTT regardless of the functional state [141].

RTT patients with highly deteriorated speech and motor functions were reported to have greater theta relative power across a variety of scalp electrodes [71]. Gratchev and colleagues found that earlier onset of RTT was associated not only with worse behavioral outcome but also with greater reduction of central and occipital alpha power and greater increase in central and frontal theta activity [138]. The largest quantitative study to date [139] found that increased delta power in 57 patients with RTT was correlated with worse performance on the Mullen scales of early learning (MSEL; [144]), a measure of multiple aspects of cognitive functioning). Vignolli and colleagues reported that RTT girls with relatively worse cognitive functioning had more severely disturbed spontaneous EEG patterns with an absence of occipitally dominant rhythmic activity (while not specified likely referring to alpha rhythms), and a marked slowing of background activity [49]. These studies provide tentative evidence for the extent of atypical low frequency activity in "background" EEG tracking with the severity of the disorder. However, since low frequency activity in EEG is not specific to RTT and characterizes a number of other neurological conditions and pervasive developmental disorders (e.g., attention deficit hyperactivity disorder: [145], obsessive compulsive disorder: [146]; Parkinson's disease: [147]), this potential biomarker of RTT severity might be related to general deterioration of brain function. 
Table 3. Quantitative EEG studies in patients with RTT.

\begin{tabular}{|c|c|c|c|}
\hline Study & Sample ( $n:$ Age) & EEG Settings & EEG Characteristics \\
\hline [139] & $\begin{array}{l}\text { RTT (57 including } 20 \text { in active regression (AR), } 29 \\
\text { post-regression (PR)): } 2-11) \\
\text { TD (37: } 2-11)\end{array}$ & $\begin{array}{l}\text { 128-channel Hydrocel Geodesic Sensor Net } \\
\text { System, 5-10 min while watching movies }\end{array}$ & 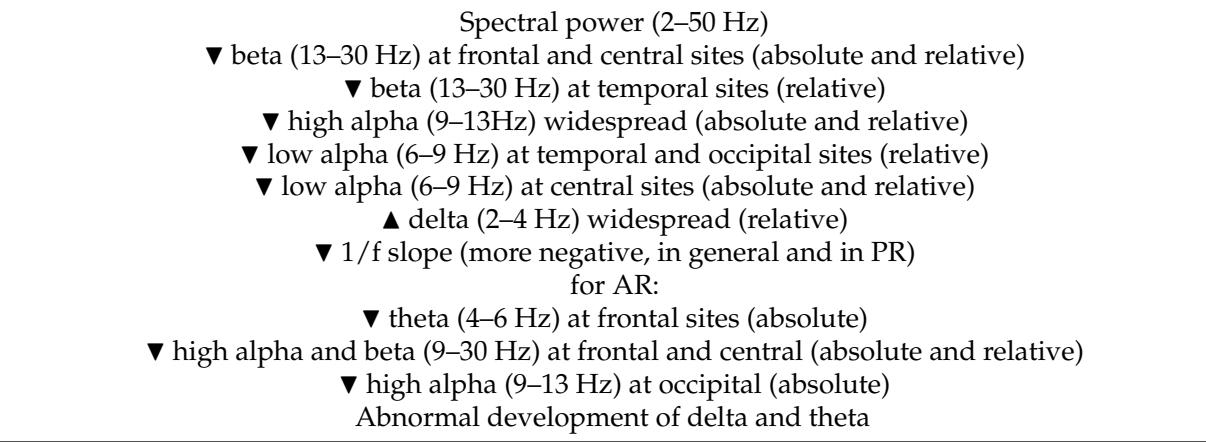 \\
\hline [140] & $\begin{array}{c}\text { RTT, MECP2 (32) } \\
\text { PSV, MECP2 (4) } \\
\text { RTT, CDKL5 (4) } \\
\text { including Resistant Epilepsy (8), Treatment } \\
\text { Responsive Epilepsy (16), without Epilepsy (18) } \\
\text { Mean age: } 7.69+/-5.22\end{array}$ & $\begin{array}{l}\text { 8-electrode EEG, minimum of } 20 \mathrm{~min} \\
\text { recordings during resting state }\end{array}$ & 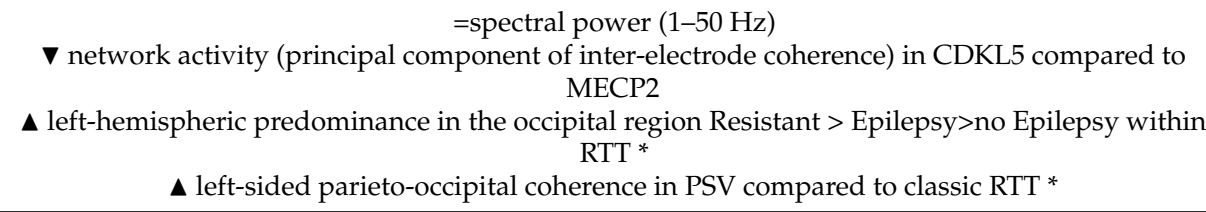 \\
\hline [141] & $\begin{array}{l}\text { RTT (10: 2-9) } \\
\text { TD (15: 2-9) }\end{array}$ & $\begin{array}{c}\text { Overnight (F3, C3, and O1), slow wave sleep } \\
\text { (SWS) }\end{array}$ & $\begin{array}{c}\text { Spectral power }(0.5-45 \mathrm{~Hz}) \\
\quad \mathbf{~ d e l t a} \\
\text { Absence of developmental decrease of gamma }(35-45 \mathrm{~Hz}) \text { * } \\
\mathbf{\nabla} \% \text { SWS }\end{array}$ \\
\hline [138] & $\begin{array}{c}\text { RTT (38(20 with disease onset }<1 \text { year and } 18>1 \\
\text { year): } 2-8) \\
\text { TD }(60: 2-8)\end{array}$ & 16 channels; $>15.4$-s epochs & $\begin{array}{c}\text { Spectral power (1.5-25 Hz) } \\
\boldsymbol{\nabla} \text { alpha } \boldsymbol{\Delta} \text { theta activity in RTT } \\
\mathbf{\nabla} \text { central and occipital alpha } \Delta \text { central and frontal theta activity in the group } 1 \text { (early disease onset) }\end{array}$ \\
\hline [137] & $\begin{array}{l}\text { RTT }(9: 2-8 \text {, stage } 3) \\
\quad \text { TD }(17: 2-8)\end{array}$ & $\begin{array}{l}16 \text { channels: eyes open }(n=6) \text { and eyes close } \\
\qquad(n=5) ;>84 \text {-s epochs }\end{array}$ & $\begin{array}{l}\text { Relative Power }(1-20 \mathrm{~Hz}) \\
\quad \boldsymbol{V} \text { alpha and beta } \\
\boldsymbol{\Delta} \text { theta band }\end{array}$ \\
\hline [142] & $\begin{array}{l}\text { RTT (1:10) } \\
\text { TD }(10: 10)\end{array}$ & $\begin{array}{l}16 \text { channels: } \\
20 \text { artifact-free 5-s epochs }\end{array}$ & $\begin{array}{l}\text { Spectral power }(1.5-30 \mathrm{~Hz}) \\
\mathbf{\Delta} \text { delta and left anterior theta } \\
\quad \mathbf{v} \text { posterior alpha } 1\end{array}$ \\
\hline$[143]$ & $\begin{array}{l}\text { RTT (9: 10-22) } \\
\text { Compared to unspecified normative data }\end{array}$ & $n=11: 16-20$ channels; $5-10 \mathrm{~min}$ of recording & $\begin{array}{c}\text { Spectral power }(1.0-16 \mathrm{~Hz}) \\
\Delta \text { low frequency activity (unspecified, statistical values not provided) }\end{array}$ \\
\hline
\end{tabular}


Spectral Slope

EEG power spectral density is characterized by a negative slope if presented in the semi-log or log-log space, because power of the signal frequency content decreases rapidly as a function of the frequency. Steepness of the $1 / \mathrm{f}$ spectral slope correlates with slowing of the background EEG, reflecting prevalence of low frequency EEG over high frequency signals. According to recently developed dynamic neuronal communication framework, more negative 1/f slope of EEG power spectral density represents more synchronous activity of the neuronal population, while flattened (less negative) spectral power slope is related to higher background rates of neuronal firing decoupled from an oscillatory carrier frequency-noise [148]. Higher neuronal noise indexed by a flatter $1 / \mathrm{f}$ slope was associated with aging, while pathological overcoupling of neuronal oscillations reflected in the steeper $1 / \mathrm{f}$ slope was seen in several neurological and developmental disorders, such as Parkinson's disease and attention deficits and hyperactivity disorder (ADHD) [148]. Notably, in a study of ADHD, $1 / \mathrm{f}$ slope correlated with theta to beta ratio but had greater power to differentiate ADHD from controls. The authors suggested that the novel measure of $1 / \mathrm{f}$ slope was a better reflection of underlying pathophysiology over the traditional indexes of EEG background slowing [149]. Given a proposed dependency of a steeper 1/f slope on a decrease in the local excitation/inhibition ratio [148], this EEG measure is of value to researchers of RTT. However, 1 / $\mathrm{f}$ slope of EEG spectral density was assessed in only one, but large-scale study conducted on 57 RTT patients [139]. Roche and colleagues showed that girls with RTT had significantly more negative (steeper) $1 / \mathrm{f}$ slope than their typicallydeveloping peers and the steepness of the slope was correlated with decreases in cognitive functioning as measured with MSEL. Taking into account this promising finding, $1 / \mathrm{f}$ slope might be suggested as a potential biomarker of altered neural excitation/inhibition balance in RTT.

\section{Cortical Gamma Oscillations (30-100 Hz)}

Cortical gamma oscillations $(30-100 \mathrm{~Hz})$ are generated in recurrent circuits of excitatory and inhibitory neurons $[150,151]$ and their amplitude reflects the excitatory state of the neural network. In humans and animals these oscillations are most reliably induced in response to sensory stimuli [152], but might be also recorded in the spontaneous mode, both during wakefulness and sleep [153]. The animal studies revealed that gamma oscillations contain at least two functionally different sub-bands, with a conventional band of low- and high-frequency gamma bands being $30-60 \mathrm{~Hz}$ and $>70 \mathrm{~Hz}$ respectively [154-156]. In humans, gamma band activity is usually measured between 30 and $50 \mathrm{~Hz}$ in scalp EEG recordings without division into functionally distinct gamma sub-bands. The human EEG gamma band can be contaminated by myogenic artifacts having the same frequencies as neural gamma activity [157]. Despite these challenges, spontaneous gamma oscillations were consistently found to be abnormally enhanced in awake patients with increased E/I ratio, e.g., patients with ASD, schizophrenia and epilepsy [158-160]. Studies of spontaneous gamma-band activity in patients with RTT have been limited to relatively low gamma frequency $[139,141]$. Ammanuel and colleagues found that in patients with RTT $(n=10)$ the power of $35-45 \mathrm{~Hz}$ oscillations during slow wave sleep (SWS) did not follow a typical and highly significant decrease from 2-5 to 6-9 years of age, suggesting that subjects with RTT do not exhibit a normal developmental reduction in cortical excitability [141]. In contrast to sleep state, gamma band activity of $30-50 \mathrm{~Hz}$ recorded during wakefulness was unremarkable in a sample of 57 girls with RTT of similar age when they watched self-chosen video [139]. Taking into account the decreased muscle tone during sleep as compared to awake state, sleep EEG recordings might be much better suited than awake EEG for detecting "true" gamma activity, especially in patients with muscle dystonia and stereotypic movements since this can contaminate the signal. While the low gamma-band abnormalities during SWS might have the potential to serve as objective biomarkers of increased cortical excitability in RTT, they need to be independently replicated in a larger 
sample. In addition, specificity to this functional state needs to be further investigated in the future studies.

\section{EEG Abnormalities in Relation to the Developmental Stage}

As mentioned in the introduction, patients with RTT are characterized by specific patterns of developmental EEG changes that depend on the progression of the disease. This knowledge can be used as an aid in the RTT diagnosis and can help to stage the disorder $[5,39]$. At stage I of the disorder no clear EEG abnormalities have been reported, probably because this period is largely understudied due to a lack of clear symptoms at this initial stage. However, some rare evidence suggests that epileptogenic activity might already be present at this early stage of the disorder [74]. At the same time, EEG abnormalities might be the only pathological laboratory investigation in patients with RTT at the time when the diagnosis is made (see e.g., [90]). EEG abnormalities usually described during stage II of RTT disorder contain focal spikes with centro-temporal scalp topography (CTS), and/or focal sharp-wave discharges [48,81]. Stage II is also characterized by marked slowing of resting EEG oscillations that progresses further in stage III. Multifocal spikes and sharp-wave discharges also appear at stage III. No occipital dominant activity might be present in awake EEG $[83,86]$. Intriguingly, these EEG abnormalities might become either more pronounced or, to the contrary, ameliorate at stage IV— the most advanced stage of the disorder $[48,68,71,81,83,161,162]$. Despite the above described general tendency in EEG development in RTT, there is considerable interindividual variation of EEG patterns, especially in clinical stages III and IV [77]. At these advanced stages spontaneous EEG vary from a "normal" pattern without epileptiform discharges to some rare, very abnormal variants $[48,68,81]$. For example, Izhizaki and colleagues described a RTT girl with awake EEG at age 23 dominated by monotonous theta rhythm activity that was not influenced by either opening or closing of the eyes but attenuated only by a loud noise or strong pain stimulus [83]. Future large-scale experimental longitudinal studies are needed to identify different trajectories of EEG development and the potential for prognostic value of spontaneous EEG patterns at the earliest stages of the RTT disorder.

The only study that quantitatively examined EEG in girls with RTT during the active regression stage (stage II, $n=20$ ) revealed interesting results [139]. While the higherfrequency activity ranging from 6 to $30 \mathrm{~Hz}$ was attenuated similarly in patients with RTT regardless of disease stage, the low frequency activity differentiated between the RTT stages. In contrast to widely reported increased power of low frequency activity in patients with RTT $[137,142,143]$, girls with RTT in the active regression period were characterized by lower frontal and central theta and delta activity as compared to typically-developing peers. Decrease in frontal theta activity was so dramatic that about half of the patients had theta power values below the lowest value in the control group, clearly indicative of underlying neuropathology (Figure 3A in [139]). The developmental course of low-frequency activity was also different in patients with RTT and TD: unlike the typical decrease that is seen in the power of delta and theta activity with age, girls with RTT show an increase in delta and theta power with age. Thus, studies suggest atypical developmental trajectory of low-frequency EEG activity with initially low delta and theta activity in girls with RTT for the active regression period and subsequent increase in this activity in the postregression period.

The results are summarized in Figure 2. The primary findings from human studies are the general slowing of background EEG, that might be also characterized with a new measure of 1 /f spectral slope, related to decreased $\mathrm{E} / \mathrm{I}$ imbalance at rest corresponding to increased tonic inhibition suggested from animal studies. At the same time, not only predominance of low over high frequency oscillation might contribute to this background EEG slowing, but also a shift towards lower values of dominant frequency within particular functionally distinct EEG rhythms, e.g., sensory-motor mu rhythm or visual alpha rhythm. More studies are needed to quantify these shifts, especially related to motor mu-rhythm as motor problems are among the core deficits in RTT. 


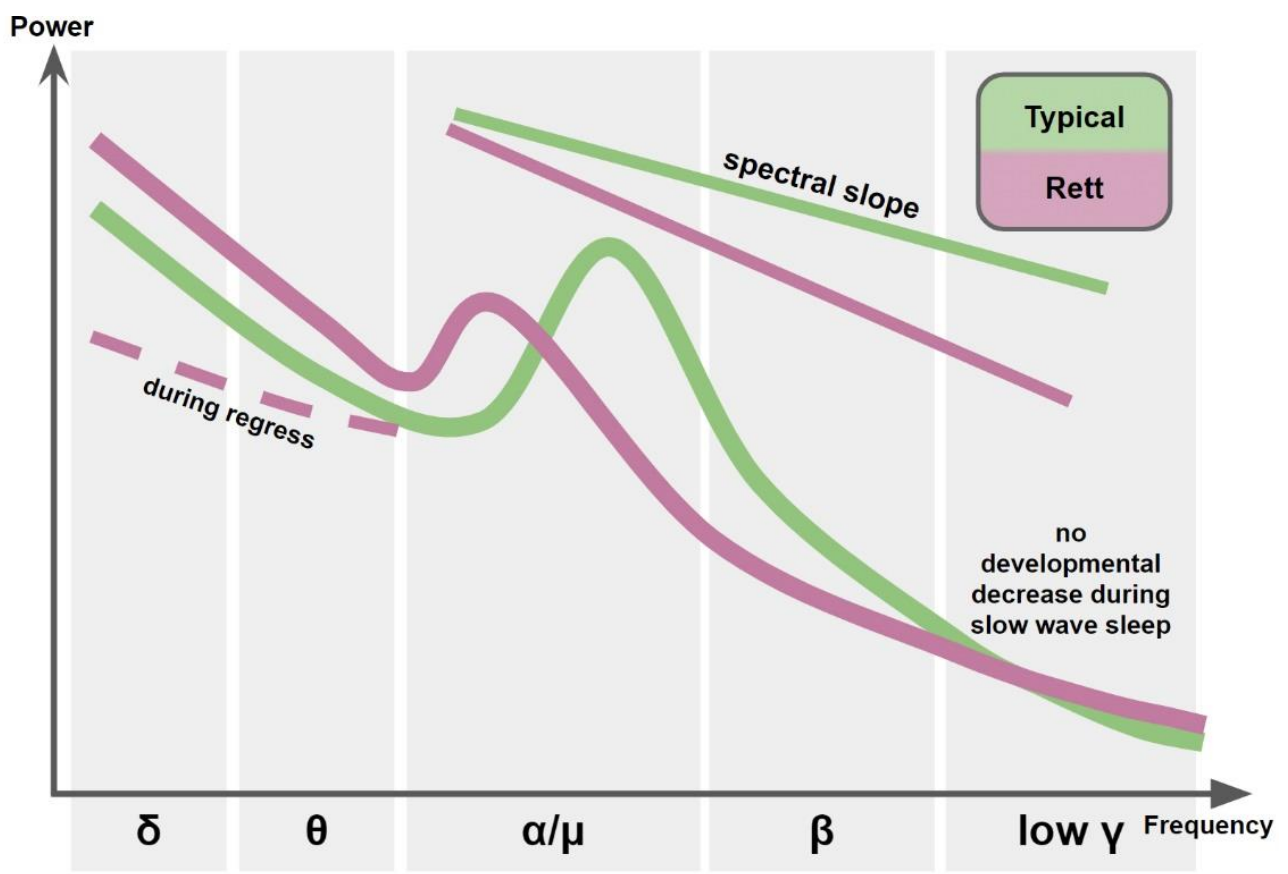

Figure 2. Spectral features of EEG in RTT.

\subsubsection{Animal Studies}

Animal EEG studies in waking resting state have been limited to gamma band activity (Table 2). Consistent with observations on interrelations between excessive high frequency gamma $(>70 \mathrm{~Hz})$ and epileptogenesis $[160,163,164]$, symptomatic stage male mice with T158A mutation and total deficiency of MECP2 were characterized by atypically increased power of spontaneous high frequency gamma oscillations in waking EEG suggestive of constitutive cortical hyperexcitability [29]. Abnormally exacerbated high frequency oscillations were absent at a presymptomatic stage, which resembles findings from human patients who usually develop epileptic phenotype after regression. Unlike high frequency gamma, power of low frequency gamma in the awake state of the same mice was indistinguishable from that in wild type mice, for both symptomatic and presymptomatic stages.

Spontaneous EEG rhythms in MECP2-deficient mice were also studied during exploratory behavior. They found that frequency of hippocampal theta activity in RTT was shifted toward abnormally low values $[107,111,118]$. Given that theta frequency is strongly modulated by drugs stimulating catecholaminergic and especially dopaminergic systems $[165,166]$, that are known to play a major role in exploratory locomotor behavior, theta deceleration in RTT may be linked to the deficiency of neuromodulatory influences on the hippocampal activity. In line with this idea, preservation of MECP2 expression only in catecholaminergic neurons in MECP2-deficient male mice resulted in normalization of theta frequency almost up to the wild-type level, in parallel with improvements in ambulatory rate, motor coordination and nest-building [118]. Remarkably, abnormally attenuated exploratory behavior in mice lacking MECP2 and decelerated theta oscillations has been accompanied by atypically decreased power of hippocampal low frequency gamma $[111,118]$. Coupled theta-gamma dynamics is explained by the fact that in all mammals including humans, low frequency gamma oscillations are modulated by concurrent theta rhythm, whose frequency and amplitude increase during exploratory behavior [154,155,167]. This means that a deceleration of cortico-hippocampal theta and decreased low frequency gamma power in RTT individuals might index deficient catecholaminergic modulation that results in decline of their behavioral state and attenuates locomotor activity.

To sum up, there are very few studies on spectral analysis of EEG in animal models of RTT and findings are difficult to reconcile. The slowing of spontaneous EEG rhythms has been reported in both animal and human studies; however, different behavioral states 
were studied: exploration in animals vs. resting state in humans. The altered parameters of spontaneous gamma oscillations in RTT animals makes them an attractive target to pursue in human research, however a few methodological challenges dampen their translational potential. EEG studies during sleep and MEG might overcome some of these challenges. Future translational research is needed to clarify the neurophysiological basis of these clinically relevant features of EEG.

\subsection{EEG Abnormalities Associated with Sleep Disturbances, and Their Neurophysiological Underpinnings}

\subsubsection{Patient Studies}

Spontaneous EEG activity is influenced by many factors, such as a functional state, level of alertness, mobility and mood. These parameters are difficult to control for, especially in children with neurodevelopmental disorders. Therefore, any comparisons of spontaneous EEG rhythms between RTT and control groups should be treated with caution. EEG recordings during sleep are more immune to behavioral variability and, therefore, provide a compelling option for investigation into altered dynamics of spontaneous EEG oscillations in RTT. When characterizing epileptiform activity, sleep EEG also presents an advantage as epileptiform discharges in RTT patients prone to seizures are identified with higher probability in sleep EEG than in awake EEG [38,68,79,84,88,136,162].

Sleep-associated problems are commonly reported in patients with RTT and serve as supportive evidence for a RTT diagnosis [8]. They include dysregulation of the sleep/wake cycle with irregular sleep onset time, abnormally long daytime sleep accompanied by shorter duration of night time sleep, frequent nocturnal awakenings with episodes of night laughter or screaming [6,168-172], pointing to the absence of typical developmental maturation or even a regression in the regulation of the circadian sleep-wake cycle.

EEG with concurrent monitoring of EMG activity (polysomnography) is commonly used to differentiate the sleep stages. In 1968, Rechtschaffen and Kales described the five different sleep stages, with four stages related to slow progression from drowsiness to the deep sleep, characterized by increases in slow wave activity in the EEG (SWS for slow wave sleep) and the paradoxical sleep stage with rapid eye-movements and EEG pattern resembling that in wakefulness (REM sleep) [173]. The percentage of REM sleep within the sleep cycle is abnormally low in patients with RTT [162,174]. In contrast, the percentage of time spent in SWS is enhanced in patients with RTT [174], especially in younger age groups (2-5 years) [162]. However, the absolute duration of overnight SWS is shortened in patients with RTT [141] due to less total time spent asleep. Incidence of seizures in RTT was associated with a significantly lower absolute number of SWS cycles, pointing to more severe problems with SWS efficiency in RTT patients with epilepsy.

The existing literature on sleep EEG in RTT patients is mostly limited by qualitative descriptions of prevalent abnormalities. Three principal EEG changes, although not universally observed in all RTT patients, have been reported during sleep. First, there is a loss of the hallmarks of sleep stage II-sleep spindles and vertex transients that are absent both in young children and adults with RTT $[39,79,86]$. Second and less frequently observed is the so-called "trace alternant" sleep pattern, whose occurrence during typical development is limited to the neonatal period [175]. This pattern containing high-amplitude bursts of irregular delta activity followed by a relative suppression of EEG amplitudes was described in the early EEG studies in about two thirds of individuals with RTT irrespectively to their age $[81,87,162]$. Third, epileptiform discharges occur frequently during sleep in the majority of RTT patients [38,68,79,84,88,136,162]. In particular, Aldrich and colleagues compared the spike count at different sleep stages within night sleep and found that occurrence of spike is higher in SWS and in early morning hours [79]. The higher prevalence of spikes in the early morning hours was not due to general increase in SWS in these hours and might be related to circadian variation in cortical excitability and/or hormonal factors.

The only quantitative study of spontaneous EEG activity in RTT patients $(n=10)$ is that of Ammanuel and colleagues [141]. They found a significant increase in delta power during SWS sleep and shortened overall time spent in SWS in RTT girls aged 2-9 years 
as compared to age-matched control girls. These girls also did not demonstrate a typical decrease of delta power over consecutive SWS cycles during the night. Interestingly, this pattern characterizes the sleep architecture of typical individuals after prolonged sleep restriction [176], and is considered a protective mechanism that compensates for previous sleep loss. Considering the chronic reduction of SWS duration in RTT girls, the same compensatory mechanisms may contribute, among other factors, to their highly increased delta power during SWS and a lack of its reduction at later stages of the sleep cycle.

To sum up this section, we should point to the need for more qualitative EEG studies of EEG changes during sleep in patients with RTT as they might provide new and more reliable biomarkers of RTT than those registered during active state. Normal sleep is crucial factor for the development of cognitive functions [177-179] and this state should not be ignored by researchers of RTT pathophysiology.

\subsubsection{Animal Studies}

In line with EEG results obtained in patients with RTT, the overall time spent in SWS was significantly shortened in animal models with MECP2 dysfunction as compared to wild type animals [117]. RTT mice were also characterized by a lower number of SWS cycles in combination with a prolonged duration of each cycle [112]. However, changes in sleep delta power in MECP2-deficient mice who reached puberty go in the opposite direction to that observed in 2-9 year old girls with RTT [117]. No conclusions can be drawn from this between-species comparison, due to the small number of relevant studies and major differences in biological age between patients and animals across the studies.

The disturbed sleep-wake cycle found in both RTT patients and animal models can be understood via MECP2's influence on the circadian clock system. A recent study in mice revealed that MECP2 binds and transcriptionally activates the circadian clock genes, Per 1 and Per2, known to play major roles in circadian rhythms [180]. The suprachiasmatic nucleus (SCN) is a master circadian pacemaker controlling the timing of the sleep-wake cycle and coordinating circadian changes in the activity across brain and body tissues. The SCN is mostly active during the light part of the diurnal cycle and mainly shuts down at night. The resetting of SCN cells by light exposure is mediated via intensification of vasoactive intestinal peptide secretion, which is crucial for normal light-induced synchronization of the circadian system [181,182]. In comparison to wild type animals, Mecp2-mutant mice exhibit a reduction of vasoactive intestinal peptide expressing neurons of SCN and significant attenuation of the SCN spontaneous activity in the daytime [183]. The Mecp2-mutant mice demonstrated increased mortality to a chronic experimentally induced weekly phase shift of the light/dark cycle, possibly as a consequence of disrupted SCN functioning and resulted in sleep deprivation.

In light of animal studies, the discoordination of the circadian sleep-wake cycle that is frequently observed in RTT patients may be caused by disturbed SCN functioning and have severe consequences not only for cognitive functions but also for health status. The decreased spontaneous SCN activity might be also linked to the increased tonic inhibition suggested from other animal studies of MECP2 dysfunction reviewed in previous Section 2.1 (Figure 1). The data also suggest that avoiding any changes in daily routine is of crucial importance for the well-being of patients with RTT.

\subsection{Behavioral and EEG Abnormalities in Relation to RTT Genotype}

\subsubsection{Patient Studies}

Recent studies suggested that some MECP2 mutations might be associated with slightly different manifestations of RTT clinical symptoms [184-188] nonsense mutations in the beginning of the gene (such as R168X, R255X and R270X) and large deletions within MECP2 associated with more severe RTT phenotype [189-192]. The relationship between $M E C P 2$ mutation and seizure phenotype has been investigated in several studies with the largest studies of the last decade summarized in Figure $3[43,44,51,53,192,193]$. Noteworthy, unlike general large difference in the reported prevalence of seizures (e.g., 
close to $90 \%$ in the study of Pintaudi [44] and colleagues and less than $40 \%$ in the study of Bao and colleagues [53], the profile of changes between genotypes seems to be rather consistent. For example, seizures were more frequently observed in patients with T158M and less frequently in those with R306C mutations across these studies. As Cuddapah and colleagues did not report the percentage of individuals affected with seizures in each genotype group, but characterized the between genotype difference by average scores [192], we did not present their results in the figure. Nonetheless, these authors' findings are compatible with previous reports as they found that seizures were less frequent in R306C cases as compared to R255X and R294X in a sample of 815 patients with typical RTT [192]. At the same type, there are discrepancies between studies. Patients with the R106W mutation were associated with higher risk for seizures in all but one study ([193]; notably, this was the largest $n=1135$ ), and patients with R255X mutations in all but the study of Glaze and colleagues [51]. The reason for this inconsistency needs to be further identified. Probably, these genotypes are particularly sensitive to the methods of seizure assessment. Noteworthy, more clinically severe genotype (e.g., R270X) did not always correspond to phenotypes with higher prevalence of epilepsy, supporting the idea about the non-causative role of epilepsy in RTT development.

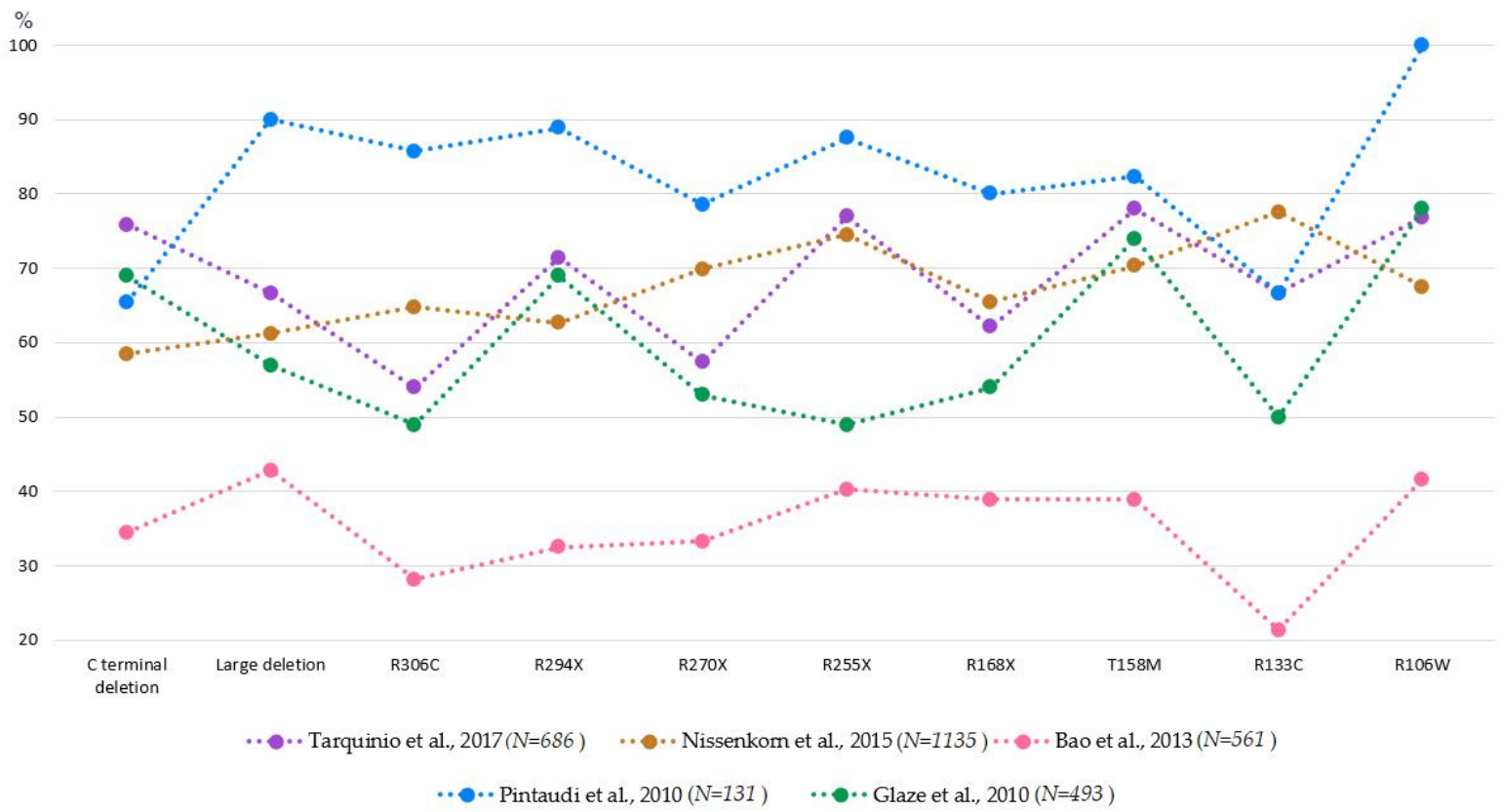

Figure 3. Prevalence (\%) of seizures in patients with RTT depending on the particular mutation in the MECP2 gene.

Some links between sleep disturbances and $M E C P 2$ mutations were also suggested. Data from patient fibroblasts [183] pointed to the dependence of circadian disturbances on the mutation types in the MECP2 gene: the phase delay of Per2 rhythms were not found in the fibroblasts from patients with the T158M mutation, but in those with R106W, who also have high prevalence of night sleep disturbances according to the epidemiological study [170]. Considering these findings, it is interesting to compare sleep EEG patterns between patients with these mutations to shed the light on potential neurophysiological distinction between these mutations.

$M E C P 2$ can also be duplicated in human cells, leading to the $M E C P 2$ duplication syndrome. The clinical phenotype of those patients resembles that of patients with RTT and includes infantile hypotonia, intellectual disability, autistic features, progressive neurological declines, choreiform movements and recurrent respiratory infections [194-196]. The similarities of clinical symptoms in the conditions with opposite changes in MECP2 expression highlight the importance of the optimal level of MECP2 for normal development. $M E C P 2$ duplication syndrome has the lowest severity scores, and the greatest median age of 
seizure onset (6 years) among developmental encephalopathies. The available reports suggest epilepsy in patients with $M E C P 2$ duplication to be mostly drug-resistant [42,58,197]. A recent report suggested that valproic acid (VPA) monotherapy can be efficient in managing epilepsy in these patients [198]. Contrary to patients with classic RTT caused by MECP2 mutations, in patients with $M E C P 2$ duplication the emergence of neurologic regression coincides with the onset of epilepsy, suggesting that the epileptic process underlying seizures also serves as a trigger for progression of the disease. However, while severity of $M E C P 2$ mutations is linked to the RTT clinical phenotype, MECP2 duplication size and gene content predict neither presence of epilepsy, seizure type, age of seizure onset or responsiveness to treatment. Mechanisms by which $M E C P 2$ gene duplications modulate the spectrum and severity of neurocognitive phenotype remain unclear [199].

Patients with mutations in CDKL5 and FOXG1 genes shares many of the RTT symptoms including relatively normal initial motor-cognitive development, hypotonia, poor or no spoken language, gait abnormalities, intellectual impairment, microcephaly and stereotypic hand movements and historically has been considered an RTT-like disorder. However, there are clear symptomatic distinctions between patients with typical RTT caused by MECP2 mutations and patients with deficient CDKL5 and FOXG1 genes. First, the latter variants are associated with a significantly earlier age of seizure onset. Second, this is a difference in seizure semiology: patients with CDKL5 mutations had epileptic spasms (45.3\%) more often than those with other genotypes ( $0.4 \%$ for typical RTT with MECP2 mutations, $4.7 \%$ for FOXG1) [42]. In addition, patients with CDKL5 mutations are more often characterized by global developmental delay, cortical visual impairment and severely impaired gross motor function, while patients with FOXG1 mutations are more frequently reported to have postnatal microcephaly, typically associated with corpus callosum abnormalities and marked dyskinetic movements [200-203]. Thus, it is recommended to classify these disorders as distinct from RTT to secure proper treatment [42].

Clinical assessment of background EEG in patients with CDKL5 and FOXG1 mutations and with $M E C P 2$ duplication shows some slowing of brain oscillations, resembling that in patients with $M E C P 2$-mutations. However, no quantitative analysis was performed to support these observations [58]. Buoni and colleagues studied three girls with mutations in the CDKL5 gene that caused RTT-like disorder. The authors reported unique background EEG with diffuse high voltage sharp waves of $6-7 \mathrm{~Hz}$, and absence of the typical rhythmic frontal-central theta activity present in Rett syndrome caused by MECP2 mutations [69]. Keogh and colleagues quantitatively investigated differences in EEG spectra between RTT patients with $M E C P 2$ and CDKL5 mutations [140]. While no difference in the power spectra characteristics were found, measures of interelectrode coherence differed between groups: CDKL5 variants showed lower interhemispheric coherence between occipital (O1-O2) and temporal (T3-T4) electrodes, probably related with more frequent left- or right-lateralized epileptiform abnormalities in patients with this rare mutation. However, considering the low number of patients with CDKL5 mutations $(n=4)$, these findings must be considered with caution.

It is evident that investigation of the relationship of EEG abnormalities with genetic variants of RTT syndrome is an important direction for future research that might provide better understanding of RTT phenotype and lead to more personalized treatment. A large-scale multicenter consortium would greatly facilitate this endeavor.

\subsubsection{Animal Studies}

The relationship between mutation type and prevalence of a particular type of EEG pattern or epileptiform activity/seizure were not specifically studied in Mecp2-deficient animals. However, some influence of the extend of Meсp2 dysfunction and seizure type might be suggested: absence seizures were typically reported in Mecp 2 knockout mice, while myoclonic jerks were found in animal model of RTT with truncated Mecp2 in Cterminal. At the same time, all studies, which described handling-induced convulsive seizures, were performed on mice with full or conditional Mecp 2 knockout. 
Early onset of seizures is one of the important symptoms of syndromes caused by mutations in the CDKL5 and FOXG1 genes, distinguishing them from the Rett syndrome. However, seizure activity is not fully reproduced in animals with mutations in these genes. Strikingly, the pronounced seizures is also absent in the mouse model of the CDKL5 disorder [204], which is characterized by early onset of seizures in almost $100 \%$ of all patients with CDKL5 abnormalities [42,58,205]. Cdkl5-/y mice also generally demonstrate normal spontaneous EEG [204]. Nevertheless, in the studies using proconvulsive agents such as kainic acid [206] and NMDA [207], it is easier to induce behavioral seizures and epileptiform activity on the EEG in Cdkl5 knockout mice compared to wild type animals. Recordings in freely moving FoxG1+/ - mice showed higher prevalence of high-amplitude spikes on the EEG. Long-lasting spikes were accompanied by immobility but not by behavioral seizures [208]. However, more pronounced behavioral seizures were registered in FoxG1+/ - mice after kainic acid intake compared to wild-type animals. As described above, in contrast to syndromes that are caused by mutations in genes that play a primary role in the formation of neuronal excitability (for example, Dravet syndrome and SCN1A gene), abnormalities in spontaneous EEG and behavioral seizures are observed much less often in Mecp2-, Cdkl5- and FoxG1-deficient mice (reviewed in [205]). All three genes, which are causative for Rett-like conditions, are general regulators of activity of other genes and are not directly involved in neuronal excitability.

Optimal level of MECP2, CDKL5 and FOXG1 is necessary for the normal functioning of neurons, and its deviation both towards decrease or increase can lead to similar symptoms. There are animal models of $M E C P 2$ duplication syndrome, such as Mecp 2 overexpression in mice [209], and monkey [210] that showed a Rett-like phenotype. Mecp2 overexpression in these models led to electrographic discharges accompanied by behavioral seizures in mice $[209,211]$. Foxg1 overexpression in mice deep-layer neocortical projection neurons also led to higher neuronal excitability assessed by frequency of electrographic high-amplitude spikes and severity of behavioral seizures induced by kainic acid [212].

In sum, EEG abnormalities are largely unexplored in animal models of RTT other than Mecp2-knockout models, making it rather speculative to talk about some EEG phenotype specific to particular genotype. Further studies are needed to explore this issue. In relation to the very evident distinction between EEG phenotype of MECP2 abnormalities and caused by CDKL5, FOXG1 mutations, e.g., in an age of seizure onset, their animal models are much more similar and even do not have clear seizure phenotype. Thus, it might be suggested that optimal levels of MECP2, CDKL5 and FOXG1 might influence the $\mathrm{E} / \mathrm{I}$ balance via some indirect influence that might be modulated differently in humans and rodents.

\subsection{EEG as a Biomarker of Treatment Efficacy}

The ultimate goal of an EEG biomarker is to serve as a monitoring, treatment response or even surrogate endpoint biomarker as described in context of use (COU) FDA statement [213]. EEG characteristics, targeted at particular neurophysiological processes, may provide a tool for assessing effects of clinical trials without relying on overt behavior and lead to individualized tuning of treatment strategy. Below we review currently available studies in patients with RTT that used EEG measures in the evaluation of the effect of pharmacological and behavioral treatments in RTT patients (summarized in Table 4). 
Table 4. Treatment effect on EEG in patients with RTT.

\begin{tabular}{|c|c|c|c|c|c|}
\hline Study & Sample (n: Age) & Treatment Schema & EEG Settings & EEG Effects & Other Treatment Effects \\
\hline [57] & $\begin{array}{c}\text { RTT 75\% MECP2 (12: 2-11, } \\
20,30)\end{array}$ & $\begin{array}{c}\text { Folinic acid: } \\
\text { 2-year prospective } \\
\text { randomized, double blinded, } \\
\text { placebo-controlled crossover }\end{array}$ & $\begin{array}{c}\text { Video 16-channel EEG (10-20 } \\
\text { system) }\end{array}$ & $\begin{array}{c}\text { Improvement: } \\
\nabla \text { Seizure rate (only in } 2 \text { out of } 8 \text { patients who } \\
\text { had seizures at baseline) } \\
\text { ₹ Frequency of epileptiform discharges (only in } \\
3 \text { patients) } \\
\text { Worsening: } \\
3 \text { patients developed seizure during treatment } \\
\Delta \text { Frequency of epileptiform discharges } \\
\text { (2 patients) }\end{array}$ & $\mathrm{N} / \mathrm{A}$ \\
\hline [214] & $\begin{array}{c}\text { RTT } 100 \% \text { MECP2 with } \\
\text { drug-resistant epilepsy } \\
(8: 8-18)\end{array}$ & $\begin{array}{c}\text { levetiracetam (LEV) } \\
\text { prospective, pragmatic, OLE: } \\
\text { mean dose } \\
\text { achieved was } \\
44.84 \mathrm{mg} / \mathrm{kg} / \text { day } \\
\text { SD } 18.02 \\
\end{array}$ & $\begin{array}{l}\text { EEG at baseline } \\
\text { and } 6 \text {-months } \\
\text { after beginning } \\
\text { of treatment }\end{array}$ & $\begin{array}{c}\text { Improvement: } \\
\text { } \boldsymbol{\nabla} \text { Seizure rate, } \\
\text { background EEG, epileptiform abnormalities } \\
\nabla \text { Frequency of epileptiform discharges (in } 6 \text { out } \\
\text { of 8 patients) }\end{array}$ & $\mathrm{N} / \mathrm{A}$ \\
\hline [215] & $\begin{array}{c}\text { RTT } 100 \% \text { MECP2 } \\
\text { post-regression }(17: 2-10)\end{array}$ & $\begin{array}{c}\text { rhIGF-1: } 20 \mathrm{wk} \text {, double-blind } \\
\text { cross over: } 0.12 \mathrm{mg} / \mathrm{kg} / \mathrm{twice} \\
\text { a day }\end{array}$ & $\begin{array}{l}128 \text { channels; } 5-10 \text { min calm } \\
\text { recording when girls watched } \\
\text { movie of their choice }\end{array}$ & 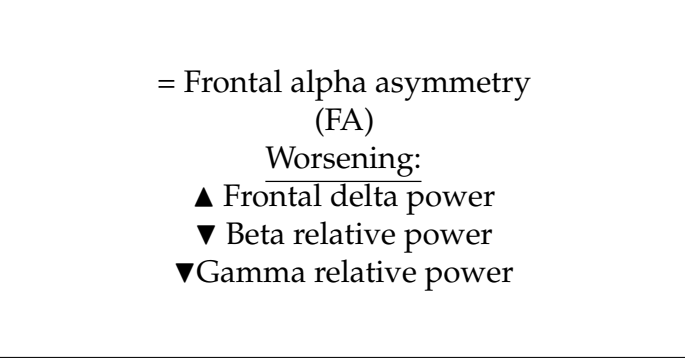 & 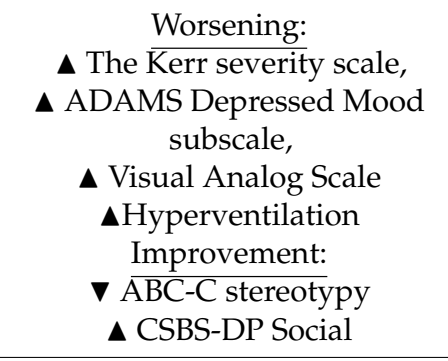 \\
\hline [216] & $\begin{array}{c}\text { RTT 100\% MECP2 stage III } \\
\text { (10: } 3-11) \\
\text { RTT untreated (9: 2-12) }\end{array}$ & $\begin{array}{l}\text { rhIGF-1: } 20-24 \text { wk: } \\
0.1 \mathrm{mg} / \mathrm{kg} / \mathrm{twice} \text { a day }\end{array}$ & 10 channels; $1-2$ h EEG & $\begin{array}{c}=\text { Frontal alpha asymmetry (FA) } \\
\text { Improvement: } \\
\text { \Theta frequency } \\
\nabla \text { Delta amplitude }\end{array}$ & 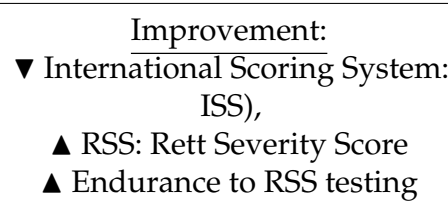 \\
\hline [217] & $\begin{array}{l}\text { RTT } 100 \% \text { MECP2 (6 out of } \\
\text { 10:2-10) }\end{array}$ & $\begin{array}{l}\text { rhIGF1: } 4 \text { wk MAD + } 20 \mathrm{wk} \\
\text { OLE: } 0.120 \mathrm{mg} / \mathrm{kg})\end{array}$ & Frontal and parietal channels & $\begin{array}{c}\text { Frontal alpha asymmetry (FA) (Pre-OLE: R > L } \\
\text { with trend to reverse Post-OLE) }\end{array}$ & 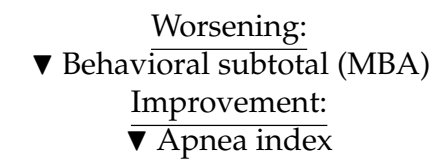 \\
\hline
\end{tabular}


Table 4. Cont.

\begin{tabular}{|c|c|c|c|c|c|}
\hline Study & Sample (n: Age) & Treatment Schema & EEG Settings & EEG Effects & Other Treatment Effects \\
\hline [218] & $\begin{array}{l}\text { RTT } 100 \% \text { MECP2 with } \\
\text { epileptiform activity } 33(13+ \\
12+8 \text { dose groups): } 2-14.5)\end{array}$ & $\begin{array}{c}\text { Dextromethorph an: } 25 \mathrm{wk} \\
\text { OLE } \\
3 \text { dose groups: } \\
0.25 \mathrm{mg} / \mathrm{kg} / \text { day; } \\
2.5 \mathrm{mg} / \mathrm{kg} / \text { day; } \\
5.0 \mathrm{mg} / \mathrm{kg} / \text { day; }\end{array}$ & $\begin{array}{l}\text { Neuroscan EEG } \\
\text { system; } \\
\text { Overnight } \\
\text { recordings }\end{array}$ & $\begin{array}{c}\text { =Epileptiform spikes and sharp waves during } \\
\text { non-REM sleep } \\
\text { Improvement: } \\
\text { Seizure rate (parental report): low dose group } \\
\text { (in all? small number of patients who had } \\
\text { seizures before OLE } n=5 / 4 / 2 \text { at each dose } \\
\text { group) }\end{array}$ & $\begin{array}{l}\text { Improvement: } \\
\text { \ Receptive Language } \\
(5.0 \mathrm{mg} / \mathrm{kg} / \text { day vs } \\
0.25 \mathrm{mg} / \mathrm{kg} / \text { day }) \\
\text { * } \text { Behavioral hyperactivity } \\
(2.5 \mathrm{mg} / \mathrm{kg} \text { dose })\end{array}$ \\
\hline [219] & $\begin{array}{c}\text { RTT 100\% MECP2 (10:10-21) } \\
\text { ambulatory }\end{array}$ & $\frac{\text { Glatiramer acetate (GA): }}{24 \mathrm{wk} \text { of } 20 \mathrm{mg} / \text { day }}$ & $\begin{array}{l}\text { A 21-channel 1-h video EEG } \\
\text { (wakefulness }(n=10) \\
\text { drowsiness }(n=5), \text { sleep } \\
(n=3))\end{array}$ & $\begin{array}{c}\text { =Background EEG abnormalities } \\
=\text { Seizure rate } \\
\text { Improvement: } \\
\text { v Frequency of epileptiform discharges (in all } \\
4 \text { patients who had them at baseline) }\end{array}$ & 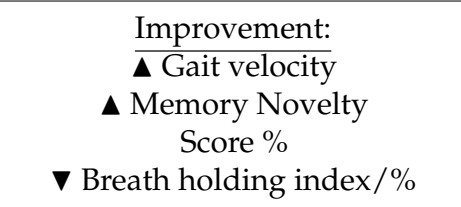 \\
\hline [137] & $\begin{array}{l}\text { RTT N/S (9:2-8, stage } 3) \\
17 \text { TD aged-matched }\end{array}$ & $\frac{\text { Cerebrolyzin (CL): } 20 \text { days }}{(2.0-2.5 \mathrm{~mL} \text { daily, i.m.). }}$ & $\begin{array}{c}16 \text { channels: eyes open }(n=6) \\
\text { and eyes close }(n=5) ;>8.4-\mathrm{s} \\
\text { epochs }\end{array}$ & $\begin{array}{l}\text { Improvement: } \\
\text { Ibeta activity in the parietal region and } \\
\text { occipital alpha in the } 8-9 \mathrm{~Hz} \text { narrow band } \\
\nabla \text { central and frontal theta the after CL }\end{array}$ & 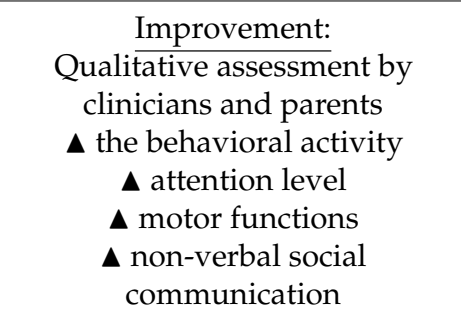 \\
\hline [220] & RTT (33: $21+13: 5-36)$ & $\begin{array}{l}\frac{\text { Visual }}{\text { discrimination }} \\
\text { training: } \\
\text { Short-term, } 30 \text { min } \\
\text { (STT: } n=13+21 \text { ) } \\
\text { Long-term, } 5 \text { days, } \\
\text { (LTT: } n=21 \text { vs. } \\
\text { Control: } n=13 \text { ) }\end{array}$ & $\begin{array}{l}19 \text { dry } \\
\text { electrodes } \\
\text { (wireless): visual } \\
\text { discrimination } \\
\text { task, at rest } \\
\text { eyes open }\end{array}$ & $\begin{array}{c}\text { v Alpha and Beta Brain Symmetry Index (shift } \\
\text { from L }>\text { R into R }>\text { L) } \\
=\text { Brain Symmetry Index } \\
\text { Improvement } \\
\text { Theta relative power (frontal left and parietal) } \\
\begin{array}{c}\text { M Beta relative power (frontal right and parietal } \\
\text { left) }\end{array}\end{array}$ & $\begin{array}{c}\text { After STT: } \\
\text { No changes } \\
\text { Improvement after LTT: } \\
\text { } \overline{\Delta \text { Length of fixation (FL) }} \\
\mathbf{\nabla} \text { Time before first fixation (TFF) }\end{array}$ \\
\hline$[221]$ & $\begin{array}{c}\text { RTT }(31: \\
13-35) \\
\text { non-sham } \\
\text { tDCS }(n=18) \text { vs. sham } \\
\text { tDCS }(n=13)\end{array}$ & 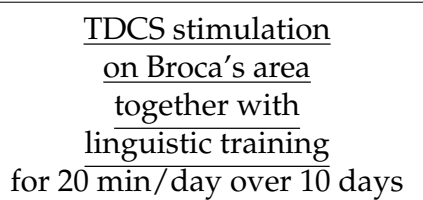 & $\begin{array}{l}21 \text { EEG } \\
\text { channels }\end{array}$ & $\begin{array}{l}\Delta \text { Frequency and Power of } \\
\text { Alpha and Beta } \\
\text { =Frequency and Power of } \\
\text { Theta }\end{array}$ & $\begin{array}{c}\text { Improvement: } \\
\mathbf{\Delta} \text { Attention } \\
\text { \ Language abilities (the } \\
\text { number of phonemes } \\
\text { produced) }\end{array}$ \\
\hline
\end{tabular}


Table 4. Cont

\begin{tabular}{|c|c|c|c|c|c|}
\hline Study & Sample (n: Age) & Treatment Schema & EEG Settings & EEG Effects & Other Treatment Effects \\
\hline$[222]$ & $\begin{array}{c}\text { RTT MECP2 mutations: } \\
\text { C468G, R133C, R306C (3: 29, } \\
\text { 30, 31) with chronic language } \\
\text { impairments }\end{array}$ & 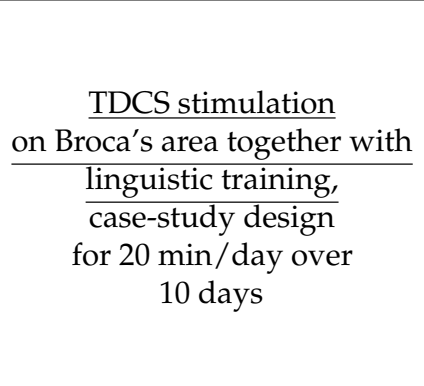 & $\begin{array}{c}\text { 19-channels } \\
\text { EEG (20 min wit eyes closed) }\end{array}$ & $\begin{array}{l}\Delta \text { Frequency and Power of } \\
\text { Alpha, Beta and Theta }\end{array}$ & $\begin{array}{l}\text { Improvement: } \\
\text { ه language abilities (the } \\
\text { number of } \\
\text { vowel/consonant sounds } \\
\text { and words and the } \\
\text { production and } \\
\text { comprehension through } \\
\text { discrimination) } \\
\Delta \text { motor coordination } \\
\text { (functional movements) }\end{array}$ \\
\hline
\end{tabular}


Antiepileptic therapy: drugs frequently used to control seizure in patients with RTT are valproic acid (VPA, broad spectrum drug with the ability to increase level of GABA by decreasing its degradation), carbamazepine (CBZ, sodium channel blocker, which binds preferentially to voltage-gated sodium channels in their inactive conformation, which prevents repetitive and sustained firing of an action potential), lamotrigine (LTG, blocks voltage-gated $\mathrm{Na}^{+}$channels), levetiracetam (LEV, that binds to SV2A synaptic vesicle protein, which leads to the reduction in the rate of vesicle release) and topiramate (TPM, blocks voltage-dependent sodium and calcium channels and augments activity at GABAa receptors) either as monotherapy or in various combinations [52]. Another emerging option is natural constituents of the cannabis plant (CBD, reduces neuronal hyperexcitability through a unique multimodal mechanism of action), currently in the phase 3 clinical trial to test its efficacy for patients with RTT Epidiolex (NCT03848832). A ketogenic diet (high-fat, adequateprotein, low-carbohydrate diet, possibly acts through increased conversion of glutamate into GABA and activation of adenosine A1 receptors, which affects potassium channels and leads to membrane hyperpolarization), although rarely used in patients with RTT, seems to have a good effect according to rare available studies [223-225]. Thus, epilepsy is controlled in RTT mainly through blocking the action potentials by affecting sodium channels and through increase of GABA concentration. Enhancing GABAa mediated inhibition may be a promising mechanism of reducing hyperexcitability caused by $M E C P 2$ disruption.

Pintaudi and colleagues nicely summed previous retrospective studies of different antiepileptic drugs' effectiveness in RTT and conducted their own retrospective analysis in a cohort of 165 patients with RTT [52]. As a result, they suggested LMG as a drug of first choice especially for patients with later than typical epilepsy onset in RTT (4-5 years of age), followed by VPA and CBZ being the other most effective options. Noteworthy, LMG was shown to increase gene expression of GABAa receptors subunit in primary cultured rat hippocampal cells [226] supporting the role of GABAa decrease in seizure generation in RTT. In the cohort of 110 patients with $M E C P 2$ mutations Huppke and colleagues found CBZ superiority over VPA in treating epilepsy [227]. As both MECP2 mutations and VPA were reported to induce histones hyperacetylation, the authors suggested that VPA may even in some cases exacerbate one of the underlying mechanisms for seizures in patients with RTT.

Only a few studies have examined the effectiveness of drugs on seizure reduction using prospective studies with EEG recording. Specchio and colleagues performed a prospective pragmatic open-label study to examine the effect of levetiracetam (LEV) in eight girls with RTT, who had drug-resistant epilepsy [214]. LEV significantly reduced seizure frequency in these patients and improved background EEG by decreasing the frequency of epileptiform discharges. Hagebeuk and colleagues performed a prospective randomized, double blinded placebo-controlled crossover study examining the effect of folinic acid in 12 patients with RTT [57]. The results were not very promising: reduction of seizure rate was found only in two out of eight patients who had frequent seizures prior to treatment, whereas three patients developed seizure during treatment; frequency of epileptiform discharges decreased only in three patients but increased in two patients. We suggest that prospective examination of the effects of anti-epileptic drugs on EEG epileptiform pattern and baseline activity in patients with RTT might provide important clinical and scientific insights as the dynamic of neurophysiological changes through antiepileptic therapy is of crucial importance.

Recombinant human insulin-like growth factor (rhIGF1, Mecasermin) is the most studied treatment in RTT patients that has used EEG as an outcome measure [215-217]. RhlGFI is suggested to potentiate BDNF, a key target of MECP2 transcriptional regulation, and is considered a potential treatment of RTT disorder. Promising results come from the hIPSC model in which treatment with IGF1 increased the level of KCC2, which as we noted in Section 2.1.2. may play a crucial role in epileptic phenotype in RTT, in MECP2 deficient neurons and restored the timing of the developmental switch of GABA from excitation to inhibition [134]. However, no consistent effect of rhIGF1 on spontaneous EEG 
characteristics was found. Pini and colleagues [216] reported some decrease in delta-band activity accompanied by increased theta-band activity, while O'Leary and colleagues [215] showed increased delta power with a decrease in beta and gamma relative power after rhIGF1. Concurrently, both studies found that rhIGF1 treatment was followed by slight improvement in stereotypic behavior and social communication, but also by adverse effects, with an increase in hyperventilation index and depressed mood scores $[215,216]$. At this point meaningful interpretation of the impact of rhlGF1 on normalization of EEG is hardly possible.

Another EEG measure that holds an initial promise to index the effect of rhIGF1 in patients with RTT was EEG frontal asymmetry in the alpha range $(8-13 \mathrm{~Hz})$ [217]. Studies on depression and anxiety have found lower right compared to left alpha power over frontal scalp sites, which has been attributed to a predominance of the right hemisphere activation in these conditions [228-230]. While mood disorders are not among the primary symptoms of RTT, patients with RTT do show anxiety-like behavior [231]. Three studies examined EEG frontal asymmetry in girls with RTT and monitored the effect rhIGF1 on this measure and on behavioral symptoms [215-217]. One study reported right-sided frontal alpha asymmetry in girls with RTT before the open-label extension period of the clinical trial [217]. This abnormal right-hemispheric bias was partially or completely reversed after treatment in five out of the six subjects with RTT. However, neither of these findings were replicated in independent studies $[215,216]$. The inconsistency in the results on frontal alpha asymmetry in RTT may be due to high interindividual variations of this EEG index in patient samples, questioning its potential clinical application (for a recent meta-analysis see [232]). Thus, this EEG measure may be of little value for assessing the neurophysiological systems subserving mood and anxiety in RTT.

Glatiramer acetate $(G A)$ is a collection of synthetic polypeptides that stimulate secretion of several neurotrophic factors, including BDNF, in the brain. GA was shown to normalize BDNF-level in a rodent model of RTT [233]. Djukic and colleagues performed a prospective open-label trial to assess the effect of GA on gait velocity, cognition, respiratory function, electroencephalographic measures and quality of life in 10 patients with RTT [219]. The authors found improvement in gait velocity, memory novelty score and breathing after GA in girls with RTT. GA treatment also led to a decrease in abundance of epileptiform discharges in the 1-h video EEG recording EEG in all patients who had them at the baseline $(n=4)$, although without a measurable reduction in seizure frequency. Qualitative assessment of EEG by an experienced clinician did not reveal any other treatment-related changes in the EEG patterns.

Cerebrolysin $(C B L)$ is a brain-derived peptidergic drug that includes BDNF and other neurotrophic factors. Gorbachevskaja and colleagues studied the effect of CBL in nine patients with RTT in an open-label trial and reported the amelioration of behavioral symptoms and neurophysiological indexes [137]. Twenty-days of treatment with CBL led to a significant decrease in theta and tentative increase in beta spectral power in the resting frontocentral EEG spectra of patients with RTT, thus reducing differences from the EEG spectra of typically developing peers. The positive effect of CBL on RTT symptoms has also been found in Mecp2-deficient animals [234].

Dextromethorphanpolistirex (DM) is a potent noncompetitive antagonist of the NMDA receptor channel. Considering that NMDA-receptors are implicated in pathophysiology of RTT $[235,236]$, Smith-Hicks and colleagues performed a prospective open-label trial of DM and examined its effect on spike activity, seizures and clinical severity in patients with RTT [218]. No EEG parameters other than spike counts were assessed. They found significant dose-dependent treatment-related improvements in clinical seizures, receptive language, and behavioral hyperactivity, while there was no discernible effect on spike counts. More specific EEG characteristics related to NMDA receptor functioning, e.g., the auditory steady-state response [237], are more likely to be sensitive to the effects of DM and can be used in future studies. 
Transcranial direct current stimulation (tDCS) has shown promise in improving cognitive abilities and motor skills of RTT patients. Fabio and colleagues applied anodal tDCS stimulation (C3 electrode site) together with linguistic training in three females with RTT who were previously unresponsive to linguistic training alone [222]. Using a single case design, they showed that tDCS with language training led to significant albeit small improvements in speech sound production (an increase of the number of phonemes produced) and enhanced attentional focus on the task. TDCS combined with a rehabilitation technique also increased the absolute power of theta, alpha and beta bands in patients' resting EEG. The increase in theta power reflects some worsening of EEG and was not reproduced in a recent tDCS study by the same research team [221] that included 31 RTT patients, and was carefully designed to compare tDCS effects in non-sham and sham control groups. Other results were reproduced and pointed to the improvement of behavioral and neurophysiological functions. Future independent studies are needed to replicate the effect of tDCS empowered by cognitive training on speech production in patients with RTT, and scrutinize potential adverse effects of tDCS, especially in RTT patients with epileptiform activity.

Based on animal studies, it can be assumed that deep brain stimulation might be another efficient way to improve RTT symptoms $[238,239]$. Behavioral assessment five weeks after brain deep stimulation of the fimbria-fornix showed positive effects on learning and memory, which were accompanied by improved long-term potentiation [238]. After a course of deep brain stimulation adult female Mecp2+/ - mice became indistinguishable from WT animals when tested in contextual fear conditioning and spatial memory paradigms. The improvements involved only functions with crucial hippocampal involvement, showing specificity for functions related to the stimulated region. The same protocol of deep brain stimulation decreased synchrony between hippocampal CA1 pyramidal neurons to WT-like levels and improved excitability of hippocampal interneurons [239].

Visual discrimination training: Fabio and colleagues found that after 5-days training with eye-tracking technique directed at improvement of visual discrimination and categorization abilities, girls with RTT $(n=21)$ unlike control group of RTT girls who were not trained for 5 -days $(n=13)$ demonstrated better performance of the same visual tasks that were used in the training sessions [220]. The improvements were manifested in a faster gaze shift to a target visual stimulus and longer duration of fixation on the chosen image. The extent to which such behavioral improvement can be generalized to other images, if the tasks are reasonably similar, remains unclear. Long-term training was accompanied by increase in relative beta and decrease in theta power in few electrode sites. The authors considered these EEG changes as an evidence of normalization of background EEG characteristics related to general brain functioning.

To sum up, there is a lack of well-designed studies to make a reliable general conclusion of treatment efficiency for improving verbal and cognitive skills in patients with RTT. Most of the effects demonstrated are weak or, in some cases, do not even reach statistical significance when corrected for multiple comparisons. While some EEG characteristics were used to assess the effect of treatment in patients with RTT, the results are inconsistent and lack clinical relevance. We believe that future studies should focus more on the EEG characteristics that showed promise in targeting neurophysiological processes affected in RTT. For example, 1/f slope of EEG spectrum or slowing of mu-rhythm. Event-related potential characteristics are also among promising biomarkers for RTT (see review [40]).

\section{Method}

For this review, article selection was conducted according to the preferred reporting items for systematic reviews and meta-analyses (PRISMA) [240]. A flowchart of the selection process is displayed in Figure 4. Firstly, PubMed database were searched using terms ((Mecp2 OR Rett syndrome) AND EEG). All searches were limited to English language, full text publications (excluding conference communications) and performed/updated in April, 2020. This led to 195 unique articles. An additional 7 studies were added that did not come up on the search but were identified in reading the identified literature. Abstract-based screening identified 
105 studies reporting EEG characteristics/epilepsy in RTT, including 21 reviews: one review was related to systematic review of event-related potentials in Rett syndrome [40] that is out of scope of the current review; and most others $(n=11)$ focused on epileptiform discharges and seizures in patients with RTT [41,46,54,58,223,241-246]. One review was devoted to findings in RTT animal models [205]. One review was focused on non-relevant pathology [247]. The remaining review papers $(n=8)$ only briefly covered EEG abnormalities in patients with RTT, mostly summarizing available clinical evidence [136,248-253]. Among them, the most detailed study is that of Glaze and colleagues [136]. After full-text reading, 84 articles were retained for inclusion in our review: 7 articles measuring quantitative EEG characteristics in patients with RTT, 11 articles reporting treatment effects on RTT's EEG measures, 38 qualitative clinical descriptions of EEG patterns, 15 studies on seizures without reference to the EEG recordings and 11 studies on animal models of RTT. While epilepsy-related studies dominate our search, we put the major focus of our review into quantitative EEG studies trying to bridge results obtained in patients with RTT and in animal models. The following data were extracted from all quantitative and clinical EEG studies in patients with RTT: sample size, age, experimental setting and EEG results (Tables 1 and 3). Animal studies are summarized in Table 2. For the studies reporting treatment effects on EEG in patients with RTT we added the treatment schema and treatment effect on EEG and on other RTT characteristics (Table 4).

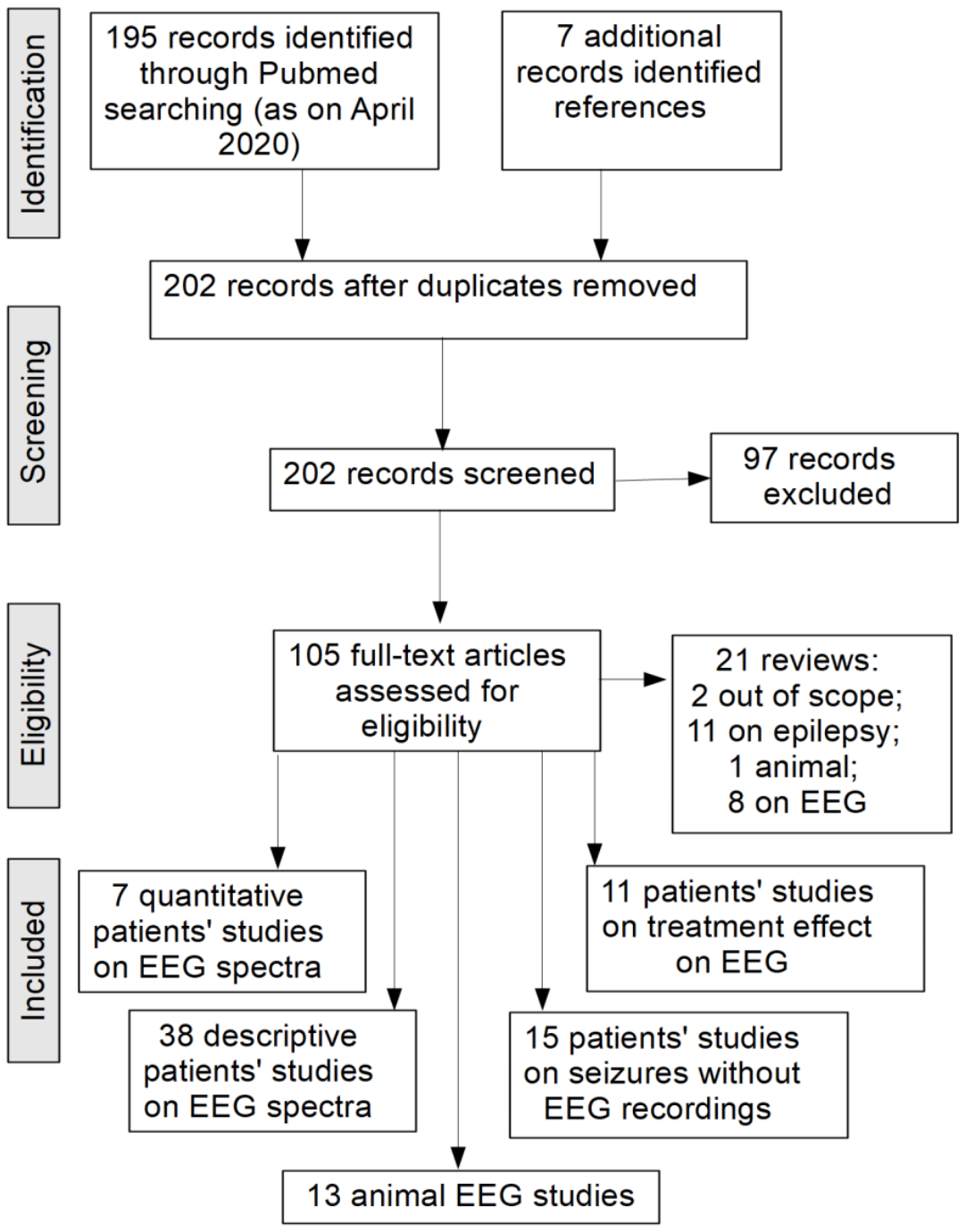

Figure 4. PRISMA flowchart. 


\section{Concluding Remarks}

Here we reviewed the available data on spontaneous EEG abnormalities in patients with Rett syndrome. We tried to link the identified potential EEG biomarkers of MECP2dysfunction with underlying particular neurophysiological processes via findings from animal studies. Through our review we examined the hypothesis about the dominant role of altered inhibition in the development of RTT. Clinically, E/I balance is usually taxing by seizure and epileptiform activity, while some quantitative measures of spontaneous EEG also show promise, e.g., $1 / \mathrm{f}$ spectral slope. At first glance these measures point to the opposite change in E/I balance in RTT: predominance of epilepsy suggests increased E/I balance while steeper $1 / \mathrm{f}$ spectral slope points to a decreased cortical excitability. However, animal studies showed that both reduced and enhanced inhibitory transmission may contribute to seizures and/or EEG epileptiform activity in RTT. In particular, there is the region-specific interplay between tonic and phasic inhibition in the development of RTT: heightened extrasynaptic GABAb receptor activation leading to increased tonic inhibition in thalamocortical system and reduced synaptic GABAa receptor activation leading to decreased phasic inhibition mainly in hippocampal circuits.

Available evidence is still inconclusive about the link of EEG abnormalities with the severity of RTT. While antiepileptic drugs efficiently control seizure in about $70 \%$ of RTT patients, they do not improve cognitive-motor development, at least at the group level. Thus, epilepsy is hardly an underlying cause, rather it is a common feature of RTT disorder. Unlike clinical seizures, multifocal epileptiform abnormalities in interictal EEG appear to correlate with more severe disturbance of cortical functions in RTT patients, whereas focal centro-temporal EEG spikes may be linked to deficient motor control in speech and movement domains. Prospective quantitative examination of antiepileptic drugs on EEG epileptiform patterns and baseline activity in patients with RTT might provide important clinical and scientific insights and contribute to personalized epilepsy treatment. Predominance of low frequency activity and a relative decrease in the power of alpha and beta rhythms in the background EEG, consistently reported in patients with RTT, was also related to RTT severity. Although the above-described EEG abnormalities are not specific to RTT and characterize several other neurological conditions and other developmental disorders, spontaneous EEG may help to target the specific neurophysiological processes thought to be involved in RTT pathogenesis.

For example, changes in alpha and theta frequencies are known to be valuable biomarkers of the prodromal state of neurodegenerative diseases, such as Alzheimer (e.g., [254]) and Huntington [255] diseases, and correlate with severity of early structural damage [254]. Furthermore, computational modeling suggests that the slowing of alpha rhythms and a simultaneous decrease of alpha band power in the brain may reflect the reduced number of active synapses in the thalamo-cortical cell populations [256]. At the same time, spontaneous occurrence of rhythmic theta in RTT patients, and especially slowing of its peak frequency, according to the Mecp2-deficient animal models, may be more specifically linked to the deficiency of catecholaminergic modulation of cortico-hippocampal circuitry in RTT [111]. Another useful quantitative alpha index, which is accessible in RTT patients, is alpha reactivity (open vs. closed eyes). Marked decrease in alpha reactivity is shown in brain disorders, which share some symptoms with RTT and characterized by deficits within the cholinergic system (e.g., Lewy body dementia) [257]. There is strong evidence that cholinergic deficit may be critical for the etiology of social disturbances in RTT animal models [258]. Thus, future studies should include this measure in their analysis.

A shift of the alpha and theta peaks to slower frequencies represent another promising RTT biomarker, which is while frequently reported, was, surprisingly, not studied systematically and quantitatively in RTT. One of the questions that needs to be answered is whether this shift is specific to motor areas and function or represents general phenomena.

Among the EEG parameters that are abnormal in animal models of RTT are highfrequency gamma rhythms, another index of $\mathrm{E} / \mathrm{I}$ balance. The lack of studies of gammaband activity in patients with RTT reflects the low sensitivity of scalp recorded EEG to high 
frequencies mostly due to its heavy contamination by muscle artefacts. Sleep studies might partially overcome this problem. There is also a hope for the MEG technique, which was shown to be able to reliably assess the gamma band activity in spontaneous mode, and in response to auditory and visual stimulation [259].

Several EEG parameters, such as gamma band power in sleep and frontal lowfrequency activity when watching movies, showed atypical developmental trajectories in RTT. These findings are very promising as they might indicate the neurophysiological changes underlying disease progression. More studies are needed to examine the validity of these measures to differentiate the disease stages and to be implicated in clinical practice. There are also only few studies on the relationship between EEG abnormalities and genetic variants of the RTT syndrome, and this represents an important direction of investigation, as different mutations associated with RTT can result in different neurophysiological changes and might benefit from a mutation-tuned treatment approach. Large scale multicenter consortiums are needed to further proceed towards establishing EEG biomarkers in relation to age/disease progression and genetic mutations in patients with RTT.

While most knowledge about mechanisms underlying RTT pathophysiology currently comes from animal studies, RTT manifestation even in a validated animal model of RTT is clearly different in some aspects from that of humans. For example, RTT seizure phenotype is not fully reproduced in MECP2-knockout mice. Another promising approach to dig into the mechanisms underlying RTT phenotype is human pluripotent stem cells, which already brought several insights about alternation of cellular processes in RTT. Great progress in creating 3D cultures allows to study EEG-like activity in brain organoids [260,261]. This approach might be crucial to reveal the early signs of RTT and effects of particular mutations. We believe that translatable electrophysiological indexes will help to bridge works on cellular and whole organism levels.

Overall, consideration of the EEG characteristics opens promising directions of research that can bridge studies in animals and patients and provide informative objective index of particular neurophysiological processes that are crucial for understanding RTT pathophysiology and for assessment of treatment efficacy. The hope is to provide the patients and families with more specific counseling concerning the course of the disease, symptom surveillance, prevention and treatment.

Author Contributions: Conceptualization, T.S. and O.S.; methodology, O.S., K.S. and T.S.; formal analysis, K.S. and O.S.; investigation, K.S. and O.S.; writing-original draft preparation, K.S. and O.S.; writing-review and editing, S.M. and T.S.; visualization, K.S.; supervision, O.S.; project administration, O.S.; funding acquisition, O.S. All authors have read and agreed to the published version of the manuscript.

Funding: This research was funded by the Russia Science Foundation (RSF), grant \#20-68-46042.

Institutional Review Board Statement: Not applicable.

Informed Consent Statement: Not applicable.

Data Availability Statement: Data sharing not applicable.

Conflicts of Interest: The authors declare no conflict of interest.

\section{References}

1. Hagberg, B.; Goutières, F.; Hanefeld, F.; Rett, A.; Wilson, J. Rett Syndrome: Criteria for Inclusion and Exclusion. Brain Dev. 1985, 7, 372-373. [CrossRef]

2. Kozinetz, C.A.; Skender, M.L.; MacNaughton, N.; Almes, M.J.; Schultz, R.J.; Percy, A.K.; Glaze, D.G. Epidemiology of Rett Syndrome: A Population-Based Registry. Pediatrics 1993, 91, 445-450.

3. Laurvick, C.L.; de Klerk, N.; Bower, C.; Christodoulou, J.; Ravine, D.; Ellaway, C.; Williamson, S.; Leonard, H. Rett Syndrome in Australia: A Review of the Epidemiology. J. Pediatr. 2006, 148, 347-352. [CrossRef]

4. Wong, V.C.N.; Li, S.Y.H. Rett Syndrome: Prevalence Among Chinese and a Comparison of MECP2 Mutations of Classic Rett Syndrome With Other Neurodevelopmental Disorders. J. Child Neurol. 2007, 22, 1397-1400. [CrossRef] 
5. Hagberg, B.; Hanefeld, F.; Percy, A.; Skjeldal, O. An Update on Clinically Applicable Diagnostic Criteria in Rett Syndrome. Comments to Rett Syndrome Clinical Criteria Consensus Panel Satellite to European Paediatric Neurology Society Meeting, Baden Baden, Germany, 11 September 2001. Eur. J. Paediatr. Neurol. EJPN Off. J. Eur. Paediatr. Neurol. Soc. 2002, 6, $293-297$. [CrossRef]

6. Young, D.; Bebbington, A.; Anderson, A.; Ravine, D.; Ellaway, C.; Kulkarni, A.; Klerk, N.; Kaufmann, W.; Leonard, H. The Diagnosis of Autism in a Female: Could It Be Rett Syndrome? Eur. J. Pediatr. 2008, 167, 661-669. [CrossRef]

7. Weese-Mayer, D.E.; Lieske, S.P.; Boothby, C.M.; Kenny, A.S.; Bennett, H.L.; Ramirez, J.-M. Autonomic Dysregulation in Young Girls with Rett Syndrome during Nighttime In-Home Recordings. Pediatr. Pulmonol. 2008, 43, 1045-1060. [CrossRef]

8. Neul, J.L.; Kaufmann, W.E.; Glaze, D.G.; Christodoulou, J.; Clarke, A.J.; Bahi-Buisson, N.; Leonard, H.; Bailey, M.E.S.; Schanen, N.C.; Zappella, M.; et al. Rett Syndrome: Revised Diagnostic Criteria and Nomenclature. Ann. Neurol. 2010, 68, 944-950. [CrossRef]

9. Merrick, J.; Lotan, M.; Morad, M.; Kandel, I. Rett Syndrome and Aging. Int. J. Disabil. Hum. Dev. 2006, 5. [CrossRef]

10. Svedberg, L.; Herngren, B.; Michno, P. How Reconstructive Surgery Combined with Physiotherapy for a Painful Nontraumatic Patellar Dislocation Enabled a Woman with Rett Syndrome to Become Pain Free and Remain Physically Active: A Case Report. Clin. Case Rep. 2019, 7, 542-545. [CrossRef]

11. Amir, R.E.; Van den Veyver, I.B.; Wan, M.; Tran, C.Q.; Francke, U.; Zoghbi, H.Y. Rett Syndrome Is Caused by Mutations in X-Linked MECP2, Encoding Methyl-CpG-Binding Protein 2. Nat. Genet. 1999, 23, 185-188. [CrossRef]

12. Bienvenu, T.; Carrié, A.; de Roux, N.; Vinet, M.C.; Jonveaux, P.; Couvert, P.; Villard, L.; Arzimanoglou, A.; Beldjord, C.; Fontes, M.; et al. MECP2 Mutations Account for Most Cases of Typical Forms of Rett Syndrome. Hum. Mol. Genet. 2000, 9, 1377-1384. [CrossRef]

13. Cheadle, J.P.; Gill, H.; Fleming, N.; Maynard, J.; Kerr, A.; Leonard, H.; Krawczak, M.; Cooper, D.N.; Lynch, S.; Thomas, N.; et al. Long-Read Sequence Analysis of the MECP2 Gene in Rett Syndrome Patients: Correlation of Disease Severity with Mutation Type and Location. Hum. Mol. Genet. 2000, 9, 1119-1129. [CrossRef]

14. Neul, J.L.; Fang, P.; Barrish, J.; Lane, J.; Caeg, E.B.; Smith, E.O.; Zoghbi, H.; Percy, A.; Glaze, D.G. Specific Mutations in Methyl-CpG-Binding Protein 2 Confer Different Severity in Rett Syndrome. Neurology 2008, 70, 1313-1321. [CrossRef]

15. Guy, J.; Hendrich, B.; Holmes, M.; Martin, J.E.; Bird, A. A Mouse Mecp2-Null Mutation Causes Neurological Symptoms That Mimic Rett Syndrome. Nat. Genet. 2001, 27, 322-326. [CrossRef]

16. Chen, R.Z.; Akbarian, S.; Tudor, M.; Jaenisch, R. Deficiency of Methyl-CpG Binding Protein-2 in CNS Neurons Results in a Rett-like Phenotype in Mice. Nat. Genet. 2001, 27, 327-331. [CrossRef]

17. Schaevitz, L.R.; Gómez, N.B.; Zhen, D.P.; Berger-Sweeney, J.E. MeCP2 R168X Male and Female Mutant Mice Exhibit Rett-like Behavioral Deficits. Genes Brain Behav. 2013, 12, 732-740. [CrossRef]

18. Zhou, Z.; Goffin, D. Modeling Rett Syndrome with MeCP2 T158A Knockin Mice. In Comprehensive Guide to Autism; Patel, V.B., Preedy, V.R., Martin, C.R., Eds.; Springer: New York, NY, USA, 2014; pp. 2723-2739. ISBN 978-1-4614-4787-0.

19. Pitcher, M.R.; Herrera, J.A.; Buffington, S.A.; Kochukov, M.Y.; Merritt, J.K.; Fisher, A.R.; Schanen, N.C.; Costa-Mattioli, M.; Neul, J.L. Rett Syndrome like Phenotypes in the R255X Mecp2 Mutant Mouse Are Rescued by MECP2 Transgene. Hum. Mol. Genet. 2015, 24, 2662-2672. [CrossRef] [PubMed]

20. Rangasamy, S.; Olfers, S.; Gerald, B.; Hilbert, A.; Svejda, S.; Narayanan, V. Reduced Neuronal Size and MTOR Pathway Activity in the Mecp2 A140V Rett Syndrome Mouse Model. F1000Research 2016, 5, 2269. [CrossRef] [PubMed]

21. Vonhoff, F.; Williams, A.; Ryglewski, S.; Duch, C. Drosophila as a Model for MECP2 Gain of Function in Neurons. PLoS ONE 2012, 7, e31835. [CrossRef]

22. Nozawa, K.; Lin, Y.; Kubodera, R.; Shimizu, Y.; Tanaka, H.; Ohshima, T. Zebrafish Mecp2 Is Required for Proper Axonal Elongation of Motor Neurons and Synapse Formation. Dev. Neurobiol. 2017, 77, 1101-1113. [CrossRef]

23. Pietri, T.; Roman, A.-C.; Guyon, N.; Romano, S.A.; Washbourne, P.; Moens, C.B.; de Polavieja, G.G.; Sumbre, G. The First Mecp2-Null Zebrafish Model Shows Altered Motor Behaviors. Front. Neural Circuits 2013, 7. [CrossRef]

24. Veeraragavan, S.; Wan, Y.-W.; Connolly, D.R.; Hamilton, S.M.; Ward, C.S.; Soriano, S.; Pitcher, M.R.; McGraw, C.M.; Huang, S.G.; Green, J.R.; et al. Loss of MeCP2 in the Rat Models Regression, Impaired Sociability and Transcriptional Deficits of Rett Syndrome. Hum. Mol. Genet. 2016, 25, 3284-3302. [CrossRef]

25. Wu, Y.; Zhong, W.; Cui, N.; Johnson, C.M.; Xing, H.; Zhang, S.; Jiang, C. Characterization of Rett Syndrome-like Phenotypes in Mecp2-Knockout Rats. J. Neurodev. Disord. 2016, 8. [CrossRef]

26. Alessio, N.; Riccitiello, F.; Squillaro, T.; Capasso, S.; Del Gaudio, S.; Di Bernardo, G.; Cipollaro, M.; Melone, M.A.B.; Peluso, G.; Galderisi, U. Neural Stem Cells from a Mouse Model of Rett Syndrome Are Prone to Senescence, Show Reduced Capacity to Cope with Genotoxic Stress, and Are Impaired in the Differentiation Process. Exp. Mol. Med. 2018, 50. [CrossRef]

27. Marchetto, M.C.N.; Carromeu, C.; Acab, A.; Yu, D.; Yeo, G.W.; Mu, Y.; Chen, G.; Gage, F.H.; Muotri, A.R. A Model for Neural Development and Treatment of Rett Syndrome Using Human Induced Pluripotent Stem Cells. Cell 2010, 143, 527-539. [CrossRef]

28. Gomes, A.R.; Fernandes, T.G.; Cabral, J.M.S.; Diogo, M.M. Modeling Rett Syndrome with Human Pluripotent Stem Cells: Mechanistic Outcomes and Future Clinical Perspectives. Int. J. Mol. Sci. 2021, 22, 3751. [CrossRef]

29. Goffin, D.; Allen, M.; Zhang, L.; Amorim, M.; Wang, I.-T.J.; Reyes, A.-R.S.; Mercado-Berton, A.; Ong, C.; Cohen, S.; Hu, L.; et al. Rett Syndrome Mutation MeCP2 T158A Disrupts DNA Binding, Protein Stability and ERP Responses. Nat. Neurosci. 2012, 15, 274-283. [CrossRef] 
30. Brust, V.; Schindler, P.M.; Lewejohann, L. Lifetime Development of Behavioural Phenotype in the House Mouse (Mus Musculus). Front. Zool. 2015, 12, S17. [CrossRef]

31. Tudor, M.; Akbarian, S.; Chen, R.Z.; Jaenisch, R. Transcriptional Profiling of a Mouse Model for Rett Syndrome Reveals Subtle Transcriptional Changes in the Brain. Proc. Natl. Acad. Sci. USA 2002, 99, 15536-15541. [CrossRef]

32. Ehrhart, F.; Coort, S.L.M.; Cirillo, E.; Smeets, E.; Evelo, C.T.; Curfs, L.M.G. Rett Syndrome—Biological Pathways Leading from MECP2 to Disorder Phenotypes. Orphanet J. Rare Dis. 2016, 11. [CrossRef]

33. Ariani, F.; Hayek, G.; Rondinella, D.; Artuso, R.; Mencarelli, M.A.; Spanhol-Rosseto, A.; Pollazzon, M.; Buoni, S.; Spiga, O.; Ricciardi, S.; et al. FOXG1 Is Responsible for the Congenital Variant of Rett Syndrome. Am. J. Hum. Genet. 2008, 83, 89-93. [CrossRef]

34. Kadam, S.D.; Sullivan, B.J.; Goyal, A.; Blue, M.E.; Smith-Hicks, C. Rett Syndrome and CDKL5 Deficiency Disorder: From Bench to Clinic. Int. J. Mol. Sci. 2019, 20, 5098. [CrossRef]

35. Dastidar, S.G.; Bardai, F.H.; Ma, C.; Price, V.; Rawat, V.; Verma, P.; Narayanan, V.; D’Mello, S.R. Isoform-Specific Toxicity of Mecp2 in Postmitotic Neurons: Suppression of Neurotoxicity by FoxG1. J. Neurosci. 2012, 32, 2846-2855. [CrossRef]

36. Ward, L.M. Synchronous Neural Oscillations and Cognitive Processes. Trends Cogn. Sci. 2003, 7, 553-559. [CrossRef]

37. Lopes da Silva, F. EEG and MEG: Relevance to Neuroscience. Neuron 2013, 80, 1112-1128. [CrossRef]

38. Hagberg, B.; Aicardi, J.; Dias, K.; Ramos, O. A Progressive Syndrome of Autism, Dementia, Ataxia, and Loss of Purposeful Hand Use in Girls: Rett's Syndrome: Report of 35 Cases. Ann. Neurol. 1983, 14, 471-479. [CrossRef]

39. Garofalo, E.A.; Drury, I.; Goldstein, G.W. EEG Abnormalities Aid Diagnosis of Rett Syndrome. Pediatr. Neurol. 1988, 4, 350-353. [CrossRef]

40. Sysoeva, O.V.; Smirnov, K.; Stroganova, T.A. Sensory Evoked Potentials in Patients with Rett Syndrome through the Lens of Animal Studies: Systematic Review. Clin. Neurophysiol. Off. J. Int. Fed. Clin. Neurophysiol. 2020, 131, 213-224. [CrossRef]

41. Krajnc, N. Management of Epilepsy in Patients with Rett Syndrome: Perspectives and Considerations. Ther. Clin. Risk Manag. 2015, 925. [CrossRef]

42. Cutri-French, C.; Armstrong, D.; Saby, J.; Gorman, C.; Lane, J.; Fu, C.; Peters, S.U.; Percy, A.; Neul, J.L.; Marsh, E.D. Comparison of Core Features in Four Developmental Encephalopathies in the Rett Natural History Study. Ann. Neurol. 2020, 88, 396-406. [CrossRef]

43. Tarquinio, D.C.; Hou, W.; Berg, A.; Kaufmann, W.E.; Lane, J.B.; Skinner, S.A.; Motil, K.J.; Neul, J.L.; Percy, A.K.; Glaze, D.G. Longitudinal Course of Epilepsy in Rett Syndrome and Related Disorders. Brain J. Neurol. 2017, 140, 306-318. [CrossRef]

44. Pintaudi, M.; Calevo, M.G.; Vignoli, A.; Parodi, E.; Aiello, F.; Baglietto, M.G.; Hayek, Y.; Buoni, S.; Renieri, A.; Russo, S.; et al. Epilepsy in Rett Syndrome: Clinical and Genetic Features. Epilepsy Behav. 2010, 19, 296-300. [CrossRef]

45. Buoni, S.; Zannolli, R.; Felice, C.D.; Saponari, S.; Strambi, M.; Dotti, M.T.; Castrucci, E.; Corbini, L.; Orsi, A.; Hayek, J. DrugResistant Epilepsy and Epileptic Phenotype-EEG Association in MECP2 Mutated Rett Syndrome. Clin. Neurophysiol. 2008, 119, 2455-2458. [CrossRef]

46. Operto, F.F.; Mazza, R.; Pastorino, G.M.G.; Verrotti, A.; Coppola, G. Epilepsy and Genetic in Rett Syndrome: A Review. Brain Behav. 2019, 9. [CrossRef]

47. Leung, H.T.T.; Ring, H. Epilepsy in Four Genetically Determined Syndromes of Intellectual Disability. J. Intellect. Disabil. Res. JIDR 2013, 57, 3-20. [CrossRef]

48. Glaze, D.G.; Schultz, R.J.; Frost, J.D. Rett Syndrome: Characterization of Seizures versus Non-Seizures. Electroencephalogr. Clin. Neurophysiol. 1998, 106, 79-83. [CrossRef]

49. Vignoli, A.; Fabio, R.A.; La Briola, F.; Giannatiempo, S.; Antonietti, A.; Maggiolini, S.; Canevini, M.P. Correlations between Neurophysiological, Behavioral, and Cognitive Function in Rett Syndrome. Epilepsy Behav. 2010, 17, 489-496. [CrossRef]

50. Buoni, S.; Zannolli, R.; De Felice, C.; De Nicola, A.; Guerri, V.; Guerra, B.; Casali, S.; Pucci, B.; Corbini, L.; Mari, F.; et al. EEG Features and Epilepsy in MECP2-Mutated Patients with the Zappella Variant of Rett Syndrome. Clin. Neurophysiol. Off. J. Int. Fed. Clin. Neurophysiol. 2010, 121, 652-657. [CrossRef]

51. Glaze, D.G.; Percy, A.K.; Skinner, S.; Motil, K.J.; Neul, J.L.; Barrish, J.O.; Lane, J.B.; Geerts, S.P.; Annese, F.; Graham, J.; et al. Epilepsy and the Natural History of Rett Syndrome. Neurology 2010, 74, 909-912. [CrossRef]

52. Pintaudi, M.; Calevo, M.G.; Vignoli, A.; Baglietto, M.G.; Hayek, Y.; Traverso, M.; Giacomini, T.; Giordano, L.; Renieri, A.; Russo, S.; et al. Antiepileptic Drugs in Rett Syndrome. Eur. J. Paediatr. Neurol. EJPN Off. J. Eur. Paediatr. Neurol. Soc. 2015, 19, 446-452. [CrossRef] [PubMed]

53. Bao, X.; Downs, J.; Wong, K.; Williams, S.; Leonard, H. Using a Large International Sample to Investigate Epilepsy in Rett Syndrome. Dev. Med. Child Neurol. 2013, 55, 553-558. [CrossRef]

54. Dolce, A.; Ben-Zeev, B.; Naidu, S.; Kossoff, E.H. Rett Syndrome and Epilepsy: An Update for Child Neurologists. Pediatr. Neurol. 2013, 48, 337-345. [CrossRef] [PubMed]

55. d'Orsi, G.; Demaio, V.; Minervini, M.G. Myoclonic Status Misdiagnosed as Movement Disorders in Rett Syndrome: A VideoPolygraphic Study. Epilepsy Behav. EB 2009, 15, 260-262. [CrossRef]

56. d'Orsi, G.; Trivisano, M.; Luisi, C.; Demaio, V.; Di Claudio, M.T.; Pascarella, M.G.; Sciruicchio, V.; Galeone, D.; La Neve, A.; Scarpelli, F.; et al. Epileptic Seizures, Movement Disorders, and Breathing Disturbances in Rett Syndrome: Diagnostic Relevance of Video-Polygraphy. Epilepsy Behav. 2012, 25, 401-407. [CrossRef] [PubMed] 
57. Hagebeuk, E.E.O.; Koelman, J.H.T.M.; Duran, M.; Abeling, N.G.; Vyth, A.; Poll-The, B.-T. Clinical and Electroencephalographic Effects of Folinic Acid Treatment in Rett Syndrome Patients. J. Child Neurol. 2011, 26, 718-723. [CrossRef] [PubMed]

58. Guerrini, R.; Parrini, E. Epilepsy in Rett Syndrome, and CDKL5- and FOXG1-Gene-Related Encephalopathies. Epilepsia 2012, 53, 2067-2078. [CrossRef]

59. Gulati, P.; Jain, P.; Borlot, F.; Munn, R.; Ochi, A. Teaching Video NeuroImages: Needle-like Central Spikes Evoked by Hand Tapping in Rett Syndrome. Neurology 2019, 93, e422-e423. [CrossRef]

60. Luo, X.; Li, C.; Wang, X.; Yu, X.; Jiang, J. Tapping-Lips Aggravated Interictal Bilateral Discharges in EEG in the Patients with Rett Syndrome: A Case Report. BMC Neurol. 2019, 19, 77. [CrossRef]

61. Weber, A.R.B.; Ostendorf, A. Teaching NeuroImages: A Central Theta EEG Rhythm in Rett Syndrome Can Masquerade as Seizure. Neurology 2016, 87, e29-e30. [CrossRef]

62. Lv, Y.; Liu, C.; Shi, M.; Cui, L. Clapping-Surpressed Focal Spikes in EEG May Be Unique for the Patients with Rett Syndrome: A Case Report. BMC Neurol. 2016, 16, 91. [CrossRef] [PubMed]

63. Alfei, E.; Raviglione, F.; Franceschetti, S.; D'Arrigo, S.; Milani, D.; Selicorni, A.; Riva, D.; Zuffardi, O.; Pantaleoni, C.; Binelli, S. Seizures and EEG Features in 74 Patients with Genetic-Dysmorphic Syndromes. Am. J. Med. Genet. A 2014, 164 A, $3154-3161$. [CrossRef] [PubMed]

64. Bhat, S.; Ming, X.; Dekermenjian, R.; Chokroverty, S. Continuous Spike and Wave in Slow-Wave Sleep in a Patient with Rett Syndrome and in a Patient with Lhermitte-Duclos Syndrome and Neurofibromatosis 1. J. Child Neurol. 2014, 29, NP176-NP180. [CrossRef] [PubMed]

65. Nissenkorn, A.; Ben-Zeev, B. Unilateral Rhythmic Hand Tapping in Rett Syndrome: Is This Stereotypy? J. Child Neurol. 2013, 28, 1210-1214. [CrossRef] [PubMed]

66. Roche Martínez, A.; Alonso Colmenero, M.I.; Gomes Pereira, A.; Sanmartí Vilaplana, F.X.; Armstrong Morón, J.; Pineda Marfa, M. Reflex Seizures in Rett Syndrome. Epileptic Disord. Int. Epilepsy J. Videotape 2011, 13, 389-393. [CrossRef]

67. Pelc, K.; Dan, B. Postural Cortical Myoclonus during Gait in Rett Syndrome. Epilepsy Behav. 2009, 16, 188. [CrossRef]

68. Moser, S.J.; Weber, P.; Lütschg, J. Rett Syndrome: Clinical and Electrophysiologic Aspects. Pediatr. Neurol. 2007, 36, 95-100. [CrossRef]

69. Buoni, S.; Zannolli, R.; Colamaria, V.; Macucci, F.; di Bartolo, R.M.; Corbini, L.; Orsi, A.; Zappella, M.; Hayek, J. Myoclonic Encephalopathy in the CDKL5 Gene Mutation. Clin. Neurophysiol. Off. J. Int. Fed. Clin. Neurophysiol. 2006, 117, $223-227$. [CrossRef]

70. Valente, K.D. Another Rett Patient with a Typical Angelman EEG. Epilepsia 2003, 44, 873-874. author reply 874. [CrossRef]

71. Bashina, V.M.; Simashkova, N.V.; Grachev, V.V.; Gorbachevskaya, N.L. Speech and Motor Disturbances in Rett Syndrome. Neurosci. Behav. Physiol. 2002, 32, 323-327. [CrossRef]

72. Laan, L.A.E.M.; Vein, A.A. A Rett Patient with a Typical Angelman EEG. Epilepsia 2002, 43, 1590-1592. [CrossRef]

73. Laan, L.A.E.M.; Brouwer, O.F.; Begeer, C.H.; Zwinderman, A.H.; Gert van Dijk, J. The Diagnostic Value of the EEG in Angelman and Rett Syndrome at a Young Age. Electroencephalogr. Clin. Neurophysiol. 1998, 106, 404-408. [CrossRef]

74. Cooper, R.A.; Kerr, A.M.; Amos, P.M. Rett Syndrome: Critical Examination of Clinical Features, Serial EEG and Video-Monitoring in Understanding and Management. Eur. J. Paediatr. Neurol. EJPN Off. J. Eur. Paediatr. Neurol. Soc. 1998, 2, 127-135. [CrossRef]

75. Lappalainen, R.; Liewendahl, K.; Sainio, K.; Nikkinen, P.; Riikonen, R.S. Brain Perfusion SPECT and EEG Findings in Rett Syndrome. Acta Neurol. Scand. 1997, 95, 44-50. [CrossRef]

76. Niedermeyer, E.; Naidu, S.B.; Plate, C. Unusual EEG Theta Rhythms over Central Region in Rett Syndrome: Considerations of the Underlying Dysfunction. Clin. EEG Electroencephalogr. 1997, 28, 36-43. [CrossRef] [PubMed]

77. Elian, M.; Rudolf, N.D. EEG and Respiration in Rett Syndrome. Acta Neurol. Scand. 1991, 83, 123-128. [CrossRef]

78. Kerr, A.; Southall, D.; Amos, P.; Cooper, R.; Samuels, M.; Mitchell, J.; Stephenson, J. Correlation of Electroencephalogram, Respiration and Movement in the Rett Syndrome. Brain Dev. 1990, 12, 61-68. [CrossRef]

79. Aldrich, M.S.; Garofalo, E.A.; Drury, I. Epileptiform Abnormalities during Sleep in Rett Syndrome. Electroencephalogr. Clin. Neurophysiol. 1990, 75, 365-370. [CrossRef]

80. Niedermeyer, E.; Naidu, S. Further EEG Observations in Children with the Rett Syndrome. Brain Dev. 1990, 12, 53-54. [CrossRef]

81. Hagne, I.; Witt-Engerström, I.; Hagberg, B. EEG Development in Rett Syndrome. A Study of 30 Cases. Electroencephalogr. Clin. Neurophysiol. 1989, 72, 1-6. [CrossRef]

82. Espinar-Sierra, J.; Toledano, M.A.; Franco, C.; Campos-Castello, J.; González-Hidalgo, M.; Oliete, F.; García-Nart, M. Rett's Syndrome: A Neurophysiological Study. Neurophysiol. Clin. Clin. Neurophysiol. 1990, 20, 35-42. [CrossRef]

83. Ishizaki, A.; Inoue, Y.; Sasaki, H.; Fukuyama, Y. Longitudinal Observation of Electroencephalograms in the Rett Syndrome. Brain Dev. 1989, 11, 407-412. [CrossRef]

84. Robb, S.A.; Harden, A.; Boyd, S.G. Rett Syndrome: An EEG Study in 52 Girls. Neuropediatrics 1989, 20, 192-195. [CrossRef]

85. Robertson, R.; Langill, L.; Wong, P.K.; Ho, H.H. Rett Syndrome: EEG Presentation. Electroencephalogr. Clin. Neurophysiol. 1988, 70, 388-395. [CrossRef]

86. Percy, A.K.; Zoghbi, H.Y.; Glaze, D.G. Rett Syndrome: Discrimination of Typical and Variant Forms. Brain Dev. 1987, 9, 458-461. [CrossRef]

87. Trauner, D.A.; Haas, R.H. Electroencephalographic Abnormalities in Rett Syndrome. Pediatr. Neurol. 1987, 3, 331-334. [CrossRef] 
88. Verma, N.P.; Chheda, R.L.; Nigro, M.A.; Hart, Z.H. Electroencephalographic Findings in Rett Syndrome. Electroencephalogr. Clin. Neurophysiol. 1986, 64, 394-401. [CrossRef]

89. Rolando, S. Rett Syndrome: Report of Eight Cases. Brain Dev. 1985, 7, 290-296. [CrossRef]

90. Brunel, R.; Gilly, R. A Case of the Rett Syndrome. Brain Dev. 1985, 7, 313-315. [CrossRef]

91. Völkl-Kernstock, S.; Bauch-Prater, S.; Ponocny-Seliger, E.; Feucht, M. Speech and School Performance in Children with Benign Partial Epilepsy with Centro-Temporal Spikes (BCECTS). Seizure 2009, 18, 320-326. [CrossRef]

92. Vannest, J.; Tenney, J.R.; Gelineau-Morel, R.; Maloney, T.; Glauser, T.A. Cognitive and Behavioral Outcomes in Benign Childhood Epilepsy with Centrotemporal Spikes. Epilepsy Behav. EB 2015, 45, 85-91. [CrossRef]

93. Niedermeyer, E.; Rocca, U. The Diagnostic Significance of Sleep Electroencephalograms in Temporal Lobe Epilepsy. A Comparison of Scalp and Depth Tracings. Eur. Neurol. 1972, 7, 119-129. [CrossRef] [PubMed]

94. Niedermeyer, E. Niedermeyer Frontal Lobe Disinhibition, Rett Syndrome and Attention Deficit Hyperactivity Disorder. Clin. Electroencephalogr. 2001, 32, 20-23. Available online: https://www.ncbi.nlm.nih.gov/pubmed/11202137 (accessed on 14 March 2017). [CrossRef]

95. Jiang, Y.; Song, L.; Li, X.; Zhang, Y.; Chen, Y.; Jiang, S.; Hou, C.; Yao, D.; Wang, X.; Luo, C. Dysfunctional White-Matter Networks in Medicated and Unmedicated Benign Epilepsy with Centrotemporal Spikes. Hum. Brain Mapp. 2019, 40, 3113-3124. [CrossRef] [PubMed]

96. Cheng, D.; Yan, X.; Gao, Z.; Xu, K.; Zhou, X.; Chen, Q. Common and Distinctive Patterns of Cognitive Dysfunction in Children With Benign Epilepsy Syndromes. Pediatr. Neurol. 2017, 72, 36-41.e1. [CrossRef]

97. Sceniak, M.P.; Lang, M.; Enomoto, A.C.; James Howell, C.; Hermes, D.J.; Katz, D.M. Mechanisms of Functional Hypoconnectivity in the Medial Prefrontal Cortex of Mecp2 Null Mice. Cereb. Cortex 2016, 26, 1938-1956. [CrossRef] [PubMed]

98. Zhang, W.; Peterson, M.; Beyer, B.; Frankel, W.N.; Zhang, Z.-W. Loss of MeCP2 From Forebrain Excitatory Neurons Leads to Cortical Hyperexcitation and Seizures. J. Neurosci. 2014, 34, 2754-2763. [CrossRef]

99. Guerrini, R.; Bonanni, P.; Parmeggiani, L.; Santucci, M.; Parmeggiani, A.; Sartucci, F. Cortical Reflex Myoclonus in Rett Syndrome. Ann. Neurol. 1998, 43, 472-479. [CrossRef]

100. Yamanouchi, H.; Kaga, M.; Arima, M. Abnormal Cortical Excitability in Rett Syndrome. Pediatr. Neurol. 1993, 9, $202-206$. [CrossRef]

101. Yoshikawa, H.; Kaga, M.; Suzuki, H.; Sakuragawa, N.; Arima, M. Giant Somatosensory Evoked Potentials in the Rett Syndrome. Brain Dev. 1991, 13, 36-39. [CrossRef]

102. Steffenburg, U.; Hagberg, G.; Hagberg, B. Epilepsy in a Representative Series of Rett Syndrome. Acta Paediatr. 2001, 90, 34-39. [CrossRef]

103. Nissenkorn, A.; Gak, E.; Vecsler, M.; Reznik, H.; Menascu, S.; Zeev, B.B. Epilepsy in Rett Syndrome-The Experience of a National Rett Center. Epilepsia 2010, 51, 1252-1258. [CrossRef]

104. Jian, L.; Nagarajan, L.; de Klerk, N.; Ravine, D.; Christodoulou, J.; Leonard, H. Seizures in Rett Syndrome: An Overview from a One-Year Calendar Study. Eur. J. Paediatr. Neurol. 2007, 11, 310-317. [CrossRef]

105. Henriksen, M.W.; Breck, H.; von Tetzchner, S.; Paus, B.; Skjeldal, O.H.; Brodtkorb, E. Epilepsy in Classic Rett Syndrome: Course and Characteristics in Adult Age. Epilepsy Res. 2018, 145, 134-139. [CrossRef]

106. Shahbazian, M.D.; Young, J.I.; Yuva-Paylor, L.A.; Spencer, C.M.; Antalffy, B.A.; Noebels, J.L.; Armstrong, D.L.; Paylor, R.; Zoghbi, H.Y. Mice with Truncated MeCP2 Recapitulate Many Rett Syndrome Features and Display Hyperacetylation of Histone H3. Neuron 2002, 35, 243-254. [CrossRef]

107. D'Cruz, J.A.; Wu, C.; Zahid, T.; El-Hayek, Y.; Zhang, L.; Eubanks, J.H. Alterations of Cortical and Hippocampal EEG Activity in MeCP2-Deficient Mice. Neurobiol. Dis. 2010, 38, 8-16. [CrossRef]

108. Zhang, L.; Wither, R.G.; Lang, M.; Wu, C.; Sidorova-Darmos, E.; Netchev, H.; Matolcsy, C.B.; Snead, O.C.; Eubanks, J.H. A Role for Diminished GABA Transporter Activity in the Cortical Discharge Phenotype of MeCP2-Deficient Mice. Neuropsychopharmacology 2016, 41, 1467-1476. [CrossRef]

109. Goffin, D.; Brodkin, E.S.; Blendy, J.A.; Siegel, S.J.; Zhou, Z. Cellular Origins of Auditory Event-Related Potential Deficits in Rett Syndrome. Nat. Neurosci. 2014, 17, 804-806. [CrossRef]

110. Ito-Ishida, A.; Ure, K.; Chen, H.; Swann, J.W.; Zoghbi, H.Y. Loss of MeCP2 in Parvalbumin-and Somatostatin-Expressing Neurons in Mice Leads to Distinct Rett Syndrome-like Phenotypes. Neuron 2015, 88, 651-658. [CrossRef]

111. Lang, M.; Wither, R.G.; Colic, S.; Wu, C.; Monnier, P.P.; Bardakjian, B.L.; Zhang, L.; Eubanks, J.H. Rescue of Behavioral and EEG Deficits in Male and Female Mecp2-Deficient Mice by Delayed Mecp2 Gene Reactivation. Hum. Mol. Genet. 2014, 23, 303-318. [CrossRef]

112. Wither, R.G.; Colic, S.; Wu, C.; Bardakjian, B.L.; Zhang, L.; Eubanks, J.H. Daily Rhythmic Behaviors and Thermoregulatory Patterns Are Disrupted in Adult Female MeCP2-Deficient Mice. PLoS ONE 2012, 7, e35396. [CrossRef]

113. Wither, R.G.; Colic, S.; Bardakjian, B.L.; Snead, O.C.; Zhang, L.; Eubanks, J.H. Electrographic and Pharmacological Characterization of a Progressive Epilepsy Phenotype in Female MeCP2-Deficient Mice. Epilepsy Res. 2018, 140, 177-183. [CrossRef] [PubMed]

114. Letts, V.A.; Beyer, B.J.; Frankel, W.N. Hidden in Plain Sight: Spike-Wave Discharges in Mouse Inbred Strains. Genes Brain Behav. 2014, 13, 519-526. [CrossRef]

115. Sitnikova, E. Neonatal Sensory Deprivation Promotes Development of Absence Seizures in Adult Rats with Genetic Predisposition to Epilepsy. Brain Res. 2011, 1377, 109-118. [CrossRef] [PubMed] 
116. Meng, X.; Wang, W.; Lu, H.; He, L.; Chen, W.; Chao, E.S.; Fiorotto, M.L.; Tang, B.; Herrera, J.A.; Seymour, M.L.; et al. Manipulations of MeCP2 in Glutamatergic Neurons Highlight Their Contributions to Rett and Other Neurological Disorders. eLife 2016, 5, e14199. [CrossRef]

117. Johnston, M.V.; Ammanuel, S.; O’Driscoll, C.; Wozniak, A.; Naidu, S.; Kadam, S.D. Twenty-Four Hour Quantitative-EEG and in-Vivo Glutamate Biosensor Detects Activity and Circadian Rhythm Dependent Biomarkers of Pathogenesis in Mecp2 Null Mice. Front. Syst. Neurosci. 2014, 8. [CrossRef]

118. Lang, M.; Wither, R.G.; Brotchie, J.M.; Wu, C.; Zhang, L.; Eubanks, J.H. Selective Preservation of MeCP2 in Catecholaminergic Cells Is Sufficient to Improve the Behavioral Phenotype of Male and Female Mecp2-Deficient Mice. Hum. Mol. Genet. 2013, 22, 358-371. [CrossRef]

119. Chao, H.-T.; Chen, H.; Samaco, R.C.; Xue, M.; Chahrour, M.; Yoo, J.; Neul, J.L.; Gong, S.; Lu, H.-C.; Heintz, N.; et al. Dysfunction in GABA Signalling Mediates Autism-like Stereotypies and Rett Syndrome Phenotypes. Nature 2010, 468, 263-269. [CrossRef]

120. Ure, K.; Lu, H.; Wang, W.; Ito-Ishida, A.; Wu, Z.; He, L.; Sztainberg, Y.; Chen, W.; Tang, J.; Zoghbi, H.Y. Restoration of Mecp2 Expression in GABAergic Neurons Is Sufficient to Rescue Multiple Disease Features in a Mouse Model of Rett Syndrome. eLife 2016, 5, e14198. [CrossRef]

121. McLeod, F.; Ganley, R.; Williams, L.; Selfridge, J.; Bird, A.; Cobb, S.R. Reduced Seizure Threshold and Altered Network Oscillatory Properties in a Mouse Model of Rett Syndrome. Neuroscience 2013, 231, 195-205. [CrossRef] [PubMed]

122. Jin, X.; Cui, N.; Zhong, W.; Jin, X.-T.; Jiang, C. GABAergic Synaptic Inputs of Locus Coeruleus Neurons in Wild-Type and Mecp2 -Null Mice. Am. J. Physiol.-Cell Physiol. 2013, 304, C844-C857. [CrossRef] [PubMed]

123. Liu, Z.; Vergnes, M.; Depaulis, A.; Marescaux, C. Involvement of Intrathalamic GABAb Neurotransmission in the Control of Absence Seizures in the Rat. Neuroscience 1992, 48, 87-93. [CrossRef]

124. Crunelli, V.; Lőrincz, M.L.; McCafferty, C.; Lambert, R.C.; Leresche, N.; Di Giovanni, G.; David, F. Clinical and Experimental Insight into Pathophysiology, Comorbidity and Therapy of Absence Seizures. Brain 2020, 143, 2341-2368. [CrossRef]

125. Destexhe, A. Spike-and-Wave Oscillations Based on the Properties of GABAB Receptors. J. Neurosci. Off. J. Soc. Neurosci. 1998, 18, 9099-9111. [CrossRef]

126. Okamoto, N.; Miya, F.; Tsunoda, T.; Kato, M.; Saitoh, S.; Yamasaki, M.; Shimizu, A.; Torii, C.; Kanemura, Y.; Kosaki, K. Targeted Next-Generation Sequencing in the Diagnosis of Neurodevelopmental Disorders. Clin. Genet. 2015, 88, 288-292. [CrossRef]

127. Dong, Q.; Kim, J.; Nguyen, L.; Bu, Q.; Chang, Q. An Astrocytic Influence on Impaired Tonic Inhibition in Hippocampal CA1 Pyramidal Neurons in a Mouse Model of Rett Syndrome. J. Neurosci. 2020, 40, 6250-6261. [CrossRef]

128. Rivera, C.; Voipio, J.; Payne, J.A.; Ruusuvuori, E.; Lahtinen, H.; Lamsa, K.; Pirvola, U.; Saarma, M.; Kaila, K. The K+/ClCo-Transporter KCC2 Renders GABA Hyperpolarizing during Neuronal Maturation. Nature 1999, 397, 251-255. [CrossRef] [PubMed]

129. Banerjee, A.; Rikhye, R.V.; Breton-Provencher, V.; Tang, X.; Li, C.; Li, K.; Runyan, C.A.; Fu, Z.; Jaenisch, R.; Sur, M. Jointly Reduced Inhibition and Excitation Underlies Circuit-Wide Changes in Cortical Processing in Rett Syndrome. Proc. Natl. Acad. Sci. USA 2016, 113, E7287-E7296. [CrossRef]

130. Duarte, S.T.; Armstrong, J.; Roche, A.; Ortez, C.; Pérez, A.; Maria del Mar, O.C.; Pereira, A.; Sanmartí, F.; Ormazábal, A.; Artuch, R.; et al. Abnormal Expression of Cerebrospinal Fluid Cation Chloride Cotransporters in Patients with Rett Syndrome. PLoS ONE 2013, 8, e68851. [CrossRef] [PubMed]

131. Hinz, L.; Torrella Barrufet, J.; Heine, V.M. KCC2 Expression Levels Are Reduced in Post Mortem Brain Tissue of Rett Syndrome Patients. Acta Neuropathol. Commun. 2019, 7, 196. [CrossRef]

132. Wright, R.; Newey, S.E.; Ilie, A.; Wefelmeyer, W.; Raimondo, J.V.; Ginham, R.; Mcllhinney, R.A.J.; Akerman, C.J. Neuronal Chloride Regulation via KCC2 Is Modulated through a GABAB Receptor Protein Complex. J. Neurosci. Off. J. Soc. Neurosci. 2017, 37, 5447-5462. [CrossRef]

133. Lozovaya, N.; Nardou, R.; Tyzio, R.; Chiesa, M.; Pons-Bennaceur, A.; Eftekhari, S.; Bui, T.-T.; Billon-Grand, M.; Rasero, J.; Bonifazi, P.; et al. Early Alterations in a Mouse Model of Rett Syndrome: The GABA Developmental Shift Is Abolished at Birth. Sci. Rep. 2019, 9, 9276. [CrossRef] [PubMed]

134. Tang, X.; Drotar, J.; Li, K.; Clairmont, C.D.; Brumm, A.S.; Sullins, A.J.; Wu, H.; Liu, X.S.; Wang, J.; Gray, N.S.; et al. Pharmacological Enhancement of KCC2 Gene Expression Exerts Therapeutic Effects on Human Rett Syndrome Neurons and Mecp2 Mutant Mice. Sci. Transl. Med. 2019, 11. [CrossRef] [PubMed]

135. Zhang, Y.; Cao, S.-X.; Sun, P.; He, H.-Y.; Yang, C.-H.; Chen, X.-J.; Shen, C.-J.; Wang, X.-D.; Chen, Z.; Berg, D.K.; et al. Loss of MeCP2 in Cholinergic Neurons Causes Part of RTT-like Phenotypes via A7 Receptor in Hippocampus. Cell Res. 2016, 26, 728-742. [CrossRef] [PubMed]

136. Glaze, D.G. Neurophysiology of Rett Syndrome. J. Child Neurol. 2005, 20, 740-746. [CrossRef] [PubMed]

137. Gorbachevskaya, N.; Bashina, V.; Gratchev, V.; Iznak, A. Cerebrolysin Therapy in Rett Syndrome: Clinical and EEG Mapping Study. Brain Dev. 2001, 23, S90-S93. [CrossRef]

138. Gratchev, V.V.; Bashina, V.M.; Klushnik, T.P.; Ulas, V.U.; Gorbachevskaya, N.L.; Vorsanova, S.G. Clinical, Neurophysiological and Immunological Correlations in Classical Rett Syndrome. Brain Dev. 2001, 23, S108-S112. [CrossRef]

139. Roche, K.J.; LeBlanc, J.J.; Levin, A.R.; O’Leary, H.M.; Baczewski, L.M.; Nelson, C.A. Electroencephalographic Spectral Power as a Marker of Cortical Function and Disease Severity in Girls with Rett Syndrome. J. Neurodev. Disord. 2019, 11, 15. [CrossRef] [PubMed] 
140. Keogh, C.; Pini, G.; Dyer, A.H.; Bigoni, S.; DiMarco, P.; Gemo, I.; Reilly, R.; Tropea, D. Clinical and Genetic Rett Syndrome Variants Are Defined by Stable Electrophysiological Profiles. Bmc Pediatr. 2018, 18, 333. [CrossRef]

141. Ammanuel, S.; Chan, W.C.; Adler, D.A.; Lakshamanan, B.M.; Gupta, S.S.; Ewen, J.B.; Johnston, M.V.; Marcus, C.L.; Naidu, S.; Kadam, S.D. Heightened Delta Power during Slow-Wave-Sleep in Patients with Rett Syndrome Associated with Poor Sleep Efficiency. PLoS ONE 2015, 10, e0138113. [CrossRef]

142. Faienza, C.; Capone, C.; Sani, E.; Villani, D.; Prati, G. EEG Mapping in a Child with Rett Syndrome. Psychiatry Res. 1989, 29, 425-426. [CrossRef]

143. Bader, G.G.; Witt-Engerström, I.; Hagberg, B. Neurophysiological Findings in the Rett Syndrome, II: Visual and Auditory Brainstem, Middle and Late Evoked Responses. Brain Dev. 1989, 11, 110-114. [CrossRef]

144. Akshoomoff, N. Use of the Mullen Scales of Early Learning for the Assessment of Young Children with Autism Spectrum Disorders. Child Neuropsychol. J. Norm. Abnorm. Dev. Child. Adolesc. 2006, 12, 269-277. [CrossRef] [PubMed]

145. Clarke, A.R.; Barry, R.J.; Johnstone, S.J.; McCarthy, R.; Selikowitz, M. EEG Development in Attention Deficit Hyperactivity Disorder: From Child to Adult. Clin. Neurophysiol. Off. J. Int. Fed. Clin. Neurophysiol. 2019, 130, 1256-1262. [CrossRef]

146. Perera, M.P.N.; Bailey, N.W.; Herring, S.E.; Fitzgerald, P.B. Electrophysiology of Obsessive Compulsive Disorder: A Systematic Review of the Electroencephalographic Literature. J. Anxiety Disord. 2019, 62, 1-14. [CrossRef]

147. Benz, N.; Hatz, F.; Bousleiman, H.; Ehrensperger, M.M.; Gschwandtner, U.; Hardmeier, M.; Ruegg, S.; Schindler, C.; Zimmermann, R.; Monsch, A.U.; et al. Slowing of EEG Background Activity in Parkinson's and Alzheimer's Disease with Early Cognitive Dysfunction. Front. Aging Neurosci. 2014, 6, 314. [CrossRef] [PubMed]

148. Voytek, B.; Kramer, M.A.; Case, J.; Lepage, K.Q.; Tempesta, Z.R.; Knight, R.T.; Gazzaley, A. Age-Related Changes in 1/f Neural Electrophysiological Noise. J. Neurosci. 2015, 35, 13257-13265. [CrossRef] [PubMed]

149. Robertson, M.M.; Furlong, S.; Voytek, B.; Donoghue, T.; Boettiger, C.A.; Sheridan, M.A. EEG Power Spectral Slope Differs by ADHD Status and Stimulant Medication Exposure in Early Childhood. J. Neurophysiol. 2019, 122, 2427-2437. [CrossRef] [PubMed]

150. Bartos, M.; Vida, I.; Jonas, P. Synaptic Mechanisms of Synchronized Gamma Oscillations in Inhibitory Interneuron Networks. Nat. Rev. Neurosci. 2007, 8, 45-56. [CrossRef] [PubMed]

151. Vinck, M.; Womelsdorf, T.; Buffalo, E.A.; Desimone, R.; Fries, P. Attentional Modulation of Cell-Class-Specific Gamma-Band Synchronization in Awake Monkey Area V4. Neuron 2013, 80, 1077-1089. [CrossRef]

152. Hoogenboom, N.; Schoffelen, J.-M.; Oostenveld, R.; Parkes, L.M.; Fries, P. Localizing Human Visual Gamma-Band Activity in Frequency, Time and Space. NeuroImage 2006, 29, 764-773. [CrossRef]

153. Le Van Quyen, M.; Staba, R.; Bragin, A.; Dickson, C.; Valderrama, M.; Fried, I.; Engel, J. Large-Scale Microelectrode Recordings of High-Frequency Gamma Oscillations in Human Cortex during Sleep. J. Neurosci. Off. J. Soc. Neurosci. 2010, 30, 7770-7782. [CrossRef]

154. Zhong, W.; Ciatipis, M.; Wolfenstetter, T.; Jessberger, J.; Müller, C.; Ponsel, S.; Yanovsky, Y.; Brankačk, J.; Tort, A.B.L.; Draguhn, A. Selective Entrainment of Gamma Subbands by Different Slow Network Oscillations. Proc. Natl. Acad. Sci. USA 2017, 114, 4519-4524. [CrossRef] [PubMed]

155. Buzsáki, G.; Wang, X.-J. Mechanisms of Gamma Oscillations. Annu. Rev. Neurosci. 2012, 35, 203-225. [CrossRef] [PubMed]

156. Colgin, L.L. Do Slow and Fast Gamma Rhythms Correspond to Distinct Functional States in the Hippocampal Network? Brain Res. 2015, 1621, 309-315. [CrossRef] [PubMed]

157. Yuval-Greenberg, S.; Tomer, O.; Keren, A.S.; Nelken, I.; Deouell, L.Y. Transient Induced Gamma-Band Response in EEG as a Manifestation of Miniature Saccades. Neuron 2008, 58, 429-441. [CrossRef]

158. Orekhova, E.V.; Stroganova, T.A.; Nygren, G.; Tsetlin, M.M.; Posikera, I.N.; Gillberg, C.; Elam, M. Excess of High Frequency Electroencephalogram Oscillations in Boys with Autism. Biol. Psychiatry 2007, 62, 1022-1029. [CrossRef] [PubMed]

159. Uhlhaas, P.J.; Singer, W. Neuronal Dynamics and Neuropsychiatric Disorders: Toward a Translational Paradigm for Dysfunctional Large-Scale Networks. Neuron 2012, 75, 963-980. [CrossRef] [PubMed]

160. Zijlmans, M.; Jiruska, P.; Zelmann, R.; Leijten, F.S.S.; Jefferys, J.G.R.; Gotman, J. High-Frequency Oscillations as a New Biomarker in Epilepsy. Ann. Neurol. 2012, 71, 169-178. [CrossRef]

161. Verma, N.P.; Nigro, M.A.; Hart, Z.H. Rett Syndrome-A Gray Matter Disease? Electrophysiologic Evidence. Electroencephalogr. Clin. Neurophysiol. 1987, 67, 327-329. [CrossRef]

162. Glaze, D.G.; Frost, J.D.; Zoghbi, H.Y.; Percy, A.K. Rett's Syndrome: Characterization of Respiratory Patterns and Sleep. Ann. Neurol. 1987, 21, 377-382. [CrossRef]

163. Andrade-Valença, L.; Mari, F.; Jacobs, J.; Zijlmans, M.; Olivier, A.; Gotman, J.; Dubeau, F. Interictal High Frequency Oscillations (HFOs) in Patients with Focal Epilepsy and Normal MRI. Clin. Neurophysiol. Off. J. Int. Fed. Clin. Neurophysiol. 2012, 123, 100-105. [CrossRef] [PubMed]

164. Traub, R.D. Fast Oscillations and Epilepsy. Epilepsy Curr. 2003, 3, 77-79. [CrossRef]

165. Yamamoto, R.; Yanagita, T.; Kobayashi, H.; Yokoo, H.; Wada, A. Up-Regulation of Sodium Channel Subunit MRNAs and Their Cell Surface Expression by Antiepileptic Valproic Acid: Activation of Calcium Channel and Catecholamine Secretion in Adrenal Chromaffin Cells. J. Neurochem. 1997, 68, 1655-1662. [CrossRef]

166. Dzirasa, K.; Ramsey, A.J.; Takahashi, D.Y.; Stapleton, J.; Potes, J.M.; Williams, J.K.; Gainetdinov, R.R.; Sameshima, K.; Caron, M.G.; Nicolelis, M.A.L. Hyperdopaminergia and NMDA Receptor Hypofunction Disrupt Neural Phase Signaling. J. Neurosci. Off. J. Soc. Neurosci. 2009, 29, 8215-8224. [CrossRef] 
167. Bragin, A.; Jandó, G.; Nádasdy, Z.; Hetke, J.; Wise, K.; Buzsáki, G. Gamma (40-100 Hz) Oscillation in the Hippocampus of the Behaving Rat. J. Neurosci. Off. J. Soc. Neurosci. 1995, 15, 47-60. [CrossRef]

168. Nomura, Y.; Segawa, M.; Hasegawa, M. Rett Syndrome-Clinical Studies and Pathophysiological Consideration. Brain Dev. 1984, 6, 475-486. [CrossRef]

169. Nomura, Y.; Honda, K.; Segawa, M. Pathophysiology of Rett Syndrome. Brain Dev. 1987, 9, 506-513. [CrossRef]

170. Wong, K.; Leonard, H.; Jacoby, P.; Ellaway, C.; Downs, J. The Trajectories of Sleep Disturbances in Rett Syndrome. J. Sleep Res. 2015, 24, 223-233. [CrossRef] [PubMed]

171. Boban, S.; Wong, K.; Epstein, A.; Anderson, B.; Murphy, N.; Downs, J.; Leonard, H. Determinants of Sleep Disturbances in Rett Syndrome: Novel Findings in Relation to Genotype. Am. J. Med. Genet. A 2016, 170, 2292-2300. [CrossRef] [PubMed]

172. Piazza, C.C.; Fisher, W.; Kiesewetter, K.; Bowman, L.; Moser, H. Aberrant Sleep Patterns in Children with the Rett Syndrome. Brain Dev. 1990, 12, 488-493. [CrossRef]

173. Kales, A.; Rechtschaffen, A.; University of California, L.A.; Brain Information Service; National Institute of Neurological Diseases and Blindness (U.S.). A Manual of Standardized Terminology, Techniques and Scoring System for Sleep Stages of Human Subjects; United States Government Printing Office: Washington, DC, USA, 1968.

174. Carotenuto, M.; Esposito, M.; D'Aniello, A.; Rippa, C.D.; Precenzano, F.; Pascotto, A.; Bravaccio, C.; Elia, M. Polysomnographic Findings in Rett Syndrome: A Case-Control Study. Sleep Breath. Schlaf Atm. 2013, 17, 93-98. [CrossRef]

175. Dreyfus-Brisac, C.; Monod, N.; Radvanyi, M.F.; Curzi, L. Interest of Electrophysiological Studies in Human Development. Physiol. Biochem. Basis Perinat. Med. 1981, 337-346. [CrossRef]

176. Achermann, P.; Dijk, D.J.; Brunner, D.P.; Borbély, A.A. A Model of Human Sleep Homeostasis Based on EEG Slow-Wave Activity: Quantitative Comparison of Data and Simulations. Brain Res. Bull. 1993, 31, 97-113. [CrossRef]

177. Alhola, P.; Polo-Kantola, P. Sleep Deprivation: Impact on Cognitive Performance. Neuropsychiatr. Dis. Treat. $2007,3,553-567$.

178. Ednick, M.; Cohen, A.P.; McPhail, G.L.; Beebe, D.; Simakajornboon, N.; Amin, R.S. A Review of the Effects of Sleep during the First Year of Life on Cognitive, Psychomotor, and Temperament Development. Sleep 2009, 32, 1449-1458. [CrossRef]

179. Tham, E.K.; Schneider, N.; Broekman, B.F. Infant Sleep and Its Relation with Cognition and Growth: A Narrative Review. Nat. Sci. Sleep 2017, 9, 135-149. [CrossRef] [PubMed]

180. Alvarez-Saavedra, M.; Antoun, G.; Yanagiya, A.; Oliva-Hernandez, R.; Cornejo-Palma, D.; Perez-Iratxeta, C.; Sonenberg, N.; Cheng, H.-Y.M. MiRNA-132 Orchestrates Chromatin Remodeling and Translational Control of the Circadian Clock. Hum. Mol. Genet. 2011, 20, 731-751. [CrossRef]

181. Vosko, A.; van Diepen, H.C.; Kuljis, D.; Chiu, A.M.; Heyer, D.; Terra, H.; Carpenter, E.; Michel, S.; Meijer, J.H.; Colwell, C.S. Role of Vasoactive Intestinal Peptide in the Light Input to the Circadian System. Eur. J. Neurosci. 2015, 42, 1839-1848. [CrossRef]

182. Jones, J.R.; Simon, T.; Lones, L.; Herzog, E.D. SCN VIP Neurons Are Essential for Normal Light-Mediated Resetting of the Circadian System. J. Neurosci. 2018, 38, 7986-7995. [CrossRef]

183. Li, Q.; Loh, D.H.; Kudo, T.; Truong, D.; Derakhshesh, M.; Kaswan, Z.M.; Ghiani, C.A.; Tsoa, R.; Cheng, Y.; Sun, Y.E.; et al. Circadian Rhythm Disruption in a Mouse Model of Rett Syndrome Circadian Disruption in RTT. Neurobiol. Dis. 2015, 77, 155-164. [CrossRef]

184. Bebbington, A.; Anderson, A.; Ravine, D.; Fyfe, S.; Pineda, M.; de Klerk, N.; Ben-Zeev, B.; Yatawara, N.; Percy, A.; Kaufmann, W.E.; et al. Investigating Genotype-Phenotype Relationships in Rett Syndrome Using an International Data Set. Neurology 2008, 70, 868-875. [CrossRef]

185. Bebbington, A.; Percy, A.; Christodoulou, J.; Ravine, D.; Ho, G.; Jacoby, P.; Anderson, A.; Pineda, M.; Ben Zeev, B.; Bahi-Buisson, N.; et al. Updating the Profile of C-Terminal MECP2 Deletions in Rett Syndrome. J. Med. Genet. 2010, 47, $242-248$. [CrossRef] [PubMed]

186. Bebbington, A.; Downs, J.; Percy, A.; Pineda, M.; Zeev, B.B.; Bahi-Buisson, N.; Leonard, H. The Phenotype Associated with a Large Deletion on MECP2. Eur. J. Hum. Genet. EJHG 2012, 20, 921-927. [CrossRef]

187. Archer, H.L.; Whatley, S.D.; Evans, J.C.; Ravine, D.; Huppke, P.; Kerr, A.; Bunyan, D.; Kerr, B.; Sweeney, E.; Davies, S.J.; et al. Gross Rearrangements of the MECP2 Gene Are Found in Both Classical and Atypical Rett Syndrome Patients. J. Med. Genet. 2006, 43, 451-456. [CrossRef]

188. Jian, L.; Archer, H.; Ravine, D.; Kerr, A.; Klerk, N.; Christodoulou, J.; Bailey, M.; Laurvick, C.; Leonard, H.P. R270X MECP2 Mutation and Mortality in Rett Syndrome. Eur. J. Hum. Genet. EJHG 2005, 13, 1235-1238. [CrossRef] [PubMed]

189. Frullanti, E.; Papa, F.T.; Grillo, E.; Clarke, A.; Ben-Zeev, B.; Pineda, M.; Bahi-Buisson, N.; Bienvenu, T.; Armstrong, J.; Roche Martinez, A.; et al. Analysis of the Phenotypes in the Rett Networked Database. Int. J. Genom. 2019, 2019, 6956934. [CrossRef]

190. Leonard, H.; Cobb, S.; Downs, J. Clinical and Biological Progress over 50 Years in Rett Syndrome. Nat. Rev. Neurol. 2017, 13, 37-51. [CrossRef] [PubMed]

191. Urbanowicz, A.; Downs, J.; Girdler, S.; Ciccone, N.; Leonard, H. Aspects of Speech-Language Abilities Are Influenced by MECP2 Mutation Type in Girls with Rett Syndrome. Am. J. Med. Genet. A 2015, 167, 354-362. [CrossRef]

192. Cuddapah, V.A.; Pillai, R.B.; Shekar, K.V.; Lane, J.B.; Motil, K.J.; Skinner, S.A.; Tarquinio, D.C.; Glaze, D.G.; McGwin, G.; Kaufmann, W.E.; et al. Methyl-CpG-Binding Protein 2 (MECP2) Mutation Type Is Associated with Disease Severity in Rett Syndrome. J. Med. Genet. 2014, 51, 152-158. [CrossRef] 
193. Nissenkorn, A.; Levy-Drummer, R.S.; Bondi, O.; Renieri, A.; Villard, L.; Mari, F.; Mencarelli, M.A.; Lo Rizzo, C.; Meloni, I.; Pineda, M.; et al. Epilepsy in Rett Syndrome-Lessons from the Rett Networked Database. Epilepsia 2015, 56, 569-576. [CrossRef]

194. Ramocki, M.B.; Tavyev, Y.J.; Peters, S.U. The MECP2 Duplication Syndrome. Am. J. Med. Genet. A 2010, 152A, 1079-1088. [CrossRef] [PubMed]

195. Van Esch, H. MECP2 Duplication Syndrome. Mol. Syndromol. 2012, 2, 128-136. [CrossRef] [PubMed]

196. Friez, M.J.; Jones, J.R.; Clarkson, K.; Lubs, H.; Abuelo, D.; Bier, J.-A.B.; Pai, S.; Simensen, R.; Williams, C.; Giampietro, P.F.; et al. Recurrent Infections, Hypotonia, and Mental Retardation Caused by Duplication of MECP2 and Adjacent Region in Xq28. Pediatrics 2006, 118, e1687-e1695. [CrossRef]

197. Caumes, R.; Boespflug-Tanguy, O.; Villeneuve, N.; Lambert, L.; Delanoe, C.; Leheup, B.; Bahi-Buisson, N.; Auvin, S. Late Onset Epileptic Spasms Is Frequent in MECP2 Gene Duplication: Electroclinical Features and Long-Term Follow-up of 8 Epilepsy Patients. Eur. J. Paediatr. Neurol. EJPN Off. J. Eur. Paediatr. Neurol. Soc. 2014, 18, 475-481. [CrossRef] [PubMed]

198. Rajaprakash, M.; Richer, J.; Sell, E. Valproic Acid as a Monotherapy in Drug-Resistant Methyl-CpG-Binding Protein 2 Gene (MECP2) Duplication-Related Epilepsy. Epilepsy Behav. Case Rep. 2018, 10, 133-136. [CrossRef]

199. Marafi, D.; Suter, B.; Schultz, R.; Glaze, D.; Pavlik, V.N.; Goldman, A.M. Spectrum and Time Course of Epilepsy and the Associated Cognitive Decline in MECP2 Duplication Syndrome. Neurology 2019, 92, e108-e114. [CrossRef]

200. Olson, H.E.; Demarest, S.T.; Pestana-Knight, E.M.; Swanson, L.C.; Iqbal, S.; Lal, D.; Leonard, H.; Cross, J.H.; Devinsky, O.; Benke, T.A. Cyclin-Dependent Kinase-like 5 (CDKL5) Deficiency Disorder: Clinical Review. Pediatr. Neurol. 2019, 97, 18-25. [CrossRef]

201. Demarest, S.; Pestana-Knight, E.M.; Olson, H.E.; Downs, J.; Marsh, E.D.; Kaufmann, W.E.; Partridge, C.-A.; Leonard, H.; Gwadry-Sridhar, F.; Frame, K.E.; et al. Severity Assessment in CDKL5 Deficiency Disorder. Pediatr. Neurol. 2019, 97, 38-42. [CrossRef]

202. Vegas, N.; Cavallin, M.; Maillard, C.; Boddaert, N.; Toulouse, J.; Schaefer, E.; Lerman-Sagie, T.; Lev, D.; Magalie, B.; Moutton, S.; et al. Delineating FOXG1 Syndrome: From Congenital Microcephaly to Hyperkinetic Encephalopathy. Neurol. Genet. 2018, 4, e281. [CrossRef]

203. Mitter, D.; Pringsheim, M.; Kaulisch, M.; Plümacher, K.S.; Schröder, S.; Warthemann, R.; Abou Jamra, R.; Baethmann, M.; Bast, T.; Büttel, H.-M.; et al. FOXG1 Syndrome: Genotype-Phenotype Association in 83 Patients with FOXG1 Variants. Genet. Med. Off. J. Am. Coll. Med. Genet. 2018, 20, 98-108. [CrossRef]

204. Wang, I.-T.J.; Allen, M.; Goffin, D.; Zhu, X.; Fairless, A.H.; Brodkin, E.S.; Siegel, S.J.; Marsh, E.D.; Blendy, J.A.; Zhou, Z. Loss of CDKL5 Disrupts Kinome Profile and Event-Related Potentials Leading to Autistic-like Phenotypes in Mice. Proc. Natl. Acad. Sci. USA 2012, 109, 21516-21521. [CrossRef] [PubMed]

205. Fallah, M.S.; Eubanks, J.H. Seizures in Mouse Models of Rare Neurodevelopmental Disorders. Neuroscience 2020, 445, 50-68. [CrossRef]

206. Amendola, E.; Zhan, Y.; Mattucci, C.; Castroflorio, E.; Calcagno, E.; Fuchs, C.; Lonetti, G.; Silingardi, D.; Vyssotski, A.L.; Farley, D.; et al. Mapping Pathological Phenotypes in a Mouse Model of CDKL5 Disorder. PLoS ONE 2014, 9, e91613. [CrossRef]

207. Okuda, K.; Kobayashi, S.; Fukaya, M.; Watanabe, A.; Murakami, T.; Hagiwara, M.; Sato, T.; Ueno, H.; Ogonuki, N.; Komano-Inoue, S.; et al. CDKL5 Controls Postsynaptic Localization of GluN2B-Containing NMDA Receptors in the Hippocampus and Regulates Seizure Susceptibility. Neurobiol. Dis. 2017, 106, 158-170. [CrossRef] [PubMed]

208. Testa, G.; Olimpico, F.; Pancrazi, L.; Borello, U.; Cattaneo, A.; Caleo, M.; Costa, M.; Mainardi, M. Cortical Seizures in FoxG1+/Mice Are Accompanied by Akt/S6 Overactivation, Excitation/Inhibition Imbalance and Impaired Synaptic Transmission. Int. J. Mol. Sci. 2019, 20, 4127. [CrossRef] [PubMed]

209. Collins, A.L.; Levenson, J.M.; Vilaythong, A.P.; Richman, R.; Armstrong, D.L.; Noebels, J.L.; David Sweatt, J.; Zoghbi, H.Y. Mild Overexpression of MeCP2 Causes a Progressive Neurological Disorder in Mice. Hum. Mol. Genet. 2004, 13, 2679-2689. [CrossRef] [PubMed]

210. Liu, Z.; Li, X.; Zhang, J.-T.; Cai, Y.-J.; Cheng, T.-L.; Cheng, C.; Wang, Y.; Zhang, C.-C.; Nie, Y.-H.; Chen, Z.-F.; et al. Autism-like Behaviours and Germline Transmission in Transgenic Monkeys Overexpressing MeCP2. Nature 2016, 530, 98-102. [CrossRef] [PubMed]

211. Sztainberg, Y.; Chen, H.; Swann, J.W.; Hao, S.; Tang, B.; Wu, Z.; Tang, J.; Wan, Y.-W.; Liu, Z.; Rigo, F.; et al. Reversal of Phenotypes in MECP2 Duplication Mice Using Genetic Rescue or Antisense Oligonucleotides. Nature 2015. [CrossRef]

212. Tigani, W.; Rossi, M.P.; Artimagnella, O.; Santo, M.; Rauti, R.; Sorbo, T.; Ulloa Severino, F.P.; Provenzano, G.; Allegra, M.; Caleo, M.; et al. Foxg1 Upregulation Enhances Neocortical Activity. Cereb. Cortex 2020, 30, 5147-5165. [CrossRef]

213. Ewen, J.B.; Sweeney, J.A.; Potter, W.Z. Conceptual, Regulatory and Strategic Imperatives in the Early Days of EEG-Based Biomarker Validation for Neurodevelopmental Disabilities. Front. Integr. Neurosci. 2019, 13. [CrossRef]

214. Specchio, N.; Balestri, M.; Striano, P.; Cilio, M.R.; Nardello, R.; Patanè, S.; Margiotta, M.L.; D’Orsi, G.; Striano, S.; Russo, S.; et al. Efficacy of Levetiracetam in the Treatment of Drug-Resistant Rett Syndrome. Epilepsy Res. 2010, 88, 112-117. [CrossRef]

215. O'Leary, H.M.; Kaufmann, W.E.; Barnes, K.V.; Rakesh, K.; Kapur, K.; Tarquinio, D.C.; Cantwell, N.G.; Roche, K.J.; Rose, S.A.; Walco, A.C.; et al. Placebo-Controlled Crossover Assessment of Mecasermin for the Treatment of Rett Syndrome. Ann. Clin. Transl. Neurol. 2018, 5, 323-332. [CrossRef] [PubMed] 
216. Pini, G.; Congiu, L.; Benincasa, A.; DiMarco, P.; Bigoni, S.; Dyer, A.H.; Mortimer, N.; Della-Chiesa, A.; O’Leary, S.; McNamara, R.; et al. Illness Severity, Social and Cognitive Ability, and EEG Analysis of Ten Patients with Rett Syndrome Treated with Mecasermin (Recombinant Human IGF-1). Autism Res. Treat. 2016, 2016, 5073078. [CrossRef]

217. Khwaja, O.S.; Ho, E.; Barnes, K.V.; O’Leary, H.M.; Pereira, L.M.; Finkelstein, Y.; Nelson, C.A.; Vogel-Farley, V.; DeGregorio, G.; Holm, I.A.; et al. Safety, Pharmacokinetics, and Preliminary Assessment of Efficacy of Mecasermin (Recombinant Human IGF-1) for the Treatment of Rett Syndrome. Proc. Natl. Acad. Sci. USA 2014, 111, 4596-4601. [CrossRef] [PubMed]

218. Smith-Hicks, C.L.; Gupta, S.; Ewen, J.B.; Hong, M.; Kratz, L.; Kelley, R.; Tierney, E.; Vaurio, R.; Bibat, G.; Sanyal, A.; et al. Randomized Open-Label Trial of Dextromethorphan in Rett Syndrome. Neurology 2017, 89, 1684-1690. [CrossRef] [PubMed]

219. Djukic, A.; Holtzer, R.; Shinnar, S.; Muzumdar, H.; Rose, S.A.; Mowrey, W.; Galanopoulou, A.S.; Shinnar, R.; Jankowski, J.J.; Feldman, J.F.; et al. Pharmacologic Treatment of Rett Syndrome With Glatiramer Acetate. Pediatr. Neurol. 2016, 61, 51-57. [CrossRef] [PubMed]

220. Fabio, R.A.; Billeci, L.; Crifaci, G.; Troise, E.; Tortorella, G.; Pioggia, G. Cognitive Training Modifies Frequency EEG Bands and Neuropsychological Measures in Rett Syndrome. Res. Dev. Disabil. 2016, 53-54, 73-85. [CrossRef] [PubMed]

221. Fabio, R.A.; Gangemi, A.; Semino, M.; Vignoli, A.; Canevini, M.P.; Priori, A.; Rosa, G.D.; Caprì, T. Effects of Combined Transcranial Direct Current Stimulation with Cognitive Training in Girls with Rett Syndrome. Brain Sci. 2020, 10, 276. [CrossRef]

222. Fabio, R.A.; Gangemi, A.; Capri, T.; Budden, S.; Falzone, A. Neurophysiological and Cognitive Effects of Transcranial Direct Current Stimulation in Three Girls with Rett Syndrome with Chronic Language Impairments. Res. Dev. Disabil. 2018, 76, 76-87. [CrossRef] [PubMed]

223. Mouro, F.M.; Miranda-Lourenço, C.; Sebastião, A.M.; Diógenes, M.J. From Cannabinoids and Neurosteroids to Statins and the Ketogenic Diet: New Therapeutic Avenues in Rett Syndrome? Front. Neurosci. 2019, 13. [CrossRef]

224. Haas, R.H.; Rice, M.A.; Trauner, D.A.; Merritt, T.A.; Opitz, J.M.; Reynolds, J.F. Therapeutic Effects of a Ketogenic Diet in Rett Syndrome. Am. J. Med. Genet. 1986, 25, 225-246. [CrossRef] [PubMed]

225. Liebhaber, G.M.; Riemann, E.; Baumeister, F.A.M. Ketogenic Diet in Rett Syndrome. J. Child Neurol. 2003, 18, 74-75. [CrossRef]

226. Wang, J.-F.; Sun, X.; Chen, B.; Young, L.T. Lamotrigine Increases Gene Expression of GABA-A Receptor B3 Subunit in Primary Cultured Rat Hippocampus Cells. Neuropsychopharmacology 2002, 26, 415-421. [CrossRef]

227. Huppke, P.; Köhler, K.; Brockmann, K.; Stettner, G.M.; Gärtner, J. Treatment of Epilepsy in Rett Syndrome. Eur. J. Paediatr. Neurol. EJPN Off. J. Eur. Paediatr. Neurol. Soc. 2007, 11, 10-16. [CrossRef]

228. Henriques, J.B.; Davidson, R.J. Left Frontal Hypoactivation in Depression. J. Abnorm. Psychol. 1991, 100, 535-545. [CrossRef]

229. Kagan, J.; Snidman, N. Early Childhood Predictors of Adult Anxiety Disorders. Biol. Psychiatry 1999, 46, 1536-1541. [CrossRef]

230. Bruder, G.E.; Stewart, J.W.; McGrath, P.J. Right Brain, Left Brain in Depressive Disorders: Clinical and Theoretical Implications of Behavioral, Electrophysiological and Neuroimaging Findings. Neurosci. Biobehav. Rev. 2017, 78, 178-191. [CrossRef]

231. Barnes, K.V.; Coughlin, F.R.; O’Leary, H.M.; Bruck, N.; Bazin, G.A.; Beinecke, E.B.; Walco, A.C.; Cantwell, N.G.; Kaufmann, W.E. Anxiety-like Behavior in Rett Syndrome: Characteristics and Assessment by Anxiety Scales. J. Neurodev. Disord. 2015, 7. [CrossRef]

232. van der Vinne, N.; Vollebregt, M.A.; van Putten, M.J.A.M.; Arns, M. Frontal Alpha Asymmetry as a Diagnostic Marker in Depression: Fact or Fiction? A Meta-Analysis. NeuroImage Clin. 2017, 16, 79-87. [CrossRef]

233. Ben-Zeev, B.; Aharoni, R.; Nissenkorn, A.; Arnon, R. Glatiramer Acetate (GA, Copolymer-1) an Hypothetical Treatment Option for Rett Syndrome. Med. Hypotheses 2011, 76, 190-193. [CrossRef]

234. Doppler, E.; Rockenstein, E.; Ubhi, K.; Inglis, C.; Mante, M.; Adame, A.; Crews, L.; Hitzl, M.; Moessler, H.; Masliah, E. Neurotrophic Effects of Cerebrolysin in the Mecp2308/Y Transgenic Model of Rett Syndrome. Acta Neuropathol. (Berl.) 2008, 116, 425-437. [CrossRef] [PubMed]

235. Blue, M.E.; Naidu, S.; Johnston, M.V. Altered Development of Glutamate and GABA Receptors in the Basal Ganglia of Girls with Rett Syndrome. Exp. Neurol. 1999, 156, 345-352. [CrossRef] [PubMed]

236. Patrizi, A.; Picard, N.; Simon, A.J.; Gunner, G.; Centofante, E.; Andrews, N.A.; Fagiolini, M. Chronic Administration of the N-Methyl-D-Aspartate Receptor Antagonist Ketamine Improves Rett Syndrome Phenotype. Biol. Psychiatry 2016, 79, 755-764. [CrossRef] [PubMed]

237. Sivarao, D.V.; Chen, P.; Senapati, A.; Yang, Y.; Fernandes, A.; Benitex, Y.; Whiterock, V.; Li, Y.-W.; Ahlijanian, M.K. 40 Hz Auditory Steady-State Response Is a Pharmacodynamic Biomarker for Cortical NMDA Receptors. Neuropsychopharmacology 2016, 41, 2232-2240. [CrossRef] [PubMed]

238. Hao, S.; Tang, B.; Wu, Z.; Ure, K.; Sun, Y.; Tao, H.; Gao, Y.; Patel, A.J.; Curry, D.J.; Samaco, R.C.; et al. Forniceal Deep Brain Stimulation Rescues Hippocampal Memory in Rett Syndrome Mice. Nature 2015, 526, 430-434. [CrossRef]

239. Lu, H.; Ash, R.T.; He, L.; Kee, S.E.; Wang, W.; Yu, D.; Hao, S.; Meng, X.; Ure, K.; Ito-Ishida, A.; et al. Loss and Gain of MeCP2 Cause Similar Hippocampal Circuit Dysfunction That Is Rescued by Deep Brain Stimulation in a Rett Syndrome Mouse Model. Neuron 2016, 91, 739-747. [CrossRef]

240. Moher, D.; Liberati, A.; Tetzlaff, J.; Altman, D.G.; PRISMA Group. Preferred Reporting Items for Systematic Reviews and Meta-Analyses: The PRISMA Statement. PLoS Med. 2009, 6, e1000097. [CrossRef] [PubMed]

241. McIntosh, R.P.; Simatos, D.; Weston, H.J.; Stanley, T.V. Rett Syndrome: Case Reports and Review. N. Z. Med. J. 1990, 103, $122-125$.

242. Vignoli, A.; Borgatti, R.; Peron, A.; Zucca, C.; Ballarati, L.; Bonaglia, C.; Bellini, M.; Giordano, L.; Romaniello, R.; Bedeschi, M.F.; et al. Electroclinical Pattern in MECP2 Duplication Syndrome: Eight New Reported Cases and Review of Literature. Epilepsia 2012, 53, 1146-1155. [CrossRef] 
243. Faulkner, M.A.; Singh, S.P. Neurogenetic Disorders and Treatment of Associated Seizures. Pharmacotherapy 2013, 33, 330-343. [CrossRef] [PubMed]

244. Tanaka, M.; DeLorey, T.M.; Delgado-Escueta, A.; Olsen, R.W. GABRB3, Epilepsy, and Neurodevelopment. In Jasper's Basic Mechanisms of the Epilepsies; Noebels, J.L., Avoli, M., Rogawski, M.A., Olsen, R.W., Delgado-Escueta, A.V., Eds.; National Center for Biotechnology Information (US): Bethesda, MD, USA, 2012.

245. Sheth, R.D. Electroencephalogram in Developmental Delay: Specific Electroclinical Syndromes. Semin. Pediatr. Neurol. 1998, 5, 45-51. [CrossRef]

246. Italiano, D.; Striano, P.; Russo, E.; Leo, A.; Spina, E.; Zara, F.; Striano, S.; Gambardella, A.; Labate, A.; Gasparini, S.; et al. Genetics of Reflex Seizures and Epilepsies in Humans and Animals. Epilepsy Res. 2016, 121, 47-54. [CrossRef]

247. Khaikin, Y.; Mercimek-Andrews, S. STXBP1 Encephalopathy with Epilepsy. In GeneReviews ${ }^{\circledR}$; Adam, M.P., Ardinger, H.H., Pagon, R.A., Wallace, S.E., Bean, L.J., Mirzaa, G., Amemiya, A., Eds.; University of Washington, Seattle: Seattle, WA, USA, 1993.

248. Weng, S.-M.; Bailey, M.E.S.; Cobb, S.R. Rett Syndrome: From Bed to Bench. Pediatr. Neonatol. 2011, 52, 309-316. [CrossRef]

249. Nomura, Y. Neurophysiology of Rett Syndrome. Brain Dev. 2001, 23 (Suppl 1), S50-S57. [CrossRef]

250. Niedermeyer, E.; Naidu, S.B. Rett Syndrome, EEG and the Motor Cortex as a Model for Better Understanding of Attention Deficit Hyperactivity Disorder (ADHD). Eur. Child Adolesc. Psychiatry 1998, 7, 69-72. [CrossRef] [PubMed]

251. Jellinger, K.A. Rett Syndrome-An Update. J. Neural Transm. Vienna Austria 1996 2003, 110, 681-701. [CrossRef] [PubMed]

252. Glaze, D.G. Neurophysiology of Rett Syndrome. Ment. Retard. Dev. Disabil. Res. Rev. 2002, 8, 66-71. [CrossRef]

253. Dunn, H.G.; MacLeod, P.M. Rett Syndrome: Review of Biological Abnormalities. Can. J. Neurol. Sci. J. Can. Sci. Neurol. 2001, 28, 16-29. [CrossRef]

254. Garcés, P.; Vicente, R.; Wibral, M.; Pineda-Pardo, J.Á.; López, M.E.; Aurtenetxe, S.; Marcos, A.; de Andrés, M.E.; Yus, M.; Sancho, M.; et al. Brain-Wide Slowing of Spontaneous Alpha Rhythms in Mild Cognitive Impairment. Front. Aging Neurosci. 2013, 5. [CrossRef]

255. Ponomareva, N.; Klyushnikov, S.; Abramycheva, N.; Malina, D.; Scheglova, N.; Fokin, V.; Ivanova-Smolenskaia, I.; Illarioshkin, S. Alpha-Theta Border EEG Abnormalities in Preclinical Huntington's Disease. J. Neurol. Sci. 2014, 344, 114-120. [CrossRef]

256. Bhattacharya, B.S.; Coyle, D.; Maguire, L.P. Alpha and Theta Rhythm Abnormality in Alzheimer's Disease: A Study Using a Computational Model. Adv. Exp. Med. Biol. 2011, 718, 57-73. [CrossRef] [PubMed]

257. Schumacher, J.; Thomas, A.J.; Peraza, L.R.; Firbank, M.; Cromarty, R.; Hamilton, C.A.; Donaghy, P.C.; O’Brien, J.T.; Taylor, J.-P. EEG Alpha Reactivity and Cholinergic System Integrity in Lewy Body Dementia and Alzheimer's Disease. Alzheimers Res. Ther. 2020, 12, 46. [CrossRef] [PubMed]

258. Zhou, H.; Wu, W.; Zhang, Y.; He, H.; Yuan, Z.; Zhu, Z.; Zhao, Z. Selective Preservation of Cholinergic MeCP2 Rescues Specific Rett-Syndrome-like Phenotypes in MeCP2stop Mice. Behav. Brain Res. 2017, 322, 51-59. [CrossRef]

259. Orekhova, E.V.; Butorina, A.V.; Sysoeva, O.V.; Prokofyev, A.O.; Nikolaeva, A.Y.; Stroganova, T.A. Frequency of Gamma Oscillations in Humans Is Modulated by Velocity of Visual Motion. J. Neurophysiol. 2015, 114, 244-255. [CrossRef]

260. Trujillo, C.A.; Gao, R.; Negraes, P.D.; Gu, J.; Buchanan, J.; Preissl, S.; Wang, A.; Wu, W.; Haddad, G.G.; Chaim, I.A.; et al. Complex Oscillatory Waves Emerging from Cortical Organoids Model Early Human Brain Network Development. Cell Stem Cell 2019, 25, 558-569.e7. [CrossRef] [PubMed]

261. Fair, S.R.; Julian, D.; Hartlaub, A.M.; Pusuluri, S.T.; Malik, G.; Summerfied, T.L.; Zhao, G.; Hester, A.B.; Ackerman, W.E.; Hollingsworth, E.W.; et al. Electrophysiological Maturation of Cerebral Organoids Correlates with Dynamic Morphological and Cellular Development. Stem Cell Rep. 2020, 15, 855-868. [CrossRef] [PubMed] 